Portland State University

PDXScholar

\title{
Intercultural confrontation styles of culturally homophilous and culturally heterophilous Japanese and U.S. college students
}

Toyoko Hattori

Portland State University

Follow this and additional works at: https://pdxscholar.library.pdx.edu/open_access_etds

Part of the International and Intercultural Communication Commons, and the Interpersonal and Small Group Communication Commons

Let us know how access to this document benefits you.

\section{Recommended Citation}

Hattori, Toyoko, "Intercultural confrontation styles of culturally homophilous and culturally heterophilous Japanese and U.S. college students" (1992). Dissertations and Theses. Paper 4326.

https://doi.org/10.15760/etd.6210

This Thesis is brought to you for free and open access. It has been accepted for inclusion in Dissertations and Theses by an authorized administrator of PDXScholar. Please contact us if we can make this document more accessible: pdxscholar@pdx.edu. 
AN ABSTRACT OF THE THESIS OF TOyoko Hattori for the Master of Arts in speech Communication presented January 29, 1992.

Title: Intercultural Confrontation Styles of Culturally Homophilous and Culturally Heterophilous Japanese and U.S. College students.

APPROVED BY THE MEMBERS OF THE THESIS COMMITTEE:

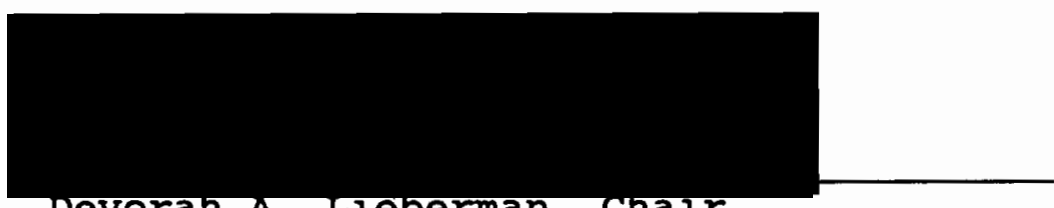

Devoran A. Lieberman, chaIr

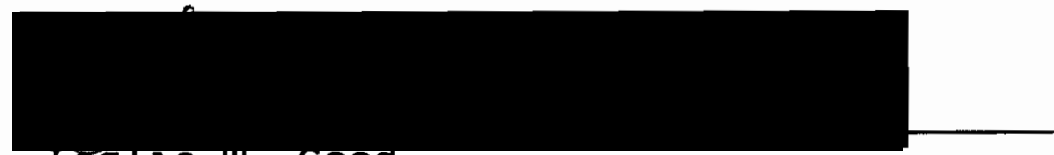

Leslie $1 \cdot$ Good

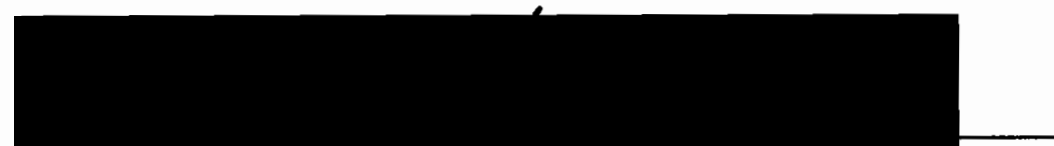

Stephen 'A. Kosokotf

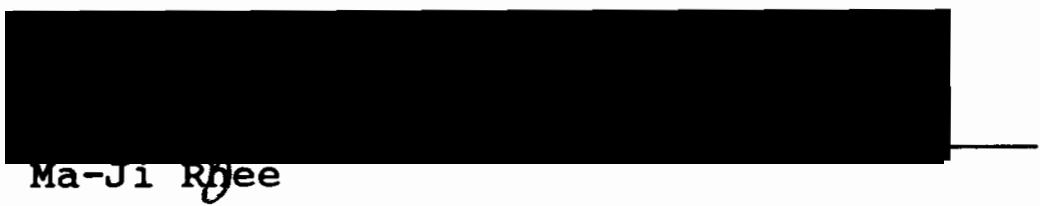

This study focuses on confrontational behavior patterns exhibited by Japanese and U.S. college students in the 
Portland Metropolitan area. Four questions are addressed: 1) is there a difference Japanese and U.S. confrontation styles? 2) do Japanese use differing confrontation styles depending upon whom they are interacting with? 3) do U.S. individuals use differing confrontation styles depending upon whom they are interacting with? and 4) is there a significant gender difference between Japanese and U.S. confrontation styles? In addition, correlations between the Japanese and U.S. reported confrontation styles and their demographic data are examined.

Four hypotheses were posited in order to answer these questions mentioned above: 1) Japanese and U.S. subjects report different confrontation styles; 2) Japanese report different interpersonal confrontation strategies when interacting with individuals from either Japanese or U.S. cultures; 3) U.S. individuals report different interpersonal confrontation strategies when interacting with individuals from either U.S. or Japanese cultures; and 4) Japanese and U.S. subjects do not report gender as a significant variable during confrontation.

One hundred Japanese and one hundred U.S. students attending universities in the Portland Metropolitan area responded to a survey questionnaire to measure the degree of passive or active confrontational behaviors exhibited with Japanese and U.S. casual friends.

All except the second hypothesis were partially 
supported. The second hypothesis was not supported. Results suggested that among Japanese and U.S. students' reported confrontation styles, Japanese and U.S. individuals tended to choose similar confrontation styles in five out of seven situations. Japanese and U.S. students' reported behaviors were different in two out of seven situations.

The results also suggested that the Japanese students' reported behaviors toward Japanese and U.S. interactants were similar. However, U.S. students reported behaviors toward U.S. and Japanese interactants as being different. U.S. individuals reported preferring more passive confrontation styles toward Japanese interactants than toward U.S. interactants in six out of seven situations. There are strong negative correlations in two areas concerning U.S. reported confrontation styles: 1) the U.S. subjects' experiences of living in Japan; and 2) the U.S. subjects' level of Japanese language.

In gender comparisons, Japanese male and female subjects reported choosing similar confrontation styles in all seven situations. U.S. students reported similar confrontation styles toward U.S. and Japanese interactants in six out of seven situations. In one significant situation, U.S. male students reported more passive confrontation styles toward both U.S. and Japanese interactants than U.S. female students did.

This study indicated that Japanese and U.S. 
confrontation styles differ depending upon various situations. Japanese are likely to choose similar confrontation behaviors toward both Japanese and U.S. interactants, whereas U.S. individuals are likely to choose different confrontation behaviors according to the interactants' culture. 
INTERCULTURAL CONFRONTATION STYLES OF CULTURALLY HOMOPHILOUS AND CULTURALLY HETEROPHILOUS JAPANESE AND U.S. COLLEGE STUDENTS

by

TOYOKO HATTORI

A thesis submitted in partial fulfillment of the requirements for the degree of

\author{
MASTER OF ARTS \\ in \\ SPEECH COMMUNICATION
}

Portland State University

1992 
TO THE OFFICE OF GRADUATE STUDIES:

The members of the Committee approve the thesis of Toyoko Hattori presented January 29, 1992.

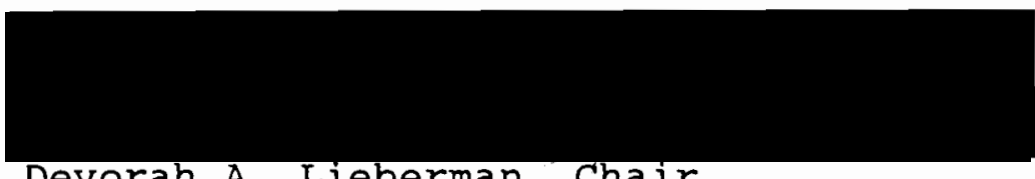

Devorah A. Lieberman, Chair

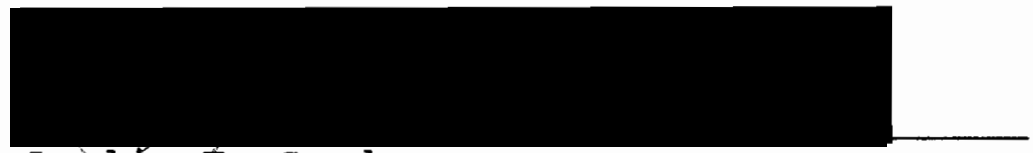

Lestie T. Good

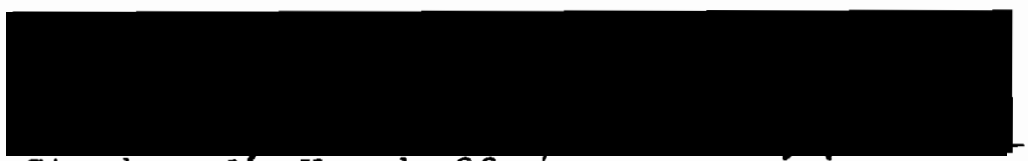

Stephen $A^{\prime}$. Kosokoff

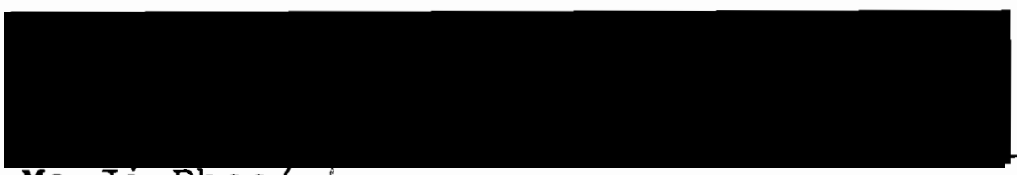

Ma-Ji Rhee/

APPROVED :

Theodore G. Grove, Chair, Department of Speech Communication 


\section{ACKNOWLEDGEMENTS}

I have many people to thank for their time and contributions toward the completion of this thesis. I am indebted to the extensive support of my family and friends, as well as to the following faculty members who provided encouragement and positive support.

First and foremost, I would like to express my heartfelt appreciation to Professor Devorah A. Lieberman, who was my academic advisor and the chair person of my thesis committee. I would like to thank Dr. Lieberman for her generosity, her flexibility, and her encouragement, guidance, and inspiration. It was her faith in this study which gave me courage and confidence, and allowed me to complete the project.

I am especially grateful to Dr. Leslie T. Good, one of my thesis committee members, for her excellent guidance in regard to the methodology of this project. I also thanks Dr. Stephen A. Kosokoff for his humor, understanding, and meticulous editorial skills which were a definite contribution to the quality of this thesis. I was also fortunate to have Dr. Ma-Ji Rhee, a faculty member of the Foreign Language Department, on my thesis committee. Dr. Rhee has been an encouragement to me throughout my work. I owe a special debt of gratitude to my network of 
friends, who have supported and encouraged me in many ways during the good times and the bad. Their assistance was invaluable to me, and without them this thesis would never have been completed. I would also like to thank the student respondents who offered their time and provided the data for this project.

Most importantly, I am particularly thankful to my parents, Yasunori and Tsuruko Hattori, who have given me strong support throughout my time in the United states. I give my love, respect, and appreciation to them. 
TABLE OF CONTENTS

PAGE

ACKNOWLEDGEMENT . . . . . . . . . . . . . . . . . . iii

LIST OF TABLES . . . . . . . . . . . . . . . . . viii

LIST OF FIGURES . . . . . . . . . . . . . . . . . . . iX

CHAPTER

I INTRODUCTION . . . . . . . . . . . . . 1

Background and Justification . . . . 1

II LITERATURE REVIEW . . . . . . . . . . 6

Definitions . . . . . . . . . 6

Self-Disclosure . . . . . . . . 11

Basic structures of

Japanese and U.S. Society . . . . . 21

Characteristics of Groups

in Japan and the U.S. . . . . . . . 23

Functions in Societies . . . . . . 24

Communication styles

in Japanese aand U.S. Societies . . . 31

Male and Female Communication Styles • 35

Confrontation Situations . . . . . 40

Young Japanese in Today's society . . . 44

Purpose of This study . . . . . . . 46

Hypotheses . . . . . . . . . . . 46 
Definitions of the Variables . . . . 50

Research Method . . . . . . . . 52

subjects . . . . . . . . . 53

Development of the Questionnaire . . . 54

Translation . . . . . . . . . 65

Data collection . . . . . . . 66

Data Analysis . . . . . . . . 66

IV RESULTS . . . . . . . . . . . 69

Characteristics of the Samples . . . 69

Independent Variables and

Confrontation Styles . . . . . . . 73

Examination of Hypothesis one . . . . 74

Examination of Hypothesis Two . . . 80

Examination of Hypothesis Three . . . 84

Examination of Hypothesis Four . . . 93

V DISCUSSION . . . . . . . . . . . 101

Japanese and U.S. Subjects Report

Different Confrontation Styles . . . 101

Japanese Report Different Interpersonal

Confrontation strategies When

Interacting with Individuals from

Either Japanese or U.S. Cultures . . 108

U.S. Individuals Report Different

Interpersonal Confrontation Strategies

When Interacting with Individuals from

Either U.S. or Japanese Cultures . . . 111

Japanese and U.S. Subjects Do Not

Report Gender as a Significant Variable

during Confrontation . . . . . . . 115 
VI FUTURE STUDY AND CONCLUSION . . . . . . . 117 Unexpected Results . . . . . . . 117 Limitations of the Research . . . . 119 Possibilities for Future Research . . 120 Conclusion . . . . . . . . . . 121

REFERENCES APPENDICES
A DEMOgRAPHIC DATA • . . . . . . . . . . . . 133
B INTERPERSONAL CRITICISM QUESTIONNAIRE . • . . 142
C RANK ORDERING OF THE RESPONSE SCALE . . . . . 146
D QUESTIONNAIRE . . . . . . . . . . . . . . 149
E VARIABLES •. • . . . . . . . . . . . . 161
E CODING DATA . . . . . . . . . . . . 166 
LIST OF TABLES

TABLE

PAGE

I Overall cultural comparison:

Japanese and U.S. Samples . . . . . . . . . 74

I Confrontation styles in Social situation

between Japanese U.S. • • • . • • • • . • • 76

II Overall Comparison of Japanese Confrontation

styles

IV Comparison of Japanese Confrontation styles in Each Situation . . . . . . . . . . . . 82

V Correlations between confrontation styles

and Demographic information within

the Japanese sample

VI Overall U.S. Confrontation Styles . . . . . . . 84

VII U.S. Confrontation style in Each situation • . 86

VIII Correlations between confrontation styles

and Demographic Information within

the U.S. Sample

IX Comparison of U.S. who had been to Japan

to those who had never been to Japan . . . . 89

$\mathrm{X}$ Comparison in Each Situation between

U.S. who had been to Japan and U.S.

who had never been to Japan . . . . . . . . . 92

XI Overall confrontation styles:

Japanese Males and Japanese Females . . . . . 94

XII Comparison of Confrontation styles

in Each Situation between Japanese Males

and Females . . . . . . . . . . . . . . 95

XIII Overall Confrontation styles:

U.S. Males and U.S. Females . . . . . . . • 97

XIV Comparison of Confrontation styles in Each

Situation between U.S. Males and Females . • 98 


\section{IIST OF FIGURES}

FIGURE

PAGE

1. Frequency of choice by homophilous dyads

(Japanese interacting with Japanese/

$$
\text { U.S. interacting U.S.) . . . . . . . } 78
$$

2. Frequency of choice by heterophilous dyads

(Japanese intar cting with U.S.)

' Japanese) . . . . . 79 


\section{CHAPTER I}

\section{INTRODUCTION}

\section{BACKGROUND AND JUSTIFICATION}

Due to the technological advances in communication and transportation, Japan has become a principle trading partner and key businesses investor in the state of Oregon (Ross, 1987). An increase in the number of Japanese who have come to study at oregon colleges and universities has also been noted. In the Fall term of 1980, the International Students office at Portland State University (PSU) reported that 45 of the 1,414 foreign students registered were Japanese. In 1986, the Consulate of Japan, in Portland, reported that 740 Japanese students were enrolled in Oregon colleges and universities, 56 of whom were registered at PSU. During that same year, the total number of foreign students at PSU decreased to 623. BY 1989, the number of Japanese students in Oregon had risen to 1,724 . During that year, Japanese were the most represented international population on the PSU campus. A total of 107 of the 781 foreign students were Japanese. This increase in the Japanese student population has provided Japanese and U.S. students numerous opportunities to communicate cross-culturally. When people from 
different cultural systems interact, they bring with them different types and levels of needs. Interpersonal interaction and conflict seem almost unavoidable (Nadler, Nadler, \& Broome, 1985). As Lande and Womack observed, "growth in intercultural communication increases both the opportunities for international understanding and international conflict" (Nadler, Nadler, \& Broome, 1985, p. 87).

The types of cross cultural human interactions with which Japanese and U.S. individuals may frequently engage involve a wide variety of communicative behaviors, both verbal and nonverbal (Hall, 1976). These behaviors convey meaning to a person's communicative partner (Porter \& Samovar, 1985). Examples of these communicative behaviors may be: choosing a topic of conversation, initiating a conversation, selecting and exhibiting gestures and facial expressions, managing time, space and silence, making requests or apologies, and complimenting (Hall, 1976).

Along with cultural values, the behaviors of an individual are influenced by a variety of other factors. Hall (1985) identified five elements in any given communicative situation which influence behaviors. These five elements are: the subject or activity, the situation, the status of the individual within the social system, past experience and culture (p. 71). Cultures may differ in their perception of these elements, choosing to ignore or 
downplay some while emphasizing others. Once these elements are learned, the degree and importance of each element is generally understood by each individual within the culture (Hall, 1985).

Pennington (1985) concluded that culture is fundamental for communication. Similarly, Porter and Samovar (1985) stated that, "culture and communication are inseparable" (p. 19). Each culture develops its own unique language form, expressions, and manner of message interpretation. These mutually agreed upon communicative behaviors are learned and shared by each of its members and transmitted from one generation to the next through a shared symbol system (Condon \& Yousef, 1985; Pennington, 1975). Behaviors and styles of communication, therefore, are directly linked to the culture. When individuals of different cultures interact, each person derives his or her decoding of the message from his or her cultural experiences (Porter \& Samvor, 1985). Interpretation of what is good or bad, or what is right or wrong, is based on the value system of the culture (Condon \& Yousef, 1975). Cultural elements such as beliefs, values, attitude systems, world views, and social organizations have a direct influence on perception and meaning (Porter \& Samovar, 1985). Each culture tends to be permeated with its own values which influence the behaviors of its people. 
conflict is the basic form of disagreement between individuals (Devito, 1985) and occurs in our daily lives (Hocker \& Wilmot, 1985; DeVito, 1985). Even within the same culture, people experience conflict in interpersonal relationships (Hocker \& Wilmot, 1985). Not only may conflict occasionally result from cross-cultural interaction, but the manner in which each individual reacts to the conflict is likely to differ. Intercultural differences may frequently result in a disparity of communication patterns which may lead to communication difficulties (Condon, p. 63-64).

Condon and Yousef (1985) found that the cultural values and beliefs of the United states and Japan are quite different. In fact, Porter \& Somovar (1985) found a wide disparity between Asian and Western cultures in general.

Many theories and models regarding interpersonal conflict resolution or management have focused upon conflict resolution styles (Blake \& Monton, 1964; Hall, 1969; Kilmann \& Thomas, 1977). Miller, Rogers, and Bavelas (1984) stated that, "even a casual reading of the interpersonal conflict literature witnesses a remarkable void of attending to discourse phenomena. Few studies observe how people conflict; most focus on why people conflict" (P.232). Current intercultural theories assert that relatively little theoretical work has been done to systematically examine the conceptual bridge between 
conflict and culture (Ting-Toomey, 1985). Except for Tafoya's article on a barrier approach to interpersonal conflict, little empirical research explaining the interaction between these important constructs exist (TingToomey, 1985). Within these studies, Ting-Toomey analyzes the functional interdependence and relationship within the framework of Hall's low- and high-context cultures, and between conflict and culture. Wolfsone and Norden examine the meanings and implications of interpersonal conflict between high school students and teachers in chinese and North American cultures. Berryman and Fink studied the influence of gender differences on conflict and management styles.

Much of the conflict resolution research conducted to date has focused on Japanese/Japanese or U.S./U.S. dyads; in other words, the two styles have been compared only within their own cultural context. When faced with a confrontational situation, Japanese and U.S. individuals tend to draw upon the confrontational styles of their respective cultures. It is important to study this form of confrontational interaction to examine the intercultural communication behaviors which may occur between people of these vastly different cultures. This study compares Japanese college students' confrontational behaviors to those of U.S. college students in culturally homophilous and culturally heterophilous dyads. 
CHAPTER II

\section{LITERATURE REVIEW}

This chapter examines previous research in intracultural and intercultural styles during interpersonal confrontation. The following literature review centers around the following categories: (1) the cultural differences between Japanese and U.S. individuals in social interactions in the United States; (2) the differences between their styles of conflict management; (3) communication differences due to gender; and finally, the differences in communication styles as related to selfdisclosure.

\section{DEFINITIONS}

The central terms for this study--intercultural communication, intracultural communication, social penetration, self-disclosure, conflict, and confrontation-will be defined as follows:

\section{Intercultural communication}

Porter and Samovar (1986) describe intercultural communication as that which occurs when source and receiver come from different cultures. When two individuals' cultures are different, these differences can be catalysts 
for difficulties (Porter \& Samovar, 1985). Or, according to Pennington (1985), people from different cultures often have difficulty communicating with each other. Culture, in this case, has been broadly defined as "the form or pattern for living" (Porter \& Samovar, 1985, p. 19). Similarly, Tubbs \& Moss (1983) state that intercultural communication is "communication between members of different cultures (whether defined in terms of racial, ethnic, or socioeconomic differences, or a combination of these differences)" (p. 12-13).

Intercultural communication occurs at the point of intersection between two or more cultures, with the assumption that the groups within these cultures are different. Intercultural communication for this study refers to interactions between people from different cultures, specifically the Japanese and U.S. cultures.

\section{Intracultural communication}

Folb (1985) defined intracultural communication as "a phenomenon that functions within a single, designated culture" (p. 120). Individuals have differences within the group, but these differences are variations, and are not enough to separate them from the group (Folb, 1985). Intracultural communication, for this study, refers to interactions between people in the same culture, specifically within the Japanese and the U.S. cultures. 


\section{Conflict}

Theories concerning "conflict" and "conflict management" are based on an interdependent relationship in which interactants attempt to change the framework of their relationships in order to achieve their own interests and goals. Conflict theories in general describe the characteristics of conflict as being "ubiquitous, normal, and integral to the workings of every society" (Krauss, Rohlen, and steinhoff, 1984, p. 5). Krauss et al. (1984) pointed out that conflict within a relationship is frequently caused by the incompatibility of interests and goals.

Devito (1985) described interpersonal conflict as follows :

In its most basic form, conflict refers to disagreement. Interpersonal conflict, then, refers to disagreement between or among connected individuals. By including the word "connected," we emphasize that each person's position affects the other person; the positions in conflict are to some degree interrelated and incompatible ( $p$. 232).

In their book concerning interpersonal approaches to conflict, Hocker \& Wilmot (1985) focus on communicative interchange. They see conflict "as a natural process, inherent in the nature of all important relationships and amenable to constructive regulation through communication" (p. 6), however, people usually feel that conflict has a negative connotation (Hocker \& wilmot, 1985). Both Devito 
interpersonal conflict is a natural phenomenon. They explore various ways of conflict management which they believe will arise in the maintenance of good relationships between partners. "Conflict is a relatively common phenomenon both within and between organizations" (Cushman \& King, 1985, p. 117). Cushman and King (1985) also quote Thomas's definition of conflict as "a condition in which the concerns of two or more parties appear incompatible" (p. 117).

Lebra (1984) divided conflict into two categories: genesis and management, the latter of which is relevant to this study. She described conflict management as being, "A reaction to a conflict situation without necessarily entailing a resolution" (p. 41-42).

In her 1985 study concerning the relationship between conflict and culture, Ting-Toomey (1985) reasoned that since culture regulates the meaning and significance of social actions, conflict, which is a social action, serves a variety of functions within the culture. She defined conflict conceptually, as "a form of intense interpersonal and/or intrapersonal dissonance (tension or antagonism) between two or more interdependent parties based on incompatible goals, needs, desires, values, beliefs, and/or attitudes" (Ting-Toomey, 1985, p. 72). 
Confrontation

Confrontation is a method of addressing conflict. The root term "confront," according to the Random House Dictionary (1983), has the following definitions: "1. to face in hostility or defiance; oppose; 2 . to present for acknowledgment, contradiction, etc.; set face to face; 3 . to stand or come in front of; stand or meet facing; 4 . to be in one's way; and 5 . to bring together for examination or comparison" (p. 429). In the same volume, the term "confrontation" is defined as: a meeting of persons face to face; an open conflict of opposing ideas, forces etc.; and a bringing together of ideas, themes, etc., for comparison" (p. 429). On the other hand, Nadler, Nadler, and Broome (1985) interpret confrontation as the process, "... of being socialized in a given society, an individual develops certain orientations toward conflict and negotiation. These orientations are rooted in the value system and cultural beliefs shared by members of the society" (p. 87). In her study entitled Management of Interpersonal Conflict, Lebra (1984) defined confrontation as "a direct challenge launched by $A$ against $B$ when $A$ perceives $B$ as the source of his conflict" (p. 42).

Confrontation as adopted for this study

Confrontation is a behavior or an act engaged in to resolve situations on an interpersonal level. From the point of view of each individual, conflict results from 
contradictory perceptions of the other. confrontation is defined as the communication of attitudes at the interpersonal level in situations in which one person's dissatisfaction, disagreement, and/or feelings of discomfort are incompatible with another person's thoughts, beliefs, and/or attitudes. In circumstances of this type, one person perceives the other as the source of conflict.

\section{SELF-DISCLOSURE}

The idea of self-disclosure was developed by Sidney Jourard who conducted many investigations of patterns of disclosive behavior. Jourard (1971) described selfdisclosure as "a person's willingness to let others know his experience" (p. V). When people communicate with each other, the relationship is one of disclosure and understanding, understanding information about others, and disclosing information about oneself. The degree, or depth, of disclosure between people depends partly on how developed the relationship is, and on the amount of trust between them as well. The breadth of disclosure and the comfortable topics for conversation within a given culture vary widely, with people preferring those subjects which lie inside their respective range of comfort (Barnlund, 1975).

Jourard's ideas on self-disclosure have been utilized extensively in interpersonal research. The general 
findings related to this present study are as follows:

- Women tend to be higher disclosers than men.

- Women disclose more with individuals they like, whereas men disclose more with people they trust.

- Disclosure is regulated by norms of appropriateness. (Littlejohn, 1983, p. 197-198)

studies of self-disclosure in interpersonal

relationships have increased during the past decade (Rosenfeld \& Kendrick, 1984). Rosenfeld and Kendrick

(1984) described the trend in self-disclosure research in interpersonal relationships as follows:

Early research investigated the extent to which subjects disclosed to different target persons, differences among various groups of disclosers, and usual topics of disclosure. Early concern focused on the question, 'Who discloses what to whom?'

Recent research switched focus to the selfdisclosure process, particularly the theoretical explanations for the reciprocity effect, methodological issues, primarily the validity of popular data gathering procedures, and the effects of self-disclosure on both the intrapersonal and interpersonal levels (p. 326).

Self-disclosure has been examined in the intercultural communication literature. Barnlund was one of the first to systematically compare Japanese and U.S. communication patterns (Araki, 1982). Using Jourard's Self-Disclosure Scale, he investigated interpersonal communication in verbal self-disclosure (topic, targets, and depth), nonverbal self-disclosure, and defense against disclosure of self.

Culture influences the content of conversation. 
Culture may affect the level of self-disclosure which people feel is appropriate in a given conversation. Society, to some degree, expresses its values by encouraging or discouraging the expression of certain subjects (Barnlund, 1975). Some topics which might be acceptable to discuss in Japan may not be so acceptable in the U.S., and vice versa. These two cultures might encourage selective communication limiting the discussion of specific topics to specific target persons. Most people are not equally disclosing of themselves on all topics since their emotional comfort and self-knowledge are not equal on all topics, and people do not self-disclose equally to all others (Barnlund, 1975).

In his study, Barnlund (1975) first describes the general communication styles by means of the "Johari Window." The "Johari Window" is a rather simplistic model which contains the four windows representing a person in relation to others: "open," "blind," "hidden," and "unknown." In his study, Barnlund changes two variables represented by "known to others" and "known to self" into the "public self" and "private self." "Public self" refers to "those aspects of experience which are available and easily shared with other people" (Barnlund, 1975, p. 4445). "Private self" indicates "the materials that each of us knows about himself or thinks about or feels about that he does not or is not able to share with other people" 
(Barnlund, 1975, p. 44). Barnlund's findings suggested that "the Japanese appear to self-disclose less, manifesting a more limited public self, while Americans appear to self-disclose more, manifesting a more extensive public self" (Araki, 1982, p. 13). He not only described the different aspects of self-disclosure by topic of conversation and target person, but also pointed out that U.S. individuals were generally more open to others than Japanese (Barnlund, 1975).

In his study of defense against disclosure of self, Barnlund (1975) compared the manner in which Japanese and U.S. college students responded to two levels of threats in conversation by examining how both Japanese and U.S. students react to defend themselves in the face of anxiety or perceived threat. Barnlund went on to describe high level threat as that which was very emotionally disturbing, and low level threat as a general, uneasy feeling. The respondents chose their most likely response from a range of fourteen defensive reactions corresponding to thirteen target persons.

The findings of this study suggest that the Japanese subjects living in Japan use a variety of defensive reactions and do not rely heavily on a few specific responses, while U.S. subjects living in the United States use fewer but more specific active forms of defense reaction. The Japanese subjects predominantly chose 
options which typify passive types of defense, such as "not want to discuss it," or "hint that I did not want to discuss it," or "remain silent" (Barnlund, 1975, p. 82). on the other hand, U.S. subjects tended to prefer "active aggression to give more aggressive, or self-assertive reaction to threat," such as "answer his question directly even though uncomfortable," and "defend myself by explanation and argument" (Barnlund, 1974, p. 83). U.S. individuals chose "answer his question directly even though uncomfortable," "defend myself by explanation and argument," and "use humor or sarcasm to put him in his place" (Barnlund, 1974).

It is also assumed that the degree of threat intensity does not seem to affect U.S. defense behaviors to the extent that it does those of the Japanese. U.S. individuals preferred the three active defense choices mentioned above, regardless of being faced with a high threat or a low threat. Conversely, the Japanese were influenced by both degrees of threat. When Barnlund's Japanese subjects were faced with little perceived threat, they chose to "answer the remark directly even though uncomfortable." When these same Japanese perceived a high threat situation, they tended to withdraw, choosing to say "I do not want to discuss it," "remain silent," and "hint verbally I preferred not to discuss it" (Barnlund, 1975). With reference to the adaptation of behavior depending on 
the target person, the results demonstrated that the Japanese subjects of Barnlund's study showed a high sensitivity to the status differences of their communication partners. The Japanese kept silent, or tried to minimize the expression of their opinions directly to those who were older, or considered superior. Toward these two groups, they tended to "remain silent," or "hint verbally," or "reply in abstract language." However, toward subordinates, or those younger than they, they tended to "retain the attitude," or "not want to discuss it" (Barnlund, 1974, p. 84). Conversely, U.S. individuals consistently used self-assertive reactions, regardless of perceived differences in status, power, or relationships. The results of Barnlund's study failed to indicate the presence of a significant difference in defense reactions according to gender.

Nomura (1980) investigated modes of criticism in selfdisclosure by conducting semi-structured interviews, which were then used to build an instrument producing systematic and quantifiable data. In a study conducted by Nomura, but co-authored by both Nomura and Barnlund, "Criticism" was defined as "the expression of dissatisfaction concerning the personal qualities or behavior of another person that is offered in face-to-face dyadic encounters" (Nomura \& Barnlund, 1983, p. 2). Their study found that the Japanese exhibited more passive forms of criticism, such as "express 
to someone else," and "reply in ambiguous forms," while the U.S. subjects employed active forms, expressing criticism constructively, sarcastically, or insultingly. The relationships examined were parent-child, close friends, acquaintances, and strangers. The Japanese were found to use more active forms of criticism when interacting in closer personal relationships (e.g., with parents or close friends). They used passive forms of criticism in their more distant relationships, such as with acquaintances and strangers. The Japanese consistently adapted their critical messages to the perceived status of their communication partners, while the U.S. individuals did not. The U.S. individuals tended not to differentiate their forms of criticism in accordance with perceived differences in status with the only exception among the target groups measured--parents, close friends, acquaintances, and strangers--being the 'strangers' group. The above study also tested both male and female patterns of criticism in Japan and the United states, yet no significant gender difference emerged (Nomura \& Barnlund, 1983).

Barnlund studied Japanese and American attitudes to emotional threat, and Nomura studied their attitudes in situations of dissatisfaction. However, the two investigations are nonetheless closely connected. They suggest a close consistency regarding "the pattern of defense against disclosure of self" in the scale of self- 
reported disclosure (from most passive to most active). Both cultures demonstrated the preference for expressing dissatisfaction in a direct way. However, the Japanese scored high in all of the passive-withdrawing forms of criticism, such as "to criticize humorously," "not to show dissatisfaction," and "to criticize ambiguously" (Nomura, 1980). U.S. individuals consistently preferred to use active-aggressive forms, such as "to criticize angrily," "to give sarcastic remarks," or "through constructive suggestions" (Nomura, 1980).

clearly, the results of the above-mentioned studies indicate that Japanese and U.S. individuals used different communication styles in conflict situations. Specifically, the U.S. individuals tend to assume an assertive attitude, and consistently prefer to use active forms of communication, while the Japanese often demonstrate a reserved attitude and primarily prefer to use passive forms of communication.

A similar methodology to that of Nomura's study was used in two other cross-cultural self-disclosure studies, one by Araki focusing on complimentary behavior, and the other by Nagano on apologetic behavior. Araki (1982) found that more indirect forms of complimenting, relying more on nonverbal expressions, or verbal praise (chiefly concerning the ability or taste of their partners), were used by the Japanese, and that a higher frequency of complimenting, 
with greater verbal exaggeration (focusing on personality traits and physical attributes), was used by U.S. individuals.

In her study of apologetic behavior, Nagano (1985) found that Japanese subjects' apologetic acts were direct, but in a narrower range of modes, whereas the U.S. subjects' apologetic acts were consistently drawn from a wider choice of modes throughout the situations examined. The Japanese studied commonly chose "to apologize directly" or "to compensate," while the U.S. subjects also tended to chose "to apologize directly" or "to explain the situation," or tend to apologize with making compensation (Nagano, 1985, p. 126).

Gudykunst and Nishida have examined intercultural interactions from several theoretical perspectives. In a 1980 study, they employed Berger and Calabrese's Uncertainty Reduction Hypothesis of 1975 and Altman and Taylor's 1973 Social Penetration Theory. Altman and Taylor's social penetration theory is a gradual progressive process from superficial to intimate level of interpersonal exchange in social relationships. Interpersonal exchange proceeds gradually from a non-intimate to a more intimate stage by the process of close friendship in a mechanistic way Gudykunst \& Nishida, 1983). Altman and Taylor (1973) state that the level and rate of social penetration differs in accordance with the interpersonal cost/reward 
characteristic of the relationship. In their theory, Altman and Taylor propose a four-stage model of relationship development: orientation, exploratory affective exchange, full affective exchange, and stable exchange.

Gudykunst and Nishida (1983) examined close friendships between Japanese and Americans and found that there were no significant differences between Japanese close friendships and American close friendships. Their research also found that few significant gender differences existed.

Applying social penetration theory within Japanese and American dyads, Gudykunst and Nishida (1986) tested six relationship terms (stranger, acquaintance, classmate, friend, best friend, and lover). The Japanese perceived intimacy more in classmates, acquaintances, best friends, and strangers than did the Americans. When examining general friendship, perceived intimacy was found to be the same in both cultures. The ranking of relationships was also similar. However, one significant difference emerged. Lovers are perceived as having the most intimate relationship in the U.S. with best friend second, while best friends are perceived as having the most intimate relationship in Japan, with lovers as second.

Their 1984 study examined relationships between Japanese and U.S. individuals as strangers. The results of 
this study suggested that U.S. individuals ask questions and self-disclose with strangers more than the Japanese. Gudykunst and Nishida (1984) stated that "people in the United states engage in more verbal communication, including interrogation and self-disclosure, than do the Japanese" (p. 32). This statement is supported by the findings of Hall, Johnson and Johnson, Nakane, and Okabe (as cited by Gudykunst \& Nishida, 1984). Most research examining differences between Japanese and U.S. cultures suggest that persons in the U.S. generally self-disclose more than do those in Japan, and that they tend not to change their behaviors of self-disclosure dependent upon the partners, whereas, the Japanese degree of selfdisclosure change is dependent upon the other interactant. Between close friends, Japanese and U.S. individuals selfdisclose to the same degree.

BASIC STRUCTURES OF JAPANESE AND U.S. SOCIETY

Over the years, Japan has absorbed particular values from other cultures, but the tradition of accepting nonJapanese cultural elements is very selective. As a result, non-Japanese ideas and cultural practices have been modified, abstracted, or idealized for Japanese convenience (Suzuki, 1975). Despite this, group identity or group conformity has remained one of the most dominant values in Japan (Cathcart \& Cathcart, 1985; Clark \& Takemura, 1979; 
Condon \& Yousef, 1985; Shiba \& Keen, 1984).

The Japanese "self" exists only in the presence of the group to which he or she belongs. The individual does not perceive "self" without taking into consideration relationships with other members of the group (Cathcart \& Cathcart, 1985; Doi, 1986; Nakane, 1978; Stewart, 1971). In other words, individuals intermingle and become a unit (Nakane, 1978). When describing Japan, Condon and Yousef (1985) state that "conformity to or identity with the group--the family, the organization (business or school), and the nation (the national family) is the dominant value" (p. 67).

The basic unit of 'self' in the U.S., on the other hand, is the individual (Nakane, 1978). U.S. individuals exist as individuals and do not feel a strong need to merge with others and form groups. Individualism refers to the sense that each person has a separate but equal place in society (Condon \& Yousef, 1985). Although the perceived 'self' is influenced by the other members of a group and by group norms, the unique identity of the individual is retained (Cathcart \& Cathcart, 1985). Therefore, the U.S. concept of individual responsibility based on the belief in the value of the individual stands in sharp contrast to the value Japanese place on the group, and each person's ultimate responsibility to the group. (Cathcart \& Cathcart, 1985) 
CHARACTERISTICS OF GROUPS IN JAPAN AND THE U.S.

Nakane (1978) defines "group" in the context of the Japanese culture in the following manner: Japanese groups consist of people who meet regularly, share work, or live together. Sharing time and frequenting the same places are important elements of their relationships (Nakane, 1978), and the amount of frequenting time affects the depth of the relationship (Itasaka, 1976). Although many small groups may come together to form a larger group, the identity of each of the smaller groups remains intact. The small group identity, therefore, is "permanent and determinate" (Cathcart \& Cathcart, 1985, p. 191). These small groups are independent, yet structurally identical. They are maintained within the hierarchy of the large groups. Each individual within each small group also has an identity which fits within the hierarchical order according to age, social status, and other considerations (Nippon, 1984; Nadler, Keeshan-Nadler, \& Broome, 1985). These hierarchical relationships are understood and are not discussed (Nakane, 1978).

Compared to the Japanese hierarchical society, the U.S. society places a high value on individualism. In the United States, a group is more "a gathering of individuals," where the individual is supraordinate to the group (Cathcart \& Cathcart, 1985). In order to meet personal needs and fulfill social obligations, U.S. 
individuals tend to seek new groups with which to affiliate. They do not commit themselves solely to one group or organization (stewart, 1971). Individuals have their own principles and goals to pursue and they are free to choose or change these groups according to their goals (Cathcart \& Cathcart, 1985; Condon \& Yousef, 1985; stewart, 1971). In order to seek and maintain their identity, U.S. individuals easily form groups, dissolve them, rejoin or form other groups (Cathcart \& Cathcart, 1985).

In his 1985 study, Condon and Yousef write of individualism in the U.S. as:

This fusion of individualism and equality is so valued and so basic that many Americans find it most difficult to relate to contrasting values in other cultures where interdependence, complementary relationships, valued differences in age and sex greatly determines a person's sense of self (p. 65).

\section{FUNCTIONS IN SOCIETIES}

As a result of societal differences, the values emphasized are quite different in Japanese and U.S. cultures. Since intragroup relationships are important in Japanese culture, maintaining harmony is the aspiration of each member of the group (Cathcart \& Cathcart, 1985; Condon \& Yousef, 1985). The Japanese have many sayings which illustrate the value placed on passive attitudes and approaches, such as: "Do not have absurd ambition," "Compare only with your peers (Do not look upon people who 
are higher than you)," "Be satisfied with what you have," and "Pliable things may survive the storm when strong ones break." They encourage people to be satisfied with their place in life and encourage them to devote themselves to seeking peace within their own minds (Itasaka, 1976). Another well-known Japanese saying, "Deru kugi wa utareru (the nail that sticks up is hit)" suggests that the Japanese tend to "avoid being singled out for praise or blame" (Cathcart \& Cathcart, 1985, p. 190). Seeking to "lose oneself within the confines of a group" is the goal (Cathcart \& Cathcart, 1985, p. 190).

From the overriding desire to maintain group harmony comes a refined system of societal distinctions and communication elements, such as uchi and soto (in-group \& out-group), honne (real intentions) and tatemae (principles or official stance), amae (dependency), and ishin denshin (intuitive sense). These elements in social relations can be seen in every culture with different degrees and ranges (Itasaka, 1976). Yet the Japanese emphasize these elements to a much greater degree than do U.S. individuals. The U.S. culture, in contrast, values individualism, equality, rights and privileges, self-reliance, and self-assertion (Cathcart \& Cathcart, 1985; Connor, 1977; Stewart, 1971). The Japanese make greater distinctions between insiders and outsiders than do U.S. individuals (Hall, 1976; Kindaichi, 1975; Makino, 1978; Nakane, 1978; 
Naotsuka, 1980; Tsurumi, 1972). The Japanese remain within a fixed group for life and relate willingly to in-group members, but withdraw from members of other groups (Cathcart \& Cathcart, 1985; Kindaichi, 1975). Thus, the individual naturally grows increasingly dependent upon his or her group and more distrustful of anyone "outside." In fact, "the Japanese are often callously indifferent (although always considered polite) to anyone outside their own group" (Cathcart \& Cathcart, 1985, p. 194).

Honne (real intentions) and tatemae (principles or official stance) give flexibility and harmony to the relationships in the hierarchical society of Japan. When the real intentions (honne) and the principles (tatemae) of two parties are in disagreement with each other in business negotiations, the negotiators try to find that way which will "satisfy the honne (real intentions) without compromising the tatemae (principles or official stance), at least on the surface" (Japanese Business Glossary, 1983, p. 68). In Japanese society, each member assumes his or her position within the hierarchy in their everyday activities. The individual's degree of freedom is somewhat limited by status, role, and group, yet this strong dependency in small group relationships fosters a distinctive group identity and uniqueness. This group originality demarcates distinctive group boundaries (Nakane, 1985). The group members' behaviors toward the 
out-group (soto) tend to be grounded in principles (tatemae), but their behaviors toward ingroup (uchi) tend to reflect their real intention (honne) (Nakane, 1978). These close relationships provide members the freedom to express their own opinions or feelings (honne) which may differ from group principles (tatemae). It is necessary to be able to express their own opinions or feelings (honne) and ignore hierarchical order. These adjustments make the group active and help to maintain homeostasis within the hierarchical relationship (Nakane, 1978).

Doi (1971) explains other elements of Japanese culture, such as real intentions (honne) and principles or official stance (tatemae), as being based on dependency (amae). According to Doi, dependency (amae) has a positive connotation related to the sweet and warm dependency that a child has. (Doi, 1987) In Japanese society, dependency (amae) is essential to smooth human interaction among people within the group and within the hierarchy (Doi, 1971). Cathcart and Cathcart (1985) state that Doi believes the Japanese naturally and continually seek this dependency status in all activities. Emotional dependency (amae) is widely accepted in Japanese society (Cathcart \& Cathcart, 1985; Itasaka, 1976).

A cliche familiar to all Japanese is found in the words "to hear one and understand ten" which is commonly interpreted as the act of understanding a whole idea upon 
hearing only a part of it. This encourages Japanese to catch on quickly to another's intention or desire before the thought is completely expressed verbally (kotowaza ziten, 1987). "Intuitive sense" (ishin-denshin) is described as an important and distinctive component of communication among the Japanese (Ramsey, 1985). "Ishindenshin (intuitive sense) is communication of thought without the medium of words" (Japanese Business Glossary, 1983 , p. 68). One Japanese may understand easily what another Japanese is thinking because their society puts a priority on harmony in relationships, having developed "many formalities, conventions and common standards" (Japanese Business Glossary, 1983, p. 70). Ramsey (1985) explains this process citing Ishii's Enryo-Sasshi Communication Model. "Enryo means reserve or restraint while sasshi means to surmise or guess" (Ramsey, 1985, p. 312). A sender filters his own behavior and a receiver pays great attention to what is not said in order to "expand the message" by filling in the guessed or surmised information (Ishii, 1973). Before an idea is logically and clearly enunciated, it is valuable (for the sake of communication) for each person to adjust to the other's thought or feeling. Not surprisingly, the Japanese possess a high tolerance for ambiguity (Ishii, 1973; Nadler, Keeshan-Nadler, and Broome, 1985). The notion of sasshi (to surmise or guess) is efficient for communication in 
Japanese culture (Nakanishi, 1986).

The Japanese place immense value on harmony in interpersonal relationships (Gudykunst \& Nishida, 1984; Hall, 1976; Kunihiro,1976; Nakane, 1974; Okabe, 1983), and thus exists the need for their highly structured system of social groupings and non-confrontational styles. According to this concept, harmony is attained by determining socially appropriate behaviors within a given context (Gudykunst \& Nishida, 1984).

on the other hand, U.S. group communication tends to be characterized by "frank, open, and candid statements expressing individual personal feelings, wishes, and dislikes" (Cathcart \& Cathcart, 1985, p. 194). U.S. individuals might feel free and even obligated to express their honest thoughts and feelings and to accept the different opinions of others.

U.S. culture also stresses "equality, informality, impermanence and personal detachment in social interaction" (Stewart, 1971, p. 45). One of the most fundamental of U.s. cultural values is equality, which contrasts to Japanese hierarchical relationships (Sakamoto \& Naotsuka, 1982). In the U.S. even when people are of different ranks, they are expected to be less concerned with status differences than their Japanese counterparts (Sakamoto \& Naotsuka, 1982). In Japan, even very small age differences are important and can affect a relationship. This makes it 
difficult to form a close friendship with someone of dissimilar age (Sakamoto\& Naotsuka, 1982). U.S. individuals place less emphasis on each other's ages, and "everyone is considered to belong to the unspecified age group of 'adult'" (Sakamoto \& Naotsuka, 1982, p. 16). Sakamoto and Naotsuka (1982) mentioned the polite behaviors of both cultures:

In Japan, you must politely emphasize the other person's superiority and power, and your own corresponding inferiority and weakness.... But in America, you must politely assume, not the other person's superiority or your own inferiority, but your mutual equality (p. 32-33). Informality is another characteristic of U.S. culture which contrasts with the formality of Japanese culture. The Japanese do not become close in their relationships as quickly as U.S. individuals do, but the latter have a tendency to behave like close friends without formality from the very beginning (Naotsuka, 1980; Sakamoto \& Naotsuka, 1982). This is called, in a standard English idiom, "breaking the ice" (Sakamoto \& Naotsuka, 1982, p. 15). On the other hand, sakamoto and Naotsuka characterize the Japanese practice of lengthy formalities as melting the ice slowly, which shows "a way of gradually easing into a closer relationship" (p. 15).

The U.S. cultural value of independence stands in further contrast to the dependency (amae) of Japanese culture. Japanese families encourage dependency in their children as they develop. As a result, the children learn 
to rely on others from the time that they are very young (Cathcart \& Cathcart, 1985). On the other hand, in the United states dependency is considered "a limitation on individual growth and fulfillment," and children are taught to be "self-reliant" (Cathcart \& Cathcart, 1985, p. 192). U.S. individuals try to be objective and balanced within their social relationships, which contrasts with "the paternal benevolence of the Japanese" (Stewart, 1971, p. 52). In the United States, generally, the individual can manage on his or her own (Sakamoto \& Naotsuka, 1982).

U.S. individuals also emphasize the individual as a concrete point of reference. "Each person should be encouraged to decide for himself, develop his own opinions, solve his own problems, have his own things, and in general, learn to view the world from the point of view of the self" (Condon \& Yousef, 1985, p. 65). The Japanese, however, "regard individuality as evidence of immaturity, and autonomy as the freedom to comply with one's obligations and duties" (Stewart, 1985, p. 187).

COMMUNICATION STYLES IN JAPANESE AND U.S. SOCIETIES

The Japanese value harmony in interpersonal relationships (Gudykunst \& Nishida, 1984; Hall, 1976; Kunihiro, 1976; Nakane, 1974; Okabe, 1983). Harmony, accordingly, is achieved by determining what behavior is socially appropriate within a given context (Gudykunst \& 
Nishida, 1984, p. 27).

Clark (1986) believes that a person has two communication approaches: the intuitive approach and the rationalistic approach. The intuitive approach focuses on values and attitudes which are group oriented, human relations oriented, emotional, practical, and intuitive. In contrast, a rationalistic approach focuses on principles, argument, debate, and ideology. Western cultures encourage both approaches in their communication styles (clark, 1986). Western culture encourages intuitive communication with families and intimate friends. Rationalistic communication is reserved for the corporate or national level of communication. Given a choice, the Japanese tend to use the intuitive approach on every level of their relationships (Clark, 1986).

Hall (1976) differentiates cultures into low-context and high-context cultures. Culture provides a selective screen between people within a group and the outside world, determining what is paid attention to and what is ignored. The high and low context continuum is the degree to which one is aware of the selective screen that one places between oneself and the outside world, what one pays attention to, context, and information overload, all of which are functionally related. As "high context" increases, the awareness of the selective process increases. In a high-context culture, people need fewer 
verbal messages. In a lower-context culture, people need more verbal information (Hall, 1976). On a continuum, the Japanese culture is considered to be more high-context, and U.S. culture more low-context (Hall, 1976).

In Okabe's (1983) study, verbal skills are more valued in a low-context culture than in a high-context culture (Gudykunst \& Nishida, 1986). As a high-context culture, Japanese culture emphasizes nonverbal communication, values interdependence and harmony, and encourages people to use words implicitly and ambiguously. In this type of communication system, it is important to know the context of a verbalization in order to fully understand it (Gudykunst \& Nishida, 1986).

In Japan, "Individual expressions of opinions are few, and traditionally the person who 'stands out' is not praised" (Condon \& Yousef, 1985, p. 67). Furthermore, talkativeness was traditionally "a sign of a person's 'shallow character'" (Morsback, 1973, p. 265). Japanese respect reticent people who are good at tacit agreements and despise people who make excuses, especially those who are adroit in defending themselves. The Japanese try not to express their opposing opinions too much. As a result, the Japanese give the appearance of being pleased to agree with another's opinion and repeat their words (Kindaichi, 1975). Conformity is the norm in Japanese society: the way a Japanese behaves is greatly influenced by the 
behavior of others and by his concern for what others will think of him.

In contrast to Western people who are more likely

to express their opinions openly in a selfasserting way, Japanese tend to speak and act only after due consideration has been given to the other person's feelings and point of view. Furthermore, there is a habit of not giving a clear-cut yes or no answer, a habit based on a long tradition of avoiding unnecessary friction. The fact that Japanese behave in this way and take attitudes for granted in their dealings with each other. . . These factors are also behind the tendency of Japanese toward self-indulgence with increasing familiarity (Nippon, 1984, p. 323325).

It often seems that U.S. individuals tend to think that if an individual does not express an opinion, he or she does not have one. Jensen (1985) states that in conversations, most Asians are much more reticent than U.S. individuals and are likely to choose their remarks carefully in order not to hurt the other's feelings or cause embarrassment. In regard to the Japanese, this is largely because they are less able to separate the criticism of issues from personal criticism. Thus, to a Japanese, criticizing his/her opinions or views means the same as criticizing the person. This leads to the Japanese use of ambiguity and indirect ways of speech (Jensen, 1985). U.S. individuals, on the other hand, do not necessarily consider the criticism of opinions or views as negative, and seem able to separate the issues from the person (Jensen, 1985; Sakamoto \& Naotsuka, 1982). It is possible that U.S. frankness and open criticism make the 
Japanese feel embarrassed and rejected (Jensen, 1986).

Since the Japanese value intuition, it is important for them to be able to attain meaning from more than the words spoken in order to communicate smoothly (Naotsuka, 1980). U.S. culture places a greater trust in language, than the Japanese culture, which does not trust language but rather values unspoken agreements. In this way, Japanese culture and U.S. culture seem to differ from each other (Naotsuka, 1980). The Japanese refrain from giving their opinions, but when they are forced to do so, they tend to appeal to the listener's emotion rather thean to reason (Kindaichi, 1975, p. 142).

\section{MALE AND FEMALE COMMUNICATION STYLES}

Not only may the communication styles between Japanese and U.S. cultures differ, but also their respective gender communication styles may differ, as well. Gender oriented research in the U.S. culture has been conducted from various perspectives. Wheeless and Duran (1982) state that "men are more aggressive and independent," women are "more gentle and dependent" (Wheeless and Duran, 1982, p. 52). Warfel (1984) discusses communication styles, stating that "males' speech tends to become assertive and females' speech supportive and non-assertive" (p. 254). Warfel (1984) writes that "women tend to use language forms that communicate and generate involvement in conversational 
activity" (p. 254). Berryman-Fink and Brunner (1987) examined self-reported interpersonal conflict management styles. They found that men are more likely to compete in conflicts than women, and that women are more likely to compromise in conflicts than men. Roloff and Greenberg (1979) studied the structure of boys' and girls' social relationships. When conflict occurred among friends, girls were not permitted to assert social power or superiority as an individual to solve it. Roloff and Greenberg (1979) discussed Treichler and Kramarae's idea that males in the U.S. culture learn the ability to take charge of situations and girls learn to allow males this control. The general orientation of women tended to be interactional, relational, participatory, and collaborative (Roloff \& Greenberg, 1979).

According to the research of Tardy and Hosman (1982), gender differences may affect the degree of self-disclosure that occurs in a given exchange. A survey of gender studies by cline and Musolf (1985), however, yielded results contradictory to Tardy's. One set of findings found nonsignificant results, while another implied greater disclosure by women than by men, and still another suggested that men's disclosure is greater than women's disclosure (Cline, 1983; Cline \& Musolf, 1985).

Papa and Natalle (1989) in a summary of Brooks (1974), DeForest and Stone (1980), Dooley, Whalen, and Flowers 
(1978), Greenblatt, Hasenare, and Freimuth (1980), Kohen (1975), LeVine and Franco (1981), Littlefield (1974), Montgomery and Norton (1981), Thase and Page (1977), arrived at three different conclusions concerning gender differences in conflict situations. Women self-disclose more than men (cf. DeForest \& Stone, 1980; Dooley, Whalen, \& Flowers, 1978; Greenblatt, Hasenare, \& Freimuth, 1980; LeVine \& Franco, 1981; Littlefield, 1974); there was no difference between men and women's amount of selfdisclosure (cf. Brooks, 1974; Kohen, 1975; Montgomery and Norton, 1981; Thase and Page, 1977); and men self-disclose more than women (cf. Gilbert and Whiteneck, 1976; Sermat and Smyth, 1973).

Pearson (1985) also stated contradictory findings in disclosure between men and women. Both men and women disclose almost equal amounts of negative statements about themselves, but men are less likely to disclose positive statements about themselves (Gilbert \& Whiteneck, 1976). Gilbert and Whiteneck's findings (1976) also show that women disclose negative statements with slightly greater frequency toward their friends than do men. However, other findings show that women are more likely to disclose negative information than positive information, and they disclose negative information about themselves more often than do men (Critelli \& Neumann, 1978).

In confrontation situations, men tend to face conflict 
in ways that allow them to "compete, exploit, and select 'rational' strategies," while women seek alternatives that allow them to "compromise, cooperate (unless exploited), or avoid competition" (Papa \& Natalle (1989) cite Terhune (1970), p. 261-2).

Until about the end of the eighth century, women in Japan were placed in a position of higher status. Eventually, the introduction of Confucianism, Buddhism and feudal rule forced women into complete subordination to men (Condon, 1985; Reischauer, 1983; Robins-Mowry, 1983). Confucianists considered women inferior to men, while Buddhists believed women were instruments of defilement. After World War II, the provisions of the 1947 constitution gave women full legal equality (Ishida, 1990). Condon and Yousef (1985) states that "the status of women in Japan is a function not of law, but of the deeply ingrained cultural patterns. Radical change will come slowly, if at all" (p. 6). Japan is still definitely a male-oriented society, with women confined to subservient positions. Women's status in Japan is also reflected in the Japanese language, characterized by formality, politeness, and softness. In serious discussions or in public places, women are overwhelmed by men. Women are required to follow more strict rules of politeness. It is more important for Japanese women to keep harmony than to insist on expressing their opinions (Ide, 1979). 
Wetzel (1988) compared communication styles between females in the west and the Japanese, both male and female. She found similar interaction patterns in communication behaviors between Western females and Japanese males and females in anthropological and sociological research. Her findings suggest the following similarities:

a) Women in the West make fewer direct declarations of fact or opinion than do men, very much like both males and females in Japan.

b) Western women's speech tends toward the creation of "solidarity" with the other, and Japanese tend to bring the out-group into the in-group in order to avoid potentially stressful debate.

c) Western women tend to use silence as protest after being interrupted. The Japanese may express their emotions (frustration or anger) by silence, or they might use slight gestures, such as avoiding eye contact with his or her partner, thereby showing their strong disagreement.

d) Western women tend to be "interactional, relational, participatory, and collaborative." In Japanese culture, empathy (omoiyari) is an important attribute to be considered morally mature and respected. "Omoiyari refers to the ability and willingness to feel what others are feeling." e) Western girls tend to express their thoughts or 
feelings about offenses through intermediaries rather than state them directly. Similarly, the Japanese tend to convey their accusations or protests by describing the disagreeable situation using someone else's name to be less offensive.

f) Western women tend to build upon and continue with

a topic of conversation initiated by someone else. In an effort to move a conversation forward smoothly, showing a concern for maintaining consensus, the Japanese will avoid expressing their opinions clearly and instead will seek to show that they understand what the other is saying by continuing along the same conversational line.

\section{CONFRONTATION SITUATIONS}

As mentioned earlier, conflict occurs in every culture. "Because individuals bring different levels of needs to transactions, interpersonal conflict is inevitable, particularly in situations in which the individuals represent different cultural systems" (Nadler, Keenshan-Nadler, and Broome, 1985, p. 87). Because people from different cultures interpret and respond to similar situations differently, it is easy to understand that when Japanese and U.S. individuals face conflict, their confrontation behaviors might differ (Porter and Samovar, 1985). 
Naotsuka (1980) wrote about the different styles of complaint behavior for Japanese and U.S. individuals. She cited cultural differences that can add to misunderstandings between Japanese and U.S. individuals, the former generally using an indirect approach with ambiguous words in order to be polite, and the latter preferring a more direct form of confrontation. Naotsuka (1980) also found that the indirect approach used by the Japanese was ineffective when the complaint was directed toward a U.S. individual. According to her, intonation in English is one of the clues through which speakers convey their inner feelings. A person can express subtle nuances of feeling (coldness, irony, and intimacy) by changing intonation. The Japanese, on the other hand, generally do not try to show their feelings by tone nor do they directly convey important messages in a direct manner. In order to be polite, they use a more roundabout form of speech filled with ambiguous words. While this may seem to contradict the previous assertion that the Japanese rely less on verbal language in these situations than do U.S. individuals, it must be remembered that U.S. individuals are placing much more importance on the content of what is said rather than on the form of what is said. It is crucial, therefore, for the Japanese to attempt through various means to discern the speakers' true meanings (Naotsuka, 1980). 
As an example, a Japanese may praise the other person instead of making a direct complaint. When a Japanese person is over-praised, he or she often becomes suspicious, and attempts to determine the speaker's true meaning by asking the praiser's true intention (Naotsuka, 1980). Many Japanese think that it is better to use a roundabout way of complaint and avoid confrontation, while U.S. individuals seem to feel the need to express their feelings more directly. An indirect complaint within the Japanese cultural context is an indication of an individual's wish to maintain or restore a positive relationship with the other person.

Group solidarity and harmony within interpersonal relationships are important concepts in the traditional societal norms of Japan. It is considered important to avoid self-assertion. The individual is expected to defer personal needs and feelings in an attempt to avoid confrontation within the group (Wagatsuma \& Rosett, 1985). Wagatsuma and Rosett (1985) further studied the cultural differences underlying different apologetic behaviors toward the law, finding significant cultural differences between Japan and the U.S. Because the use of direct confrontational language is viewed as negative in the former, they opt to use more nonconfrontational language and behaviors in conflict situations than in the latter. When attempting to avoid confrontation, Japanese often 
implement a form of circumlocution. U.S. individuals, on the other hand, are more likely to confront, believing it to be the responsibility of the people involved to express their point of view in a manner that can be readily understood. Thus, from the information expressed, a mutually acceptable culmination to the conflict can be reached (Wagatsuma \& Rosett, 1985).

However, because the Japanese view direct confrontation as negative, they try to use nonconfrontational behaviors in conflict situations. Fisher (1983) asserted that the Japanese look with distaste and embarrassment upon open disagreement. (as cited in Nader, Keenshan-Nader, \& Broome, 1985) Doi (1971) pointed out that facial expression or reluctant behaviors are exhibited when the Japanese are attempting to convey unwillingness to their partners, and it is up to their partners to discern what they are actually feeling. The purpose of this is to avoid situations in which direct confrontation may occur.

As stated previously, U.S. individuals value words, and express themselves using words (Lebra, 1984; Sakamoto \& Naotsuka, 1982). Stewart (1971) asserted that "Interpersonal relations are typically horizontal, conducted between presumed equals. When a personal confrontation is required between two persons of different hierarchical levels, there is an implicit tendency to 
establish an atmosphere of equality" (Stewart, 1971, p. 46). Direct confrontations and honest opinion exchanges are encouraged in U.S. culture (Nadler, Keenshan-Nadler, \& Broome, 1985; Naotsuka, 1980). In Nakamura's (1964) study, he stated that "When confronted with people who do not identify the self with the individual, U.S. individuals react with bewilderment, since the idea of the self not being located in the individual is culturally preposterous for most Americans" (Stewart, 1971, p. 67-68).

\section{YOUNG JAPANESE IN TODAY'S SOCIETY}

With the development of mass communication and technology, the Japanese have more contact with contemporary U.S. television, movies, and music than they have with similar media from other cultures. In other words, the Japanese have more opportunities to be exposed to elements of the culture of the United states than any other foreign culture (Taguchi, 1978). Gudykunst and Hammer (1987) mentioned that in 1979 Berger identified passive strategies which are implemented by Japanese visitors in the United states to gain insight into the latter's social behavior. He discovered that the Japanese gain information about the U.S. through the use of such secondary sources as books, television, movies, and observations of U.S. individuals interacting with each other. These behaviors help create stereotypes of the U.S. 
culture within the Japanese mind (Gudykunst \& Hammer, 1987).

Japanese young people consider many of their cultural traditions antiquated, and are abandoning them (Clark \& Takemura, 1979). They tend to believe that their behaviors are not so different from those of U.S. young people. Yet, they have unconsciously learned the specific rules and values rooted in customary Japanese human relations. They often perpetuate traditional Japanese cultural values (Clark \& Takemura, 1979). One book about Japanese business information, Japanese Business Glossary (1983), also observes that Japanese young people have become more individualistic and are losing components of traditional Japanese communication, such as ishin-denshin (intuitive sense). Nishida's study indicated that Japanese college students' values are more similar to U.S. college students' values than those of their parents (1981).

As Trommsdorff (1983) argued:

Japanese adolescents especially seem to suffer from discrepancies between values introduced from the west and their own traditional beliefs. Such conflicting values may induce insecurity as to which values and behaviors to choose and how to set priorities in everyday decision making. . . Group rather than individual activities are rewarded, the Western value orientation of individuality and autonomy is not really rewarded in Japanese culture. A passive orientation and devaluation of personal control may arise in such a case of conflicting values ( $p$. 354-355). 
The Japanese people now have more exposure to U.S. mass media, and also have many more opportunities for contact with Westerners than ever before. The attitudes toward confrontation in the Japanese culture, and the attitudes toward confrontation in the U.S. culture are contradictory. How are the Japanese adjusting their communication styles in both intracultural and intercultural confrontation situations? Are the Japanese living in the United states adapting and attempting to self-disclose more, or are they trying to retain their traditional Japanese behavior patterns and continue to avoid confrontation?

\section{PURPOSE OF THIS STUDY}

The purpose of this study is to investigate the different interpersonal confrontation styles of Japanese and U.S. individuals. Based on the above review of the literature, the research to be conducted here will examine the relationships between the two groups' respective reactions to confrontation situations and the demographic variables of Japanese and U.S. university students in the Portland Metropolitan area.

\section{HYPOTHESES}

Based upon previous research in the field, and variables addressed in this study, the following hypotheses 
are posited:

1. Japanese and U.S. subjects report different confrontation styles.

This is based upon the following assumptions which are derived from the literature review. Harmony is valued within the Japanese culture. Confrontation avoidance is more acceptable than direct confrontation (Cushman \& King, 1985). Conversely, individualism and equality are valued in the U.S. culture. These cultural values lead to a general assumption on the part of U.S. individuals that conflict resolution is not something negative (Cushman \& King, 1985). Thus, in confrontational situations, Japanese tend to use nonconfrontational approaches and U.S. individuals tend to use direct, confrontational approaches.

Consequently, a question about Japanese and U.S. confrontation styles arises. Do Japanese confrontation styles differ from U.S. confrontation styles?

2. Japanese report different interpersonal confrontation strategies when interacting with individuals from either Japanese or U.S. cultures.

In order to successfully communicate with people in the United States, many Japanese seek to develop insight into U.S. styles of direct confrontation. In Japan, Japanese are now surrounded by examples of U.S. culture, such as U.S. movies, TV programs, books, and U.S. visitors in Japan (Taguchi, 1978). Japanese society, however, is 
dnot kind toward those Japanese who have acquired certain behavioral elements from the other culture. Enloe (1987) stated as follows:

There is another consideration. The attitude of the Japanese toward foreign experience is a complex one. Japanese culture is uniquely homogeneous and advanced,--and by extension; any Japanese who becomes too familiar with foreign cultures--either through living in them or having extensive contact with foreigners--is thought to be in danger of having lost, in some sense, his purity as a Japanese (p. 245).

In order to retain Japanese communication styles during an extended stay in the United States, the Japanese may continue avoiding direct confrontation when dealing with other Japanese. When interacting with U.S. individuals, however, their communication behaviors may be different from confrontational styles with Japanese. Thus, does the interactants' cultures, Japanese or U.S., influence Japanese confrontation styles?

3. U.S. individuals report different interpersonal confrontation strategies when interacting with individuals from either U.S. or Japanese cultures.

In Barnlund's study, U.S. individuals use a narrow range of defensive reactions regardless of the degree of discomfort (Barnlund, 1975). The results also suggested that U.S. individuals do not change their behaviors towards different target persons according to how well they know them. U.S. individuals, in general, choose similar confrontation styles toward both Japanese and U.S. 
interactants. U.S. individuals who have interacted with Japanese culture, however, might have a better understanding of the cultural values of the Japanese. Therefore, they might be more adept at interpreting the non-confrontational behaviors and reciprocating them toward their Japanese interaction partners within a confrontational situation.

Do U.S. confrontation styles differ when interacting with individuals from U.S. or Japanese cultures? How do U.S. individuals behave with the two cultures during confrontations depending upon the influence of the Japanese culture?

4. Japanese and U.S. subjects do not report gender as a significant variable during confrontation.

The intercultural studies of Japanese and U.S. relationships reviewed above have failed to consider gender as a significant variable (Barnlund, 1975; Gudykunst \& Nishida, 1987; Nomura \& Barnlund, 1983). Gender will, therefore, be studied as a secondary variable. Do males and females within each culture exhibit similar confrontation styles with Japanese and U.S. interactants? 


\section{CHAPTER III}

\section{METHODS}

A number of hypotheses affecting interpersonal confrontation were identified: 1) behavioral differences exist within Japanese dyads and U.S. dyads during confrontation; 2) the Japanese interpersonal confrontation strategies differ when interacting with individuals from both cultures; 3) U.S. individuals' interpersonal confrontation strategies will similar when interacting with individuals from Japanese and U.S. cultures; and 4) gender may not be a significant variable in Japanese and American confrontations. Based upon these hypotheses, the following variables were created to provide data about various confrontation situations of Japanese and U.S. students in the United states. A questionnaire was designed to identify reported confrontation styles of individuals from both cultures, measuring the interactions of these individuals with others from both the same and the other culture.

\section{DEFINITIONS OF THE VARIABLES}

The variables within this study were:

1) confrontation styles within each culture; 2) confrontation 
styles toward another culture; 3) gender; and, 4) cultural commitment.

\section{Confrontation styles within each culture}

Confrontation styles within each culture were defined as communication styles reported by Japanese or U.S. individuals interacting with a person from the same culture over a conflict situation. In each episode, a confrontation situation contained four variables in reference to behavioral styles: casual friends with the same culture and the same sex; the same culture and the opposite sex; the other culture and the same sex; and the other culture and the opposite sex. Since this study examined dyads from the same culture, two variables (a casual friend with the same culture and the same sex, and a casual friend with the same culture and the opposite sex) in confrontation situations were applied.

\section{Confrontation styles toward another culture}

Confrontation styles toward another culture were defined as communication styles reported by Japanese or U.S. individuals interacting with a person from the other culture over a conflict situation. As dyads from the two cultures were examined, two variables (a casual friend with the other culture and the same sex and a casual friend with the other culture and the opposite sex) in confrontational situations were examined. 
Gender (Male and Female)

Gender differences investigated behavioral styles concerning Japanese and U.S. individuals when confronting persons from the same culture and/or the other culture. The Japanese and U.S. responses were examined between male and female within each culture.

\section{Cultural commitment}

Cultural commitment was defined as a person's degree of commitment to both his/her own culture, and the opposing one. The variables proposed as indicating the degree to which a person favors another culture were: the length of stay in the other culture, second language ability, the level of social interaction, one's preference of cultural groups (based on comfort level), and the person's preference as to which country they chose to live.

\section{RESEARCH METHOD}

This study employed descriptive statistical analysis, defined according to Babbie as, "statistical computations describing either the characteristics of a sample or the relationship among variables in a sample" (Babbie, 1989, p. G3) .

other related topics are also discussed in this section: the subjects of the research, development of the questionnaire addressing episodes, the scale of measurement 
(e.g., the response scale), and specific characteristics of the communication partner.

\section{SUBJECTS}

The data used in this study were collected from a convenience sample of Japanese and U.S. college students. The young segment of any society is an important age cohort and "also may be more sensitive to the contemporary values of the culture than the older generation" (Nakanishi, 1986, p.173). Numerous studies of college students' research have been conducted in the United States (Nakanishi, 1986). In the present study, college students were chosen as representatives of the two cultures because of their equal educational situation and their convenience as test subjects.

As noted in chapter I, a total of 112 Japanese students ( 37 male and 75 female) were registered for the 1990 winter term at a large Northwestern university. As this was not considered a sufficient number of subjects, Japanese students at other colleges in the greater Portland area were also asked to participate. The relatively small number of Japanese students attending universities in the Portland area limited the number of questionnaire respondents to one hundred. This was balanced by the inclusion of one hundred U.S. respondents. Because of the limited number of the Japanese students available, and the 
nature of the sample, the number of Japanese male and female students were not equally divided. Similarly, the number of U.S. male and female students also were not equal.

When selecting the respondents, the following were considered: (1) The respondents should be native Japanese or U.S. citizens residing in the United States; and (2) they should be currently enrolled in universities in the Portland Metropolitan area.

\section{DEVELOPMENT OF THE QUESTIONNAIRE}

The process used to develop the questionnaire went as follows: (1) Nomura's research provided the basis of this study; (2) a face-to-face pre-test questionnaire was administered to Japanese and U.S. individuals; (3) based on the pre-test, a response scale was developed; and (4) a fictional target person in the test questionnaire was created, based upon a modified Interpersonal Criticism Questionnaire (Nomura, 1980). Data for the pre-test were collected from both the Japanese and U.S. subjects utilizing the researcher's personal network of contacts.

\section{Nomura's Research}

Nomura's research method combined a qualitative interview approach with a quantitative scaling of responses. The construction of the episodes and the way of dealing with dissatisfaction of the present study were 
based on his interviews. A variety of topics were categorized into 12 episodes. First, the communication partners in the dyads were clustered into four groups: parents; close friends; acquaintances; and strangers. Then, the dyads were classified according to gender. Thus, communication partners were categorized into eight groups. Nomura refined and developed the styles of expressing criticism within each episode into an eleven point scale. Eleven styles of criticizing were listed on the interval scale, ranging from passive-withdrawal to active-aggressive (see Appendix B) .

\section{Pre-test of the Instrument}

Even though Nomura's test exhibited high reliability, a pre-test was conducted for this study to further determine the appropriateness of this instrument for the present population. Eleven students enrolled at a Northwestern university, not included in the sample for the research, volunteered for this pre-test. Two Japanese males, seven Japanese females, and two U.S. males were interviewed for their reactions to nine of the twelve episodes included in Nomura's study. Because detailed replies of these situations took time, each student was given nine different situations out of the total 12 episodes from the Interpersonal Criticism Questionnaire (see Appendix B). The data were collected by the researcher in face-to-face interviews, conducted in 
English, from the U.S. subjects, and in Japanese from the Japanese subjects. In each case the researcher asked the subjects to describe their reaction as fully as possible to the hypothetical situations in the episodes used.

\section{Development of the Episodes}

According to Nomura (1980) the episodes noted in the Interpersonal Criticism Questionnaire occur with about the same level of probability in both cultures, and are flexible enough to accommodate a wide variety of communication partners. Since the subjects of the pre-test themselves described these episodes as situations which occur in a typical day in both cultures, confirming Nomura, these same situations were used in this study.

The majority of the pre-test Japanese interviewees reported that, in a conflict situation, they first express their opinions or feelings very delicately to see how their partner will react. If their partner agrees with them verbally, or if they feel the partner accepts their opinion or feelings nonverbally, they then express their feelings more openly. However, if the partner does not seem to agree with them, they tend to withdraw.

Based on this pre-test information, a second situation, dealing with confrontation, was added to each of the episodes. Thus, like Nomura's questionnaire, the first situation depicts an expression of dissatisfaction, while the second situation depicts an expression of 
confrontation. However, because each situation then doubled in length, this researcher was concerned that the respondents might become frustrated with the length of the questionnaire. A lengthy questionnaire might negatively influence the respondents' motivation for answering the questions (Hotta, 1990). Six out of the twelve situations from the Interpersonal Criticism Questionnaire were chosen for this study (see Appendix B).

In his questionnaire, Nomura (1980) included twelve episodes. These episodes identified Japanese and U.S. subjects' confrontational differences in situations which were dissatisfying to the participants (e.g., physical injury, disappointment, and disagreement).

In another study of self-disclosure, Gudykunst and Nishida (1983) compared cross-cultural friendships both in Japan and the United States, using items from Altman and Taylor's questionnaire. Their results suggested that Japanese dyads are likely to discuss the following five topics more frequently and more intimately than their U.S. counterparts: 1) interests and hobbies; 2) school and work activities; 3 ) physical condition and attractiveness; 4) religion; and 5) money and property. Furthermore, U.S. dyads, in comparison with the Japanese dyads, were more likely to discuss three topical areas which deal with "current or potential relationships with members of the opposite sex"--dating, marriage, and emotions (Gudykunst 
and Nishida, 1983).

of the topics mentioned above, the present researcher developed an additional situation involving money and added it to the present questionnaire.

Thus, this study consisted of six modified versions of Nomura's episodes, with one additional discomfort episode (lending money), and seven confrontational episodes created by the researcher with the assistance of other Japanese and U.S. graduate students and the guidance of her thesis adviser. These modifications were developed by the author to further study the confrontation styles of the two cultures. The seven situations are:

Situation 1. Mismanagement of time:

The respondent wanted to go to the concert with his/her casual friend. The respondent was looking forward to the concert very much. But, on the day of the show, the friend came late, and the respondent missed the first half of the concert. No explanation was offered by the friend.

Situation 2. Interference of study:

The day before an examination, the respondent's casual friend was listening to loud music in the next apartment. The respondent mentioned the music, but the friend did not turn the volume down.

Situation 3. Defamation of a friend:

A casual friend unreasonably criticized the respondent's friend of the opposite sex.

Situation 4. Criticism of school work:

A casual friend unreasonably criticized the respondent's class presentation.

Situation 5. Littering:

A casual friend threw an empty soft drink can out of the window of the car, subsequently ignoring the respondent's protests. 
Situation 6. Different values:

A casual friend persisted in attempting to

persuade the respondent to agree with his/her

opinions about gender roles in society.

Situation 7. Matters of money:

A casual friend borrowed money from the respondent and did not return it, but instead repeatedly asked to borrow more money from the respondent.

Development of the Response Scale

After the pre-test data were collected, the students' self-described reactions were compared to the items of Nomura's scale. Since Nomura adopted his final response scale from Barnlund's Defensive Strategy scale (Barnlund, 1975), the students' reactions were also compared with the items of Barnlund's scale.

The findings of the pre-test for the present research indicated that the Japanese students: (1) preferred to "reply half-jokingly" more frequently than U.S. students; (2) tended to use more nonverbal behaviors in confrontational situations than their U.S. counterparts (e.g., choosing to keep silent, make a gesture of surprise, or utter a faint surprised voice); and (3) tended to agree with the "forceful" opinions or feelings of the other, offering no strong opposition.

In contrast, U.S. students: (1) tended to reply seriously more often; (2) preferred to adopt more verbal confrontational behaviors, such as asking for the partner's explanation directly, or explaining their thoughts (or 
reasons for their behavior) without hesitation or exchanging opinions more often when disagreeing with each other.

The pre-test results contributed in several ways to the refinement of a more systematic questionnaire on confrontation styles. Two additional items, "indicate agreement with your friend even though you do not actually agree" and "brief verbal exclamation to your friend in response to your friend's remark or behavior," were added to the response scale. Furthermore, the statement, "I would probably attempt not to show my dissatisfaction" was rephrased to say "remain silent and not show my dissatisfaction or disagreement." This reversed statement was clearer to the respondents than the previous statement. Nomura concluded (1980) that the behavior for expressing dissatisfaction used most frequently by both Japanese and U.S. students was the direct approach. Since more than half of the questions involving friends and acquaintances were responded to with "in a direct way" in Nomura's results, the item "in a direct way" was divided into more detailed categories. In his follow up, Nomura focused on the "direct approach," which suggested that the Japanese "often express their complaints in a playful and half-joking manner, while U.S. students expressed theirs "in a more abrasive and trenchant manner" (Nomura \& Barnlund, 1983, p.15-16). 
Based upon the pre-test results and Nomura's follow up research, four items were added to the scale. These categories are: "nonchalantly;" "seriously;" "halfjokingly;" and "angrily."

The descriptive category of "I would probably express my dissatisfaction to a third person" was eliminated, since the conversation was between individuals in dyads only, without inclusion of a third person. The category of "I probably would not feel dissatisfaction towards such speech and behavior" was eliminated, because it concerned a person's inner feeling, but not his or her behavior.

Barnlund's descriptive categories of "hint verbally (that) I preferred not to answer" was rephrased to "express yourself with a slight gesture or facial expression or a brief verbal exclamation." The other categories of "change the subject," "say I did not want to discuss it" and "defend myself by explanation and argument" were added to the scale. The item, "use humor or sarcasm to put them in their place" was combined and also added to the list of categories for this study.

The final listing for the response scale was developed from a second pre-test. Volunteers were gathered through the researcher's personal contacts. Ten Japanese and ten U.S. students (different from those who answered the first pre-test) were asked to numerically order the twelve alternate ways of confrontation styles according to the 
perceived levels of aggressiveness for each, from the most passive/indirect to the most aggressive/direct (see Appendix C) .

From these data, the items on the scale were placed in their final order by determining the mean rating of each item by both cultures. The final form of the response scale is shown in Appendix $C$.

\section{ordering of the Response scale}

1. Indicate agreement with your friend, even though you do not actually agree.

2. Remain silent.

3. Express yourself with a slight gesture, or facial expression, or a brief verbal exclamation.

4. Change the subject.

5. Express yourself in ambiguous language.

6. Express yourself nonchalantly.

7. Express yourself half-jokingly.

8. State that you do not want to discuss it.

9. Express yourself seriously.

10. Argue your point of view.

11. Show your dissatisfaction or disagreement with a sarcastic or an insulting remark.

12. Express yourself angrily.

Communication Partner

The literature review suggested that there might be differences in behavior depending on the communication partners involved. Self-disclosure for Japanese and U.S. 
cultures in communication partners was examined: Nomura (1980) examined parents, close friends, acquaintances, and strangers; Barnlund (1975) examined parents, friends, untrusted acquaintances, and strangers; and Gudykunst and Nishida (1983) examined close friends.

In the first pre-test of the present study, the students were asked to describe their reactions to three types of communication partners: friend, acquaintance, and stranger. These were chosen because the present study examines individuals' confrontation styles in various situations in intracultural and intercultural relationships. During the pre-test, most students had difficulty imagining themselves with acquaintances and strangers in these situations (such as going to concerts with them, or repeatedly lending them money). It also seemed to be difficult for them to hypothesize about their friends' behaviors toward them in these confrontations. Gudykunst and Nishida studied the friendships based on the model of a four-stage model of relationship development: orientation, exploratory affective exchange, full affective exchange, and stable exchange (Altman and Taylor, 1973). The characteristic of casual acquaintance or non-intimate friends was included at the second stage--exploratory affective exchange. Relationships at this stage are "generally friendly and relaxed, but commitments are only limited or temporary" (Altman and Taylor, 1973). The close 
friendship characteristic is included in the third stage-full affective exchange. These relationships are "loose" and "free-wheeling," allowing both interactants to interact verbally and increase the amount of self-disclosure (Gudykunst and Nishida, 1983). The casual friend seemed the best communication partner for this study, because the volunteer respondents could imagine being in the types of situations involved. Close friends, on the other hand, would know each other too well, making it difficult to visualize them as the communication partners of the study.

\section{Instrument}

The questionnaire for this study (see Appendix D) consists of two sections: Part 1 had demographic questions, and part 2 had questions on dissatisfaction behaviors, confrontation behaviors, and the degree of discomfort in each situation. The demographic information consisted of: A) the respondent's gender, age, and academic background; B) marital status and the spouse's culture (if married); c) the culture of the respondent's close friend of the opposite sex (if he/she has one); D) the percentage of the respondent's friends from own culture; E) the length of the respondent's stay in the United States (if Japanese); F) self-rated other language proficiency (either Japanese or English); G) the preference for place of residence (either Japan or U.S.); and I) the preferred length of stay in the other country. 
In part 2 of the instrument, the respondent's confrontation style was examined according to his/her culture, gender, and the communication partner's culture. The modified version of Nomura's Interpersonal Criticism Questionnaire was administered. Each of the seven episodes included self-reported behaviors with two types of casual friends: Japanese and U.S. individuals. The choices offered in each scenario were concerned with two types of behavior: dissatisfaction and confrontation. The subjects were asked to choose one of 12 items which they felt best described, or would be most reflective of their behavior in the type of situation described in the scenario.

\section{TRANSLATION}

Two versions of the questionnaire were prepared for the subjects: Form A written in English for U.S. students and Form $J$ written in Japanese for the Japanese students. To minimize the risk of question misinterpretation, the following process was used. The researcher, as the first translator, did the translation of the questionnaire from English into Japanese. The second translator, an instructor of Japanese in the foreign language department at a large Northwestern University, translated the same document without seeing the translation completed by the first translator. They then conferred and agreed upon a common translation. A third translator, another instructor 
of Japanese at the same university, examined both the English and the agreed-upon translated questionnaire, and concurred that they accurately corresponded.

\section{DATA COLLECTION}

After the review and acceptance of the current study by the University Human subjects committee, the data was collected in three ways, with each respondent being assured in a cover letter that their questionniares were confidential. First the researcher made person-to-person contact through her personal network with the majority of the subjects and asked them to fill out the questionnaires directly. Second, the researcher distributed the questionnaires in the classroom, mainly to U.S. subjects. Third, in a snowball effect, friends of the researcher distributed the questionnaires to their friends, and then collected and returned the finished questionnaires to the researcher, mainly to Japanese subjects.

\section{DATA ANALYSIS}

Since this was a descriptive study, confrontational strategies were measured by examining the form of behavior chosen and the situations in which the behavior occurred in each of the seven episodes described. The data obtained were coded by the researcher (see Appendix F). The Statistical Package for Social Sciences (SPSSX) 
was utilized to summarize the data. A $\underline{t}$ test for independent samples was employed to identify the differences between Japanese and U.S. subjects in their general confrontation styles for Research Question 1. A paired $t$ test for related samples was applied to investigate Japanese confrontation styles with Japanese and U.S. partners for Research Question 2. Another paired $\underline{t}$ test for related samples was applied to examine the opposite situation, U.S. subjects confrontation styles with U.S. and Japanese partners for Research Questions 3. Finally, a $t$ test was employed to examine the differences between Japanese male and Japanese female confrontation styles, and also the styles of their U.S. counterparts for Research Question 4.

\section{Summary}

In order to investigate the differences and similarities in interpersonal confrontation styles of Japanese and U.S. cultures, a modification of Nomura's Interpersonal Criticism Questionnaire was utilized as the instrument for this study.

Based on the pre-test, six scenarios were taken from Nomura, and a seventh was added. A response scale of 12 items was developed, ordered from the most passive/indirect to the most active/direct form of confrontation style. A "casual friend" communication partner was created, so that the subjects could imagine being in these situations more 
easily. Subjects were 100 Japanese and 100 U.S. college students, but the number of male and female students was not equally divided. 
CHAPTER IV

RESULTS

This chapter presents the results of this research data with regard to cultural comparisons of Japan and the United States, as well as responses by gender between and within the two cultures. This research examined the confrontation style reported by the subjects.

First, the survey results will be presented in regard to the subjects' demographic information and confrontation styles. All demographic data are shown in Appendix A. Second, specific correlations between the above two points will also be discussed.

\section{CHARACTERISTICS OF THE SAMPLES}

\section{Description of the Japanese Subjects}

One hundred seventy questionnaires were administered to Japanese subjects. One hundred and ten of these questionnaires were returned, with ten questionnaires incomplete in part two. Thus, one hundred questionnaires were completed, which resulted in a return rate of 58.8 percent.

The total of 100 Japanese respondents in this study included 32 males and 68 females ranging in age from 20 to 
50 years. The mean age was 25.7 with a standard deviation of 9.8 (see Appendix A).

The educational demographics of this sample were categorized by the schools they attended, their majors, and their academic levels. Fifty-one Japanese subjects attended Portland state University, and 34 attended other universities and colleges in the state of oregon. Three subjects attended universities in other states, and four Japanese attended universities in Japan, but were studying English for a varying lengths of time in the United states. Eight did not respond.

Concerning their marital status, 15 were married, 84 were single, and one was divorced. Among the married, seven Japanese were married to Japanese, and six were married to U.S. individuals. Among those single and divorced, 35 Japanese (41.2\%) did not have close friends of the opposite sex. Forty-nine Japanese (57.6\%) had close friends of the opposite sex. One respondent did not state anything about having a close friend. The above respondents answered that their close friends' cultures were: Japanese-27; U.S.-11; Others-10. Among the 85 single Japanese, the first preference regarding the culture of potential spouses was high in Japanese: Japanese-54 (65.18); U.S. -11 (13.38); others-2 (2.4\%); and Makes Little Difference-16 (19.3\%). Two did not respond.

The culture groups with which the Japanese subjects 
reportedly felt most comfortable were: Japanese alone-64 (65.38); U.S. alone-6 (2.0\%); both Japanese and U.S. -3 (3.1\%); others-3 (3.1\%). Twenty-two (22.4\%) other Japanese said that they feel comfortable with any cultures. Two respondents did not state any cultural preference. As for friendship networks, the mean of the number of Japanese friends of each Japanese subject was $50 \%$. The average Japanese subject's self-rated English proficiency level was "Functional."

The length of their stay in the United States ranged from one month to eight years and seven months. The average length of their stay was two years and two months. Their most common purpose for living in the U.S. was to obtain a degree (65\%). Concerning which country they preferred to live in, 28 Japanese preferred to stay in the United States, 22 preferred Japan, and 49 did not mind whether they lived in either the U.S. or Japan. One did not respond (see Appendix A).

\section{Description of the U.S. Subjects}

one hundred ninety two questionnaires were distributed to U.S. university-level students. Of the total number of 115 returned questionnaires, 15 were incomplete in part 2. one hundred questionnaires were completed, which resulted in a return rate of 52.1 percent.

Among the $100 \mathrm{U} . \mathrm{S}$. respondents, there were 42 males and 58 females ranging in age from 20 to 55 . The mean age 
was 30.3 , with a standard deviation of 9.2 (see Appendix A) •

The schools which the U.S. respondents attended were mainly PSU (84) and various universities throughout oregon (13). Three did not respond.

Regarding their reported marital status, 23 of the U.S. subjects were married, 62 were single, 12 were divorced, and three separated. Among those married, 17 were married to U.S. individuals, four to Japanese, and two to individuals of other cultures. Among those U.S. respondents who were not married (a total of 77), 38 had close friends of the opposite sex, while 38 did not. The cultures of their close friends of the opposite sex were: U.S. -27 (69.2\%); Japanese-5 (12.8\%); and Other-7 (18\%). Among the single population (77 respondents), the cultural preference for a prospective spouse was: U.S. -25 (33.3\%); Japanese-5 (6.7\%); Other-8 (10.6\%); and Makes Little Difference-37 (49.3\%). Two students did not respond.

The cultures with which all U.S. respondents reported feeling most comfortable were: U.S. -26 ; Japanese-3; both Japanese and U.S.-1; and other-1. However, many U.S. subjects seemed relatively more flexible in their friendship with people of other cultures, since for 69 of them, it made little difference which culture they reported feeling most comfortable with. The mean percentage of friendships they had with U.S. friends was $75 \%$. 
The average U.S. self-reported Japanese language proficiency level was "know a few words." Thirty-three U.S. respondents had had some experience of visiting or living in Japan for various purposes, and 67 U.S. respondents had not.

Forty-eight U.S. subjects reported a preference for living in the U.S., while 16 preferred to live in Japan, and nine did not mind living either in the U.S. or Japan.

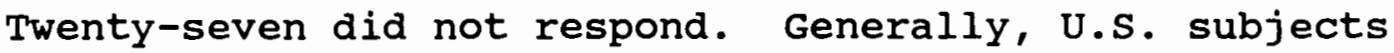
preferred living in their own country more than Japanese subjects preferred living in Japan (see Appendix A) .

\section{INDEPENDENT VARIABLES AND CONFRONTATION STYLES}

The independent variables used in relation to confrontation styles were chosen from the items on the response list with four communication partners in each situations (see Appendix E). Casual friends:

1. from the same culture and the same sex

2. from the same culture and the opposite sex

3. from the other culture and the same sex

4. from the other culture and the opposite sex

\section{The Variable Means}

The means of the variables from each culture are shown in Appendix E. These variables were utilized in several ways. First, in order to obtain the general confrontation 
styles of both groups, all the above mentioned variables were clustered into one category and divided by the number of respondents for research question one. For research questions two and three, all the above mentioned variables were divided into two categories depending on the partner's culture in each sample. In research question four, all variables in the samples were categorized by gender within cultures (Japanese male and Japanese female in the Japanese culture, and U.S. male and U.S. female in the U.S. culture).

\section{EXAMINATION OF HYPOTHESIS ONE}

HYPOTHESIS 1

Japanese and U.S. subjects report different confrontation styles.

\section{Variables}

Using a $\underline{t}$ test, Japanese and U.S. means of the confrontation scores with a casual friend from the same culture and from the other culture were compared. The significance level for this research is set at .05 .

TABLE I

OVERALL CULTURAL COMPARISON: JAPANESE AND U.S. SAMPLES

\begin{tabular}{lcclll}
\hline & $\begin{array}{l}\text { Number } \\
\text { of } \\
\text { Cases }\end{array}$ & Mean & $\begin{array}{l}\text { t } \\
\text { Value }\end{array}$ & $\begin{array}{l}\text { Degrees } \\
\text { of } \\
\text { Freedom }\end{array}$ & $\begin{array}{l}\text { 2-tail } \\
\text { Prob. }\end{array}$ \\
\hline Japanese & 90 & 5.8974 & .01 & 176.98 & p $>.05$ \\
U.S. & 89 & 5.8959 & & & \\
\hline
\end{tabular}


The $\mathrm{p}$ value of the Japanese and U.S. mean responses indicated that no significant difference (alpha $=.05$ ) existed between the two cultures regardless of who they were confronting (see Table I). The result suggests that Japanese and U.S. subjects may exhibit similar confrontation styles within the seven interpersonal situations.

\section{Types of social situations}

In order to examine cultural similarities and differences, it is important to compare the two cultures to determine if members of each culture adopt different forms of confrontation when interpersonal confrontation arises in different situations. Confrontation styles in seven situations, representing various sources of interpersonal confrontation, were compared between the two cultures.

Japanese and U.S. responses were compared with regard to each type of social situation. Comparisons between the two cultural groups were also made to see what, if any, contrasts might be found between them (see Table II).

significant differences were found with regard to "criticism of a class presentation" ( $t=2.66 ; \mathrm{p}<.05)$, "littering" ( $\underline{t}=-3.90 ; \underline{p}<.001)$. The Japanese and U.S. respondents are likely to differ in their preferred confrontation styles when the following situations arise with a member of another culture: 4) being criticized for school work, and 5) throwing an empty can from a car. 
TABLE II

CONFRONTATION STYLES IN SOCIAL SITUATIONS BETWEEN JAPANESE AND U.S.

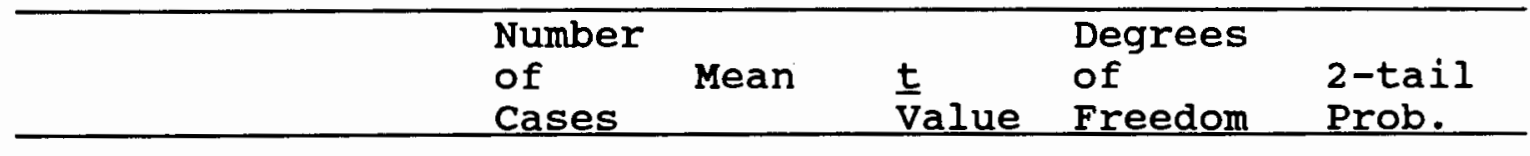

situation 1 .

Mismanagement of time:

$\begin{array}{lrrrrr}\text { Japanese } & 95 & 5.7658 & 1.30 & 189.76 & \text { p }>.05 \\ \text { U.S. } & 100 & 5.2037 & & & \end{array}$

Situation 2 .

Interference of study:
Japanese
U.S.
$96 \quad 6.9180$
$1.00 \quad 192.56$
p $>.05$
$99 \quad 2.9359$

Situation 3 .

Defamation of a friend:
Japanese
U.S.
99
$99 \quad 6.3359$
$.09 \quad 195.99$
p $>.05$

situation 4.

criticism of school work:
Japanese
U.S.
996.7260
$2.66 \quad 180.25$
p $<.05 *$
$98 \quad 5.8087$

Situation 5 .

Littering:

Japanese

U.S.

$\begin{array}{lll}94 & 3.9322 & -3.90\end{array}$

$188.86 \mathrm{p}<.001 * * *$

$98 \quad 5.5893$

Situation 6 .

Different values:

Japanese

U.S.

$\begin{array}{lllll}96 & 5.6693 & -1.26 & 178.33 & \mathrm{p}>.05\end{array}$

$93 \quad 6.1344$

Situation 7 .

Matters of money:

Japanese

U.S.

$97 \quad 6.1289$

$98 \quad 5.6582$

1.19

192.45

$\mathrm{p}>.05$

* Significant at the .05 level

** Significant at the .01 level

*** Significant at the .001 level 
Thus, Japanese respondents preferred more direct ways of handling confrontation situations than the U.S. respondents in situation 4 .

with regard to "littering", the comparison of the mean scores of the two cultures suggests that American respondents reported exhibiting more direct confrontation styles than Japanese with regard to "littering." The Japanese and U.S. confrontation styles are likely to differ when their casual friends throw an empty can from a moving car.

The data for two-tailed probability showed no significant differences within the two cultures in regard to confrontion for the other five situations (see Table II). The Japanese and U.S. respondents are likely to choose similar confrontation with regard to a friend's being late for a concert, making continuous noise during study, disagreeing about beliefs, and asking to lend money. The first hypothesis was partially supported in Japanese and U.S. subjects.

Profile of the two cultures:

Japanese and U.S. interaction

In order to obtain a clearer picture of the profiles of confrontation styles used in the two cultures, the results were summarized and translated into percentages (Figures 1 and 2). 
Form of Confrontation

Frequency of Choice

1 Indicating agreement

2 Remaining silent

3 Nonverbal/verbal exclamation

4 Changing the subject

5 Replying ambiguously

ㄱ $\begin{aligned} & 2.68 \\ & 1.08\end{aligned}$
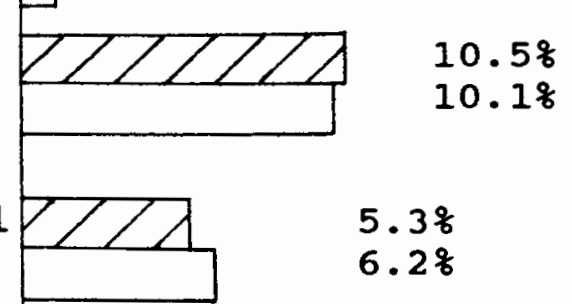

$8.6 \%$

9.78
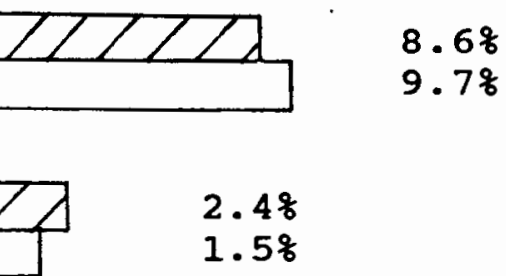

6 Replying nonchalantly

7 Replying half-jokingly

8 Not wanting to discuss

9 Replying seriously

10 Arguing

Replying with

11 sarcastic/ insulting remark

12 Replying angrily

$1.5 \%$
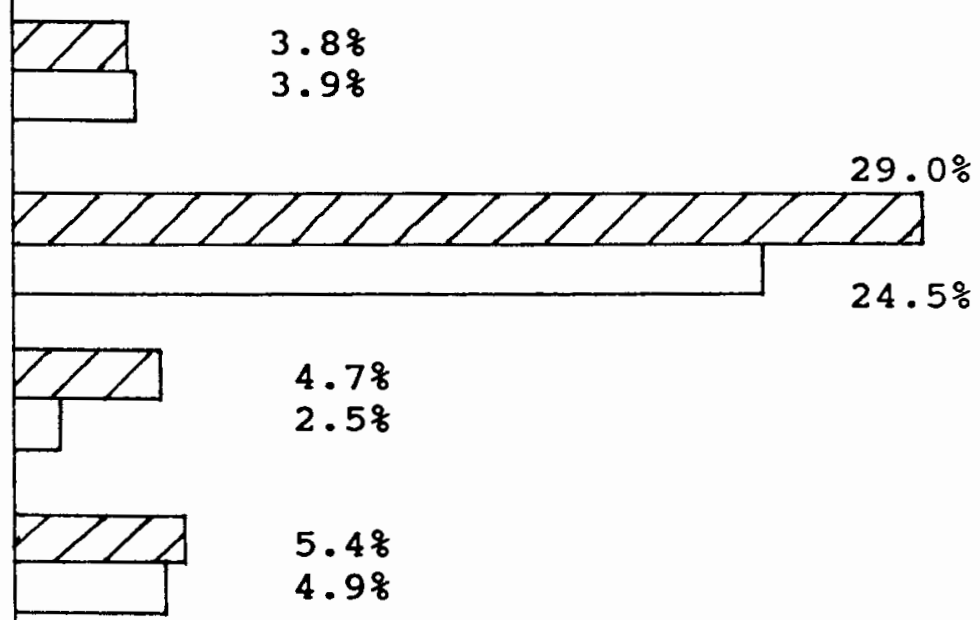

$13.7 \%$ $20.6 \%$
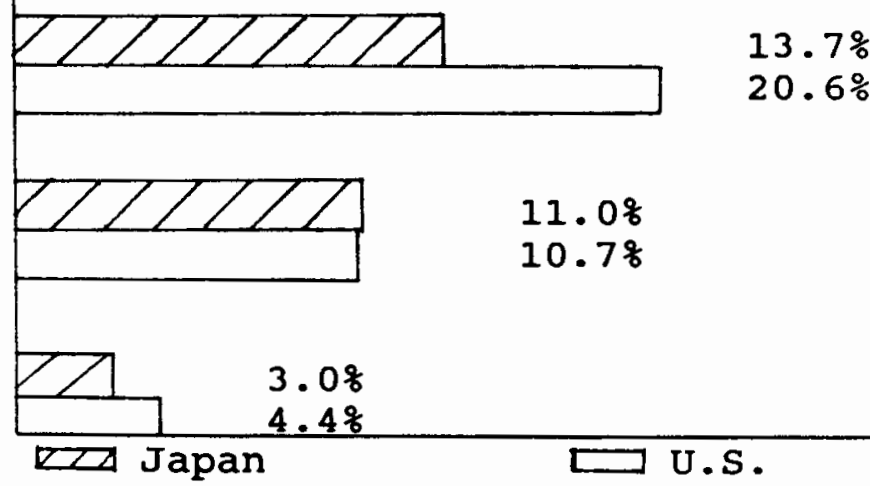

Figure 1. Frequency of choice by homophilous dyads (Japanese interacting with Japanese/ U.S. interacting U.S.). 
Form of Confrontation

Frequency of Choice

1 Indicating agreement

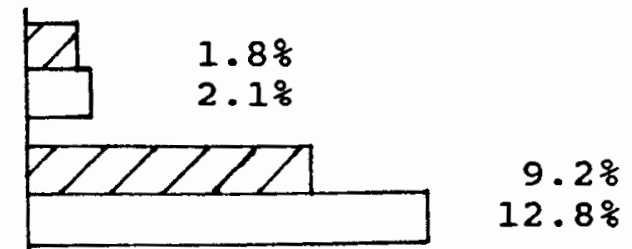

3 Nonverbal/verbal exclamation

4 Changing the subject

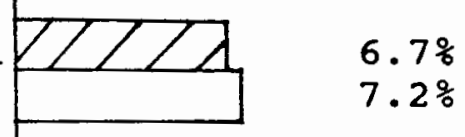

5 Replying ambiguously

6 Replying nonchalantly

$7 \quad$ Replying half-jokingly

8 Not wanting to discuss

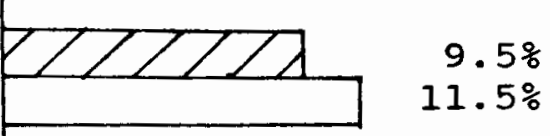

9 Repling seriously
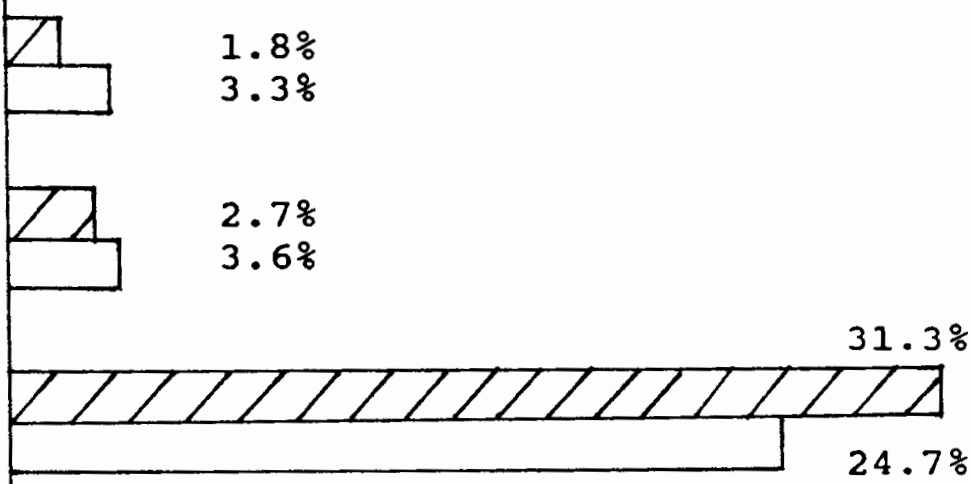

10 Arguing

Replying with

11 sarcastic/ insulting remark

12 Replying angrily

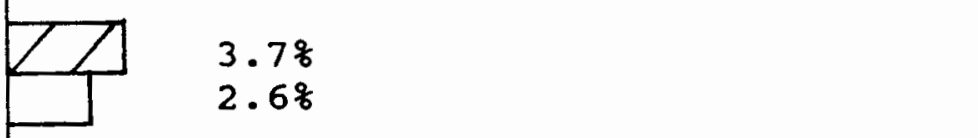

$5.8 \%$

$4.8 \%$
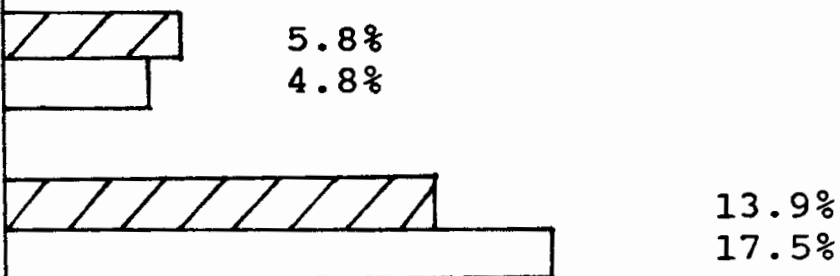

$17.5 \%$

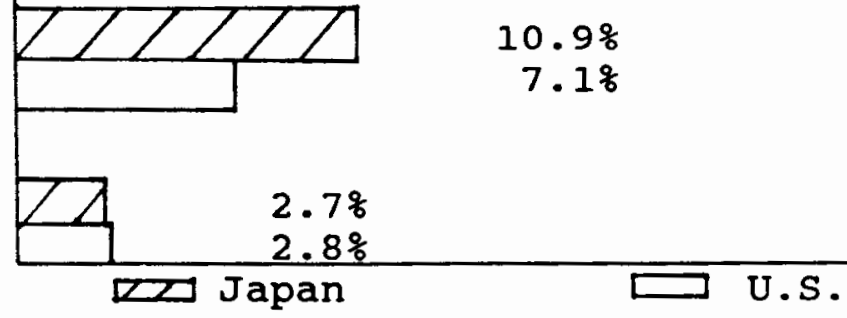

Figure 2. Frequency of choice by heterophilous dyads (Japanese interacting with U.S./ U.S. interacting Japanese). 
Visually, the charts show little difference in the confrontation styles of Japanese and U.S. within their own cultures. They were similar in their preferences for the categories "half-jokingly," "arguing," "remaining silent," and "with a sarcastic or an insulting remark."

The response scale was ordered from the least extreme to the most extreme form of confrontation style. Both groups of subjects appear to have a clear set of preferences with regard to confrontation styles. Both consistantly agreed on their choices; items "half-jokingly" and "arguing" were chosen most frequently, so there is clustering around these levels of confrontation styles. Both Japanese and U.S. subjects had similar profiles.

\section{EXAMINATION OF HYPOTHESIS TWO}

\section{HYPOTHESIS 2}

Japanese report different interpersonal confrontation strategies when interacting with individuals from either Japanese or U.S. cultures.

In the second hypothesis, only the Japanese subjects' responses were examined. A comparison was made with the interaction of Japanese toward Japanese and Japanese toward U.S. individuals. Two target persons (U.S. individuals and Japanese) were presented to each Japanese respondent. For this comparison, a paired $t$ test was utilized. The results are shown in the following Table (see Table III). 
TABLE III

OVERALL COMPARISON OF JAPANESE CONFRONTATION STYLES

\begin{tabular}{llllll}
\hline & $\begin{array}{l}\text { Number } \\
\text { of } \\
\text { Cases }\end{array}$ & Mean & $\frac{t}{V}$ Value & $\begin{array}{l}\text { Degrees } \\
\text { of } \\
\text { Freedom }\end{array}$ & $\begin{array}{l}\text { 2-tail } \\
\text { Prob. }\end{array}$ \\
\hline $\begin{array}{l}\text { Japanese confronting } \\
\text { Japanese }\end{array}$ & & & & \\
$\begin{array}{l}\text { U.S. } \\
\text { U.S }\end{array}$ & & 5.8810 & -.33 & 89 & p $>.05$ \\
\hline
\end{tabular}

Two-tailed probability for the whole of seven situations show no significant differences in confrontational styles (see Table III). Thus, the Japanese are not likely to prefer different confrontation styles whether interacting with a Japanese or U.S. casual friend.

When the seven situations are examined individually, no significant difference was found between Japanese confrontation styles toward Japanese and toward U.S. interactants in the situations (see Table IV).

Probability values show no significant difference in any of the seven situations. For the Japanese sample in the United States, very similar patterns of confrontation were found in all situations. In other words, the Japanese generally are likely not to change their behavior toward Japanese or U.S. in these seven confrontation situations. The second hypothesis was not supported in the Japanese sample. 
TABLE IV

COMPARISON OF JAPANESE CONFRONTATION STYLES IN EACH SITUATION

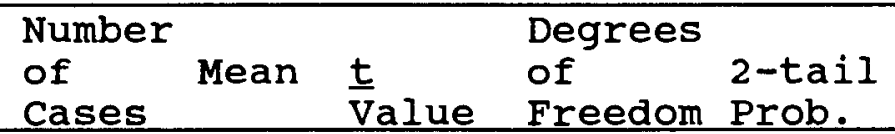

SITUATION 1.

Mismanagement of time:

Confronting Japanese

Confronting U.S.

95

$5.6526-1.07$

94

p $>.05$

5.8789

SITUATION 2 .

Interference of study:

Confronting Japanese

Confronting U.S.

96

6.9479

.35

95

p $>.05$

SITUATION 3 .

Defamation of a friend:

Confronting Japanese

Confronting U.S.

99

6.3737

.02

98

p $>.05$

6.3687

SITUATION 4.

Criticism of school work:

Confronting Japanese 99

Confronting U.S.

6.8914

1.78

98

p $>.05$

6.5606

SITUATION 5 .

Littering

Confronting Japanese 94

Confronting U.S.

$3.8218-1.67$

93

$p>.05$

SITUATION 6.

Different values:

Confronting Japanese 96

Confronting U.S.

4.0426

93 
the two cultures and the following demographic information: age; school; major; spouses or close opposite friends' cultures; American friends' proportion and other friends' cultures; length of stay in the U.S.; length of future stay in the U.S.; purspose of stay in the U.S.; preference of staying in either country (Japan or the U.S.); and English language proficiency (see Table V).

\section{TABLE V}

CORRELATIONS BETWEEN CONFONTATION STYLES AND DEMOGRAPHIC INFORMATION WITHIN THE JAPANESE SAMPLE

\begin{tabular}{|c|c|c|}
\hline \multirow[b]{2}{*}{ DEMOGRAPHIC INFORMATION } & \multicolumn{2}{|c|}{ CONFRONTATION STYLES } \\
\hline & $\begin{array}{l}\text { anese } \\
\text { ronting } \\
\text { anese }\end{array}$ & $\begin{array}{c}\text { Japanese } \\
\text { Confronting } \\
\text { U.S. }\end{array}$ \\
\hline $\begin{array}{l}\text { Confrontation styles to Japanese } \\
\text { Age } \\
\text { Length of stay in the U.S. } \\
\text { Purpose of stay in the U.S. } \\
\text { Major } \\
\text { Year of school } \\
\text { Marital status } \\
\text { Spouse's culture } \\
\text { Close friend of the opposite sex } \\
\text { close friend's culture } \\
\text { Future spouse's preferable culture (\#1) } \\
\text { Culture to be comfortable with } \\
\text { Japanese friends' percentage } \\
\text { English proficiency } \\
\text { Preference of living (Japan or U.S.) } \\
\text { Preferred length of living in the U.S. } \\
\text { Length of future stay in the U.S. }\end{array}$ & $\begin{array}{r}-. \bar{r} \\
-.1764 \\
-.0909 \\
-.0014 \\
-.0868 \\
.1009 \\
.0763 \\
-.0041 \\
.02692 \\
-.0801 \\
-.0232 \\
-.0475 \\
-.0955 \\
.01921 \\
-.0135 \\
-.01471\end{array}$ & $\begin{array}{r}.8503 * * \\
.0744 \\
.0081 \\
.0470 \\
-.0792 \\
-.0996 \\
.0235 \\
.2179 \\
.0639 \\
.3354 \\
.0167 \\
-.0479 \\
-.0198 \\
-.1016 \\
.17723 \\
-.0195 \\
-.0510\end{array}$ \\
\hline
\end{tabular}

* Significant at the .01 level
$* * \quad$ Significant at the .001 level

There are no significant correlations between Japanese confrontation styles and demographic data in this study. 
However, a strong correlation emerged for Japanese confrontation styles toward both a Japanese and a U.S. casual friend (see Table V). When Japanese would prefer more direct confrontation styles toward other Japanese, they also preferred more direct confrontation styles toward Americans $(\underline{\underline{r}}=.8073)$.

\section{EXAMINATION OF HYPOTHESIS THREE}

\section{HYPOTHESIS 3}

U.S. individuals report different interpersonal confrontation strategies when interacting with individuals from either U.S. or Japanese cultures.

This question examines how U.S. respondents reported confrontation styles with regard to communication partners: Japanese or U.S. casual friends. Comparisons within and between the two cultures were conducted to see if the U.S. reported styles of confrontation would differ between Japanese or U.S. partners (see Table VI).

\section{TABLE VI}

OVERALL U.S. CONFRONTATION STYLES

\begin{tabular}{lcccccc}
\hline & $\begin{array}{l}\text { Number } \\
\text { of } \\
\text { Cases }\end{array}$ & Mean & $\begin{array}{l}t \\
\text { Value }\end{array}$ & $\begin{array}{l}\text { Degrees } \\
\text { Freedom }\end{array}$ & $\begin{array}{l}\text { 2-tail } \\
\text { Prob. }\end{array}$ \\
\hline Confronting U.S. & 89 & $\begin{array}{l}6.2468 \\
5.5449\end{array}$ & 5.91 & 74 & p $<.001 * * *$ \\
Confronting Japanese & & 5.549 & & \\
\hline
\end{tabular}

$\star * *$ Significant at the .001 level 
A paired $\underline{t}$ test suggested a significant difference ( $\underline{t}$ $=5.91 ; \mathrm{p}<.001$ ) in confrontation styles for U.S. individuals interacting with other U.S. casual friends and interacting with Japanese casual friends living in the United states (see Table VI). U.S. subjects are likely to change their confrontation styles dependent upon whether they are interacting with other U.S. or with Japanese casual friends. The U.S. respondents' mean scores toward the two cultures suggest that generally U.S. subjects may choose much more indirect confrontation styles toward Japanese casual friends than toward other U.S. casual friends in confrontation situations.

\section{Types of social situations}

In order to obtain a clearer picture of the confrontation style profiles of the U.S. respondents, the results were examined for each situation (see Table VII).

significant differences emerged with regard to all situations except situation 5 (littering) between the two communicative partners, Japanese and U.S. In all situations except situation five (littering), U.S. subjects reported less direct confrontation to Japanese casual friends than to U.S. casual friends (see Table VII).

The results showed no significant difference in reported confrontational style toward U.S. individuals or Japanese about throwing an empty can from a car. Thus, generally the U.S. respondents are likely to choose 
TABLE VII

U.S. CONFRONTATION STYLE IN EACH SITUATION

$\begin{array}{lllr}\begin{array}{l}\text { Number } \\ \text { of } \\ \text { Cases }\end{array} & \text { Mean } t & \begin{array}{l}\text { Degrees } \\ \text { of }\end{array} & 2 \text {-tail } \\ \text { Prob. }\end{array}$

Situation 1 .

Mismanagement of time:

$\begin{array}{llllll}\text { Confronting U.S. } & 100 & 5.6425 & 4.39 & 99 & \text { p }<.001 * * * \\ \text { Confronting Japanese } & 4.7650 & & & \end{array}$

Situation 2 .

Interference of study:

Confronting U.S.

99

$6.9242 \quad 4.45 \quad 98$

$\underline{p}<.001 * * *$

Confronting Japanese

6.0606

situation 3 .

Defamation of a friend:

Confronting U.S. 99

Confronting Japanese

$\begin{array}{lll}6.6667 & 3.88 & 98\end{array}$

p $<.001 * * *$

situation 4.

Criticism of school work:

Confronting U.S. 98

Confronting Japanese

$\begin{array}{lll}6.0459 & 2.76 \quad 97\end{array}$

p $<.05 *$

Situation 5.

Littering:

Confronting U.S.

Confronting Japanese

98

5.7398

1.45

97

p $>.05$

Situation 6 .

Different values:

Confronting U.S.

Confronting Japanese

93

6.5000

3.65

92

$\mathrm{p}<.01 * *$

situtation 7 .

Matters of money:

Confronting U.S.

Confronting Japanese

98

5.7688

* Significant at the .05 level

** Significant at the .01 level

*** Significant at the .001 level

different confrontation styles toward U.S. and toward Japanese casual friends. U.S. subjects are likely to 
prefer more active/direct confrontation with other U.S. casual friends than with Japanese casual friends. The third hypothesis was partially supported in U.S. sample.

Correlation between U.S. confrontation styles and demographic data

A correlation analysis examined the relationships between U.S. confrontation styles toward the two cultures and demographic background information: age; school; major; spouses or close opposite friends' cultures; percentage of U.S. friends and percentage of other friends' cultures; preference of staying in either country (Japan or the U.S.); experience of staying in Japan; purpose of stay in Japan if they have stayed in Japan; reported Japanese language proficiency (see Table VIII).

Three significant correlations were found between both the confrontation styles of U.S. subjects toward Japanese and U.S. individuals, and the demographic data. An analysis of the data in Table VIII revealed that there are quite strong negative correlations between one's confrontation styles with U.S. and Japanese friends, and his/her experiences in Japan. The U.S. subjects' reported experiences in Japan correlated negatively with their reported confrontation styles toward Japanese $(\underline{r}=-.3584)$. Yet, their reported length of stay in Japan did not correlate with their confrontation styles toward Japanese individuals. U.S. individuals who had been to Japan tended 
to choose more indirect confrontation behaviors toward their Japanese casual friends.

\section{TABLE VIII}

CORRELATIONS BETWEEN CONFRONTATION STYLES AND DEMOGRAPHIC INFORMATION IN THE U.S. SAMPLE

\begin{tabular}{|c|c|c|}
\hline \multirow[b]{2}{*}{ DEMOGRAPHIC INFORMATION } & \multicolumn{2}{|c|}{ CONFRONTATION STYLES } \\
\hline & $\begin{array}{c}\text { U.S. } \\
\text { fronting } \\
\text { U.S. }\end{array}$ & $\begin{array}{r}\text { U.S. } \\
\text { confronting } \\
\text { Japanese }\end{array}$ \\
\hline Confrontation styles with U.S. individu & lals & $.7941 * *$ \\
\hline Age & -.0016 & .1103 \\
\hline Major & .0236 & -.0583 \\
\hline Year of school & -.0639 & -.1101 \\
\hline Marital status & .0100 & -.0078 \\
\hline Spouse's culture & .3255 & .2478 \\
\hline close friend of the opposite sex & -.0166 & .0611 \\
\hline close friend's culture & .1816 & .3047 \\
\hline Future spouse's preferable cultures(\#1) & -.0089 & -.0308 \\
\hline Culture to be comfortable with & -.0502 & .0192 \\
\hline American friends' percentage & .0311 & .1110 \\
\hline Experience staying in Japan & -.1176 & $-.3584 * *$ \\
\hline Length of staying in Japan & .1417 & -.1065 \\
\hline Purpose of staying in Japan & .0926 & -.0274 \\
\hline $\begin{array}{l}\text { Interaction with Japanese } \\
\text { Freouencies of interaction }\end{array}$ & -.0737 & -.1460 \\
\hline $\begin{array}{l}\text { Frequencies of interaction } \\
\text { with Japanese }\end{array}$ & -.0643 & -.1075 \\
\hline Japanese language proficiency & -.0219 & $-.2799 *$ \\
\hline Living preference (Japan or U.S.) & -.0129 & .1026 \\
\hline Preferred length of staying in Japan & -.0424 & -.0680 \\
\hline
\end{tabular}

* Significant at the .01 level

** Significant at the .001 level

Concerning their reported Japanese language proficiency, the U.S. respondents' level also correlated negatively with their reported confrontation styles with Japanese $(\underline{r}=-2799)$. Those individuals who had higher Japanese proficiency levels also preferred more indirect confrontation styles toward Japanese. The U.S. 
respondents' reported confrontation styles with their compatriots correlated with their reported confrontation styles with Japanese $(\underline{r}=.7941)$. The more U.S. individuals preferred direct confrontation styles toward a U.S. casual friend, the more they also preferred direct confrontation styles toward a Japanese casual friend.

The statistical data in Table IX support these observations. The U.S. responses with regard to the different confrontation situations were divided into two categories: U.S. subjects who have been to Japan, and U.S. subjects who have never been to Japan (see Table IX).

\section{TABLE IX}

COMPARISON OF U.S. WHO HAD BEEN TO JAPAN TO THOSE WHO HAD NEVER BEEN TO JAPAN

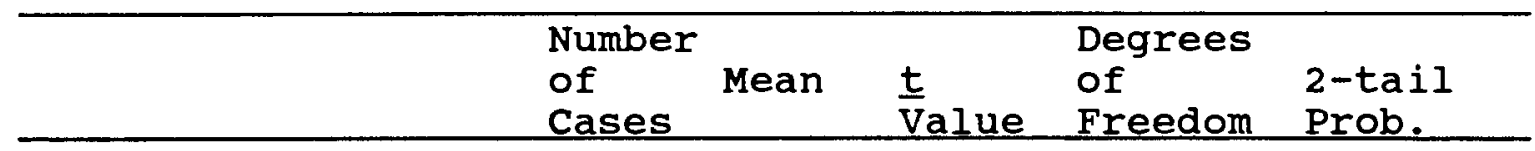

(1) Overall comparison

U.S. confronting U.S.

$\begin{array}{llllll}\text { Never been to Japan } & 58 & 6.3725 & 1.12 & 65.09 & \text { p }>.05 \\ \text { Been to Japan } & 32 & 5.9732 & & & \end{array}$

U.S. confronting Japanese

Never been to Japan $57 \quad 6.0301 \quad 3.58 \quad 64.24 \quad \underline{p}<.01 * *$
Been to Japan

$32 \quad 4.6808$

(2) U.S. who had never been to Japan ( $N=57)$

$\begin{array}{lrllll}\text { Confronting U.S. } & 57 & 6.4004 & 3.89 & 56 & \underline{p}<.01 * * * \\ \text { Confronting Japanese } & & 6.0301 & & & \end{array}$

(3) U.S. who had been to Japan $(\mathrm{N}=32)$

$\begin{array}{llllll}\text { Confronting U.S. } & 32 & 5.9732 & 5.08 & 31 & \mathrm{p}<.001 * * * \\ \text { Confronting Japanese } & & 4.6808 & & & \end{array}$


* Significant at .05 level

** Significant at .01 level

*** Significant at .001 level

U.S. confronting U.S. No significant difference was found $(\underline{t}=1.12 ; \underline{p}>.05)$ between $U . S$. respondents who had been to Japan and U.S. respondents who had never been to Japan in relation to confrontation styles toward other U.S. casual friends (see Table IX).

U.S. confronting Japanese The data of U.S. respondents who had been to Japan and U.S. respondents who had never been to Japan indicated a significant difference $(\underline{t}=3.99 ; \underline{p}<.001)$ with regard to confrontation styles toward Japnanese casual friends. U.S. individuals who had been to Japan are likely to prefer more indirect confrontation styles than U.S. individuals who had never been to Japan.

The U.S. respondents who had been to Japan and U.S. respondents who had never been to Japan also preferred more indirect confrontation styles toward Japanese than toward fellow U.S. casual friends. U.S. respondents who had been to Japan reported choosing much more indirect confrontation styles toward a Japanese casual friend than did U.S. individuals who had never been to Japan.

The reported responses of both categories of U.S. individuals were compared with respect to the seven situations posed to each respondent (see Table X). 
TABLE X

COMPARISON IN EACH SITUATION

BETWEEN U.S. WHO HAD BEEN TO JAPAN

AND U.S. WHO HAD NEVER BEEN TO JAPAN

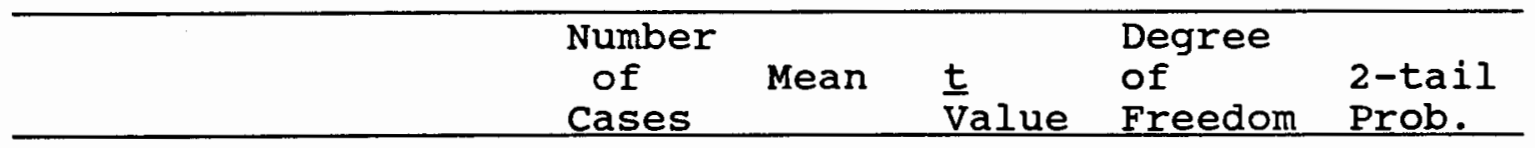

Situation 1.

Mismanagement of time:

Confronting U.S.

Never been to Japan

Been to Japan

Confronting Japanese

Never been to Japan

Been to Japan

$\begin{array}{lllll}67 & 5.9515 & 1.45 & 64.33 & \text { p }>.05 \\ 33 & 5.0152 & & & \\ & & & & \\ 67 & 5.4030 & 3.22 & 70.73 & \text { p }<.01 * * \\ 33 & 3.4697 & & & \end{array}$

situation 2 .

Interference of study:

Confronting U.S.

Never been to Japan $\begin{array}{lllll}66 & 7.1818 & 1.13 & 53.64 & \underline{p}>.05\end{array}$

Been to Japan

Confronting Japanese

Never been to Japan

Been to Japan

$33 \quad 6.4091$

$66 \quad 6.6136 \quad 2.33 \quad 52.99 \quad \underline{p}<.05 *$

$31 \quad 5.1452$

Situation 3 .

Defamation of a friend:

Confronting U.S.

Never been to Japan

Been to Japan

$\begin{array}{ll}66 & 6.6364\end{array}$

$-.14$

62.80

p $>.05$

Confronting Japanese

Never been to Japan

Been to Japan

$33 \quad 6.7273$

$\begin{array}{ll}66 & 6.2424\end{array}$

$1.20 \quad 65.88$

p $>.05$

$33 \quad 5.5303$

Situation 4.

Criticism of school work:

Confronting U.S.

Never been to Japan

Been to Japan

Confronting Japanese

Never been to Japan

Been to Japan
65

33

$65 \quad 6.1615$

$33 \quad 4.4091$
$1.3966 .90 \quad \mathrm{p}>.05$

$2.9766 .91 \quad \underline{p}<.01 * *$ 
TABLE X

COMPARISON IN EACH SITUATION

BETWEEN U.S. WHO HAD BEEN TO JAPAN

AND U.S. WHO HAD NEVER BEEN TO JAPAN

(continued)

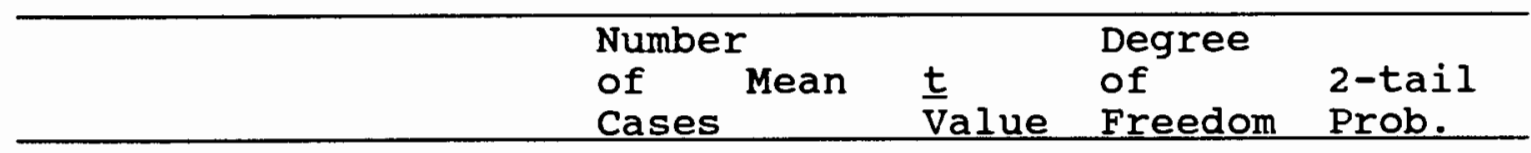

Situation 5 .

Littering

Confronting U.S.

Never been to Japan

Been to Japan

Confronting Japanese

Never been to Japan

Been to Japan

$\begin{array}{lllll}65 & 5.8462 & .46 & 69.87 & \underline{p}>.05 \\ 33 & 5.5303 & & & \\ 65 & 5.8846 & 1.91 & 62.89 & \underline{p}>.05 \\ 33 & 4.5606 & & & \end{array}$

Situation 6 .

Different values:

Confronting U.S.

Never been to Japan

Been to Japan

Confronting Japanese

Never been to Japan

Been to Japan

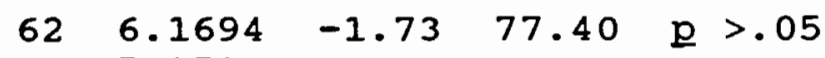

$32 \quad 7.1719$

$\begin{array}{lllll}61 & 5.8525 & .40 & 75.40 \quad \mathrm{p} & >.05\end{array}$

situation 7 .

Matters of money:

Confronting U.S.

Never been to Japan

Been to Japan

Confronting Japanese

Never been to Japan

Been to Japan

33

6.1769

1.06

65.47 p $>.05$

$\begin{array}{ll}65 & 5.8538\end{array}$

2.26

$33 \quad 4.3788$

* Significant at the .05 level

** Significant at the .01 level

*** Significant at the .001 level

When examined category by category, no significant differences were found for confrontation styles among U.S. subjects toward other U.S. casual friends. However, when confronting Japanese, there were significant differences 
between U.S. subjects who had and had never been to Japan with regard to three of seven situations. They responded significnatly to: "mismanagement of time" $(\underline{t}=3.22 ; \underline{p}<$ .01), "interference of study" $(\underline{t}=2.33 ; \underline{p}<.05)$, and "criticism of school work" ( $t=2.97 ; \underline{p}<.01)$ (see Table $\mathrm{X})$. The $\mathrm{p}$ values of these situations were all significant which suggests that U.S. subjects who had been to Japan reported more indirect confrontation styles with Japanese than those U.S. subjects who had never been to Japan.

The comparison of U.S. subjects' mean scores indicates that U.S. individuals who had and had not been to Japan reported similar confrontation styles for: "criticism of a friend of the opposite sex;" "throwing an empty can from a car;" "different gender role in society;" and "asking to lend money."

EXAMINATION OF HYPOTHESIS FOUR

HYPOTHESIS 4

Japanese and U.S. subjects do not report gender as a significant variable during confrontation.

In order to analyze the possible differences according to gender within the Japanese and U.S. samples, a similar test was used to analyze differences between Japanese males and Japanese females, and U.S. males and U.S. females. 
Comparison between gender:

Japanese males and Japanese females

The data of Japanese males and females indicated no significant difference in their confrontation styles toward either Japanese or U.S. individuals (see Table XI).

\section{TABLE XI}

OVERALL CONFRONTATION STYLES:

JAPANESE MALES AND JAPANESE FEMALES

\begin{tabular}{|c|c|c|c|c|c|}
\hline & $\begin{array}{l}\text { Number } \\
\text { of } \\
\text { Cases }\end{array}$ & Mean & $\frac{t}{V a l u e}$ & $\begin{array}{l}\text { Degrees } \\
\text { of } \\
\text { Freedom }\end{array}$ & $\begin{array}{l}2 \text {-tail } \\
\text { Prob. }\end{array}$ \\
\hline \multicolumn{6}{|c|}{ Confronting Japanese } \\
\hline $\begin{array}{l}\text { Japanese male } \\
\text { Japanese female }\end{array}$ & $\begin{array}{l}28 \\
62\end{array}$ & $\begin{array}{l}6.1250 \\
5.7707\end{array}$ & .87 & 45.97 & $\underline{p}>.05$ \\
\hline $\begin{array}{l}\text { Confronting U.S. } \\
\text { Japanese male } \\
\text { Japanese female }\end{array}$ & $\begin{array}{l}29 \\
62\end{array}$ & $\begin{array}{l}5.8103 \\
5.9637\end{array}$ & -.35 & 44.86 & $\mathrm{p}>.05$ \\
\hline
\end{tabular}

\section{Overall}

Confronting Japanese. Examining the overall/average t-test scores, the result showed no significant difference between Japanese males and females when confronting another Japanese (see Table XI).

Confronting U.S. interactants. The overall t-test result also showed no significant difference between Japanese male and Japanese female respondents when confronting U.S. casual friends (see Table XI). Also, Japanese male and female respondents, in general, reported similar confrontation styles toward both Japanese and U.S. individuals (see Tabel XI). 
The seven individual situations

No significant difference was found between reported Japanese male confrontation style and reported Japanese female confrontation style in the seven situations (see Table XII).

TABLE XII

COMPARISON OF CONFRONTATION STYLES IN EACH SITUATION BETWEEN JAPANESE MALES AND FEMALES

\begin{tabular}{lllll}
\hline $\begin{array}{l}\text { Number } \\
\text { of } \\
\text { Cases }\end{array}$ & Mean & $t$ & $\begin{array}{l}\text { Degrees } \\
\text { of }\end{array}$ & $2-$ tail \\
& Value & Freedom & Prob. \\
\hline
\end{tabular}

Situation 1.

Mismanagement of time:

Confronting Japanese

$\begin{array}{llllll}\text { Japanese male } & 29 & 6.1207 & 1.00 & 60.91 & \mathrm{p}>.05 \\ \text { Japanese female } & 66 & 5.4470 & & & \\ \text { Confronting U.S. } & & & & & \\ \text { Japanese male } & 29 & 5.7069 & -.32 & 52.19 & \mathrm{p}>.05 \\ \text { Japanese female } & 66 & 6.9545 & & & \end{array}$

situation 2 .

Interference of study:

Confronting Japanese

Japanese male 3

Japanese female 66

307.0500

.22

55.83

p $>.05$

confronting U.S.

Japanese male

Japanese female

30

6.9015

66

$6.8833-.01$

54.53

p $>.05$

situation 3 .

Defamation of a friend:

Confronting Japanese
Japanese male
30
7.2000
1.85
55.60
p $>.05$
Japanese female
Confronting U.S.
Japanese male
69
6.0145
30
6.4833
.25
52.56
p $>.05$
Japanese female
$69 \quad 6.3188$ 
TABLE XII

COMPARISON OF CONFRONTATION STYLES IN EACH SITUATION BETWEEN JAPANESE MALES AND FEMALES

(continued)

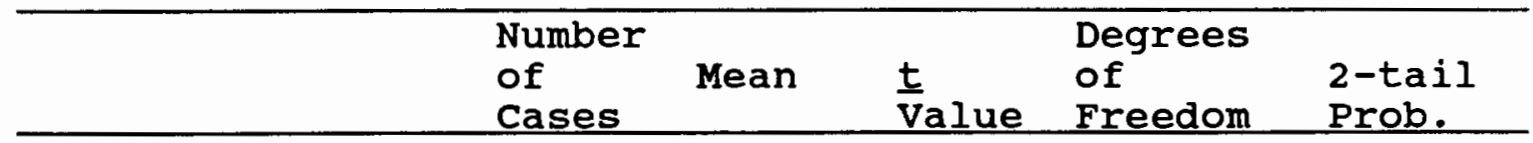

Situation 4 .

Criticism of school work:

Confronting Japanese

Japanese male 30

Japanese female 69

Confronting U.S.

$\begin{array}{llllll}\text { Japanese male } & 30 & 6.1500 & -1.08 & 45.73 & \text { p }>.05 \\ \text { Japanese female } & 69 & 6.7391 & & & \end{array}$

Situation 5 .

Littering:

Confronting Japanese

Japanese male 29

Japanese female 65

4.8190

2.12

44.39

p $>.05$

confronting U.S.

Japanese male $\quad 30$

Japanese female

$\begin{array}{ll}30 & 4.7167\end{array}$

3.6846

1.56

48.61

$\underline{p}>.05$

Situation 6 .

Different values:

Confronting Japanese

Japanese male 30

Japanese female 66

$4.7500-1.86$

58.50

$\underline{p}>.05$

Confronting U.S.

Japanese male

30

5.7955

$66 \quad 6.2879$

$4.9500 \quad-2.53$

$48 \cdot 37$

p $>.05$

Japanese female

situation 7 .

Matters of money:

Confronting Japanese

Japanese male $\quad 30$

Japanese female 67

$\begin{array}{llll}6.3333 & .33 & 40.59 \quad \underline{p}>.05\end{array}$

Confronting U.S.

Japanese male

Japanese female

30

6.1045

67

$5.9167-.34$

40.51

p $>.05$

Confronting Japanese. Among Japanese respondents, males and females reported similar confrontation styles in 
all seven situations. Japanese males and females are likely to choose similar confrontation styles (see Table XII).

Confronting U.S. The data did not reveal a significant difference in confrontation styles. Japanese respondents, regardless of gender, reported similar confrontation styles toward U.S. individuals in the seven situations (see Table XII).

Comparison between gender: U.S. males and U.S. females

Overall. No significant difference for U.S. male and U.S. female subjects was found with regard to handing confrontation with either other U.S. individuals or with Japanese. Both U.S. males vand females reported that they would confront Japanese in similar ways (see Table XIII).

TABLE XIII

OVERALL CONFRONTATION STYLES:

U.S. MALES AND U.S. FEMALES

\begin{tabular}{llllll}
\hline & $\begin{array}{l}\text { Number } \\
\text { of } \\
\text { Cases }\end{array}$ & Mean & $\begin{array}{l}\text { t } \\
\text { Value }\end{array}$ & $\begin{array}{l}\text { Degree } \\
\text { of } \\
\text { Freedom }\end{array}$ & $\begin{array}{l}\text { 2-tail } \\
\text { Prob. }\end{array}$ \\
\hline Confronting U.S. & & & & & \\
U.S. male & 36 & 6.0714 & -.78 & 84.03 & p >.05 \\
$\begin{array}{l}\text { U.S. female } \\
\text { Confronting Japanese }\end{array}$ & 54 & 6.3366 & & & \\
U.S. male & 35 & 5.3980 & -.64 & 81.42 & p >.05 \\
U.S. female & 54 & 5.6402 & & & \\
\hline
\end{tabular}

The Seven Individual Situations. U.S. male and female responses were compared with respect to the individual 
social situations that are likely to provoke confrontation. The t-test results reported significance for "asking to lend money" (see Table XIV).

\section{TABLE XIV}

COMPARISON OF CONFRONTATION STYLES IN EACH SITUATION BETWEEN U.S. MALES AND FEMALES

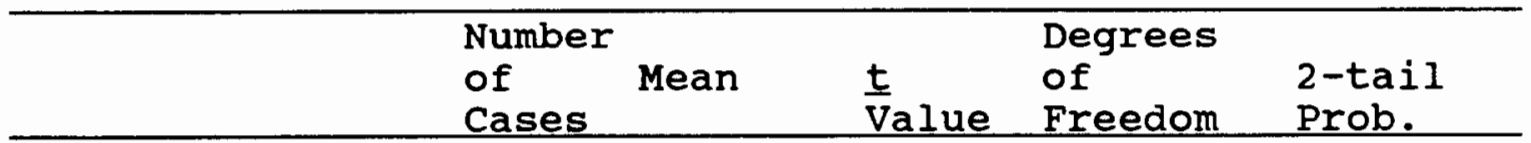

Situation 1 .

Mismanagement of time:

Confronting U.S.

$\begin{array}{lrrrrr}\text { U.S. male } & 42 & 5.5714 & -.20 & 87.46 & \mathrm{p}>.05 \\ \text { U.S. female } & 58 & 5.6940 & & & \\ \text { Confronting Japanese } & & & & \\ \text { U.S. male } & 42 & 4.5238 & -.65 & 80.81 & \mathrm{p}>.05 \\ \text { U.S. female } & 58 & 4.9397 & & & \end{array}$

Situation 2 .

Interference of study:

Confronting U.S.
U.S. male
$42 \quad 7.1786$
.72
86.48
p $>.05$
U.S. female
$57 \quad 6.7368$

Confronting Japanese
U.S. male
$42 \quad 6.3810$
.86
90.34
$\underline{p}>.05$
U.S. female
$57 \quad 5.8246$

situation 3 .

Defamation of a friend:

confronting U.S.
U.S. male
$41 \quad 6.8293$
.45
84.16
p $>.05$
U.S. female
$58 \quad 6.5517$
Confronting Japanese
U.S. male
$41 \quad 6.1585$
.45
85.23
p $>.05$
U.S. female
$58 \quad 5.8966$

Situation 4 .

Criticism of school work:

Confronting U.S.
U.S. male
$40 \quad 6.1625$
.35
89.59
p $>.05$
U.S. female
$58 \quad 5.9655$

Confronting Japanese

$\begin{array}{llllll}\text { U.S. male } & 40 & 5.6000 & .08 & 88.48 & \mathrm{p}>.05 \\ \text { U.S. female } & 58 & 5.5517 & & & \end{array}$


TABLE XIV

COMPARISON OF CONFRONTATION STYLES IN EACH SITUATION BETWEEN U.S. MALES AND U.S. FEMALES

(continued)

\begin{tabular}{llll}
\hline $\begin{array}{l}\text { Number } \\
\text { of }\end{array}$ & \multicolumn{3}{c}{ Degrees } \\
Cases & Mean & of & $2-t a i l$ \\
& Value & Freedom & Prob. \\
\hline
\end{tabular}

Situation 5 .

Littering:

Confronting U.S.
U.S. male
41
U.S. female
57
$5.3537-1.00$
90.94
$\underline{p}>.05$

Confronting Japanese
U.S. male
41
U.S. female
57
$5.0732-.95$
89.08
p $>.05$
5.7018

situation 6 .

Different values:

Confronting U.S.
U.S. male
37
57
6.2297
$-.77$
83.75
p $>.05$
U.S. female
6.6930

Confronting Japanese
U.S. male
U.S. female
36
5.6806
$-.23$
78.61
$\mathrm{p}>.05$

Situation 7 .

Matters of money:

Confronting U.S.
U.S. male
U.S. female
$41 \quad 5.1585$
$-2.34$
78.83
$\mathrm{p}<.05 *$

Confronting Japanese
U.S. male
U.S. female
$4.4512 \quad-2.53$
84.54
p $<.05 *$

* Significant at the .05 level

Comparing U.S. respondents' reported confrontation styles with U.S. and with Japanese subjects, two significant differences were revealed: situation 7: "asking to lend money" to individuals from the U.S. culture $(\underline{t}=-2.34 ; \underline{p}<.05)$ and to Japanese $(\underline{t}=-2.53 ; \underline{p}<.05)$. 
Confronting U.S. Among U.S. respondents, U.S. males reported more passive/indirect confrontation styles than U.S. female respondents when "asking to lend money" to other U.S. casual friends. U.S. male and female respondents might confront in a similar style with U.S. casual friends in the other six situations (see Table XIV). Confronting Japanese. The $p$ values in the $\underline{t}$ test indicate that there was a significant difference in the reported confrontation preferences of U.S. male and female subjects with regard to "asking to lend money" to Japanese casual friends. When they were asked to lend money, U.S. male subjects also reported more passive/indirect confrontation styles than U.S. males toward Japanese casual friends (see Table XIV).

From the analysis of Table XI, Table XII, Table XIII, and Table XIV, Japanese males and females are likely to prefer similar confrontation styles in the seven situations, but U.S. males and females are likely to choose similar confrontation styles in six out of seven situations. The fourth hypothesis was supported in Japanese sample, and was partially supported in U.S. sample. 
CHAPTER V

\section{DISCUSSION}

This chapter presents a discussion of Japanese and U.S. subjects' confrontation styles. The discussion focuses on four areas: (1) overall cultural comparisons between Japanese and U.S. respondents; (2) cultural comparisons of Japanese confrontation styles with Japanese and U.S. Casual friends in the United States; (3) a comparison of U.S. confrontation styles with U.S. and Japanese casual friends within the U.S. culture; and gender comparisons between Japanese and U.S. subjects in confrontation situations.

JAPANESE AND U.S. REPORT DIFFERENT CONFRONTATION STYLES

The $t$ tests were not strong enough to support the first hypothesis of the Japanese and U.S. having different confrontation styles. Though the overall p-value suggests no significant difference between the Japanese and U.S. respondents in confrontation situations, when examined situationally, significant differences emerged (see Table I on p. 74 and Table II on p. 76). The results indicate that two of the seven situations yielded significant differences: criticism of school work, and littering. No 
significant differences were evident in the other five situations. The Japanese mean scores were significantly higher than the U.S. mean scores in one situation (criticism of school work), while the other situation (littering) displayed a higher U.S. mean. The present study found a significant preference for a more direct confrontation style in regard to studying for its Japanese subjects (e.g., being criticized after a class presentation), a result consistent with Gudykunst and Nishida (Gudykunst, 1983). However, it was also found in the current study that, concerning money (e.g., the lending of it), there was no significant difference between the Japanese and U.S. subjects' responses. This is not consistent with the results Gudykunst and Nishida (1983) 102 found in their research. In contrast, their study of close friendships (as opposed to the casual friendships of the present study) revealed that the Japanese disclosed at a more intimate level (from superficial to very intimate) than their U.S. counterparts in the categories of school and work, biographic information, interests and hobbies, money and property, and religion. U.S. individuals, on the other hand, disclosed more intimately than the Japanese in the areas of love, dating, and sex, their own marriages, and their emotions.

In partially supporting the hypothesis, it may be because education is highly important in the Japanese 
society. The enthusiasm for education, and the serious competition to pass university entrance examinations does not exist in the west to the degree it exists in Japan (Inamura, 1980). This is because "obtaining work depends principally on one's personal capabilities. Social background, family lineage and wealth have almost no bearing." (Nippon, 1984, p.171) Thus, it is quite natural for Japanese to have an enthusiasm for education. (Nippon, 1984; Nakane, 1977) The majority of the Japanese students in the sample, according to the demographic data, came to the United States in order to complete degrees, either graduate or undergraduate. It is, therefore, understandable for these subjects to be serious about their study, and that it is important for them to have good scores on tests or presentations in class. Upon hearing criticism of his/her class presentation, a Japanese student might become frustrated, and consequently become more confrontive than a U.S. student.

However, no significant difference in the present study emerged for the situation, "asked to lend money." Interestingly, this finding was contrary to Gudykunst and Nishida's findings (1983). They found that Japanese disclosed more than U.S. subjects when discussing personal money matters with close friends. Since Gudykunst and Nishida's study focused on close friend relationships, it is possible that the confrontation styles with regard to 
lending money within casual friend relationships might exhibit more similarities than the confrontation styles within the close friend relationships. Japanese might disclose more or prefer more direct confrontation styles with their close friends than with their casual friends. Concerning money issues, people in the U.S. tend to view money lending as an invasion of a person's privacy. Japanese, on the other hand, tend to consider it an expression of affection (Naotsuka, 1980). As an example, she mentions the question, "How much is your salary?" Japanese have a choice in answering this question: they can tell the amount of their salary honestly, or evade the question, saying "It's so-so." Japanese might disclose more about money in their close friendships than their U.S. counterparts.

In regard to littering, the Japanese subjects chose a significantly more indirect confrontation style than did the U.S. subjects. The former may think that, since they were riding with the owner of the car as a guest, it was impolite to comment on the host's behavior of throwing an empty can out the window. To maintain a warm relationship with a friend is generally more important for Japanese than to oppose his/her behavior. Thus, they may be modest and not blame the friend for his/her inappropriate behavior in order to avoid direct confrontation, even if that behavior was against the law. Japanese tend to put the most 
importance upon emotional relationships, whereas people in the U.S. put more importance upon general rules (Clark \& Takemura, 1979). As a possible reason for this, clark and Takemura (1979) referred to Japanese society as a society of shame, and the U.S. as a society of sin. It seems that the Japanese tend not to think of breaking a rule as sin (Clark and Takemura, 1979). On the other hand, people in the U.S. may not feel any restraint in expressing their opinions freely concerning the upholding of a rule. For example, during the pre-test, many American students reacted to this situation by saying they would take immediate action against the behavior, pointedly noting the $\$ 500$ fine against littering.

As another potential explanation, U.S. individuals seem to be more conscientious of environmental issues than the Japanese. Nowadays, the U.S. media has focused on environmental disruption and the need for recycling, restoration, and preservation. Consequently, U.S. citizens are confronted with their responsibility to safeguard the environment. Japanese individuals, in comparison, might not feel as much responsibility for nature.

Among the seven situations studied, no significant differences emerged between Japanese and U.S. casual friendships in five of the situations. The level of disclosure reported was similar between Japanese and U.S. subjects in the areas of mismanagement of time, making 
continuous loud noise during study, criticism about a friend of the opposite sex, disagreement about gender roles in society, and matters of money. Recent research has tended to support this, indicating that there are many similarities between Japanese and U.S. college students. Gudykunst and Nishida (1983), for example, found that there were more similarities than differences between their two groups of subjects. The result of Nomura's (1980) study suggested that both Japanese and U.S. subjects preferred to "express dissatisfaction in a direct way." The results of these studies, however, are not consistent with Hall (1976), Nakane (1974), or Johnson and Johnson (1983), who all stated that U.S. subjects generally engaged in more verbal communication, including self-disclosure, than do Japanese. It is possible that there are other situations which may affect Japanese and U.S. confrontation styles. Comparing the bar graphs (Figure I on p.78 and Figure II on p. 79), certain trends emerged in the selection of strategies which support the $t$ test results between both cultures. Both the Japanese and U.S. cultures seemed to prefer similar strategies in self-report responses to confrontation situations. The two most commonly chosen strategies by both groups were: "expressing half-jokingly" and "arguing."

When the third most commonly chosen behaviors were analyzed, the Japanese respondents reported a preference 
for the "sarcastic or insulting remark" with both U.S. and Japanese interactants. The U.S. subjects, however, while choosing the same response as the above with U.S. casual friends, chose instead the "remaining silent" option with Japanese casual friends. U.S. subjects reported a preference for more indirect behaviors with Japanese friends than friends from their own culture, yet Japanese subjects chose the same direct style toward both U.S. and Japanese interactants.

As Naotsuka (1980) mentioned, the Japanese reported a preference for an indirect approach in order not to allow contrary opinions to come out and threaten agreement held by both sides, while the U.S. respondents reported a willingness to exchange opinions, and solve any differences in opinion or problems in a more direct way. The Japanese subjects reported a greater preference for "expressing half-jokingly" than U.S. subjects, and U.S. subjects chose "arguing" more often than the Japanese subjects (Naotsuka, 1980) .

Interestingly, for the current study, the Japanese subjects chose "replying with a sarcastic or an insulting remark" as their third choice. This behavior is very direct, the second from the most aggressive option on the response scale. In the Japanese culture, harmony is important, and both parties try to maintain this harmony to avoid confrontational situations. Yet, once a casual 
friend breaks the rule of harmony, a Japanese might not try to keep harmony and choose more direct confrontation styles toward him/her, as exemplified in the Japanese saying, "The nail that sticks up will be hammered down" (Nichiei-Hikaku Kotowaza Ziten, 1980).

\section{JAPANESE REPORT DIFFERENT INTERPERSONAL CONFRONTATION STRATEGIES WHEN INTERACTING WITH INDIVIDUALS FROM EITHER JAPANESE OR U.S. CULTURES}

No significant differences were noted for the Japanese subjects' self-reported confrontation styles dependent upon the partner's culture. The Japanese subjects generally reported similar confrontation styles to their casual friends, from both Japan and the U.S. (see Table III on p.81 and Table IV on p. 82).

Among the seven social situations, no significant differences emerged either. The data analysis did not support any differences between Japanese and U.S. partners concerning Japanese confrontation styles. The former chose similar confrontation styles with Japanese and with U.S. casual friends in all seven situations (e.g., mismanagement of time, interference of study, criticism of a friend of the opposite sex, criticism of school work, littering, disagreeing with gender role in society, and lending money) •

The reason, why the hypothesis was not supported, was that Japanese subjects might not feel that they need to 
choose more direct confrontation styles in talking with U.S. individuals than with Japanese casual friends in these seven situations. Perhaps this might be due to the Japanese subjects having gained some insight into U.S. culture from secondary sources before coming to the United States (Gudykunst and Hammer, 1987; Taguchi, 1978). Thus, their choice of reactions might be more neutral toward their casual-friendships than toward those having closefriendship status.

The Japanese subjects may also prefer the similar confrontation styles of the U.S., as they might believe that their general behavior patterns are similar to those of U.S. young people. While Japanese college student behaviors may indeed be similar to that of their U.S. peers, the behavior of the older generation in each culture differs greatly (Nishida, 1981). The U.S. college students in Nishida's (1981) study, perceived their parents as selfcentered, whereas Japanese college students perceived their parents as group-oriented. Both the U.S. and Japanese students view themselves as group-oriented in work and political areas, and individualistic in interpersonal and family spheres (Nishida, 1981).

In the Japanese sample for the present study, no relationship emerged between the Japanese self-reported confrontation styles with Japanese and U.S. casual friends, and their demographic information. This may be explained 
by the fact that the Japanese subjects reported that they did not change their preference of confrontation styles depending upon their conversation partners, whether they were Japanese or U.S. casual friends. The Japanese respondents also chose confrontation styles on a similar level, regardless of whether they had stayed in the U.S. many years or a few months; whether they were younger or older; whether they spoke English well or spoke few words; whether they had mostly Japanese friends or many friends from other cultures; or whether they were freshmen or in graduate school. Even though the Japanese subjects had at least some general experience of intercultural interaction with the culture and people of the Portland area, their confrontation styles appeared to have not changed in any significant way toward their Japanese and U.S. casual friends, as shown by their reported responses.

In general, Japanese do not experience intercultural interactions as they are growing up (Nakane, 1974, 1977). Japanese society consists of a homogeneous race isolated from other societies with different cultures. Nakane (1974) also mentioned that Japanese who go abroad are usually older, they are over twenty years old, their thought patterns have already become strongly established, hindering adaptation and the reception of other cultural practices. As a result, Japanese might become locked into choosing the same confrontation styles toward their 
communication partner, regardless of their partner's cultures.

U.S. INDIVIDUALS REPORT DIFFERENT INTERPERSONAL CONFRONTATION STRATEGIES WHEN INTERACTING WITH INDIVIDUALS FROM EITHER U.S. OR JAPANESE CULTURES

In the test of the third hypothesis, the U.S. subjects' data showed a significant difference in the confrontation styles used between U.S. and Japanese partners. It was found that the U.S. subjects generally reported relying on passive-indirect responses more heavily toward Japanese in confrontations than with their U.S. casual friends (see Table VI on p.84 and VII on p. 86). The U.S. subjects reported that they tended not to change their style of criticism in accordance with perceived differences in status (Nomura \& Barnlund, 1983). Yet, according to the data of this study, they appear to change their forms of confrontation style in accordance with perceived differences in culture.

The U.S. sample reported a preference for more indirect confrontation styles toward Japanese in six of the seven situations (except with regard to littering). A possible reason for this may be that U.S. subjects might have acquired an understanding of Japanese culture through the influence of mass media: newspaper, radio, television, and movies which may be reinforced by observations or interactions with Japanese students at the university 
level. People in the U.S. might consequently think that, in general, Japanese are polite and less direct in manner and attitude.

Thus, U.S. subjects seem to choose more indirect confrontation styles toward Japanese than toward U.S. interactants, something the former noticed. The Japanese subjects reported U.S. confrontation behaviors to be similar to Japanese modes, because U.S. subjects chose more indirect confrontation styles with them. As a consequence, this might induce the Japanese subjects not to feel a necessity to choose a different confrontation style toward U.S. interactants than that used with Japanese interactants.

Furthermore, U.S. individuals have grown up surrounded by people of many cultures, whether they actually interacted with them or not. U.S. respondents might have perceived intercultural differences in their interacting with people with other cultures, such as Japanese. On the other hand, Japanese students in this study did not report any differences in either interaction. This tendency cannot be seen in the results of the Japanese subjects. The proficiency level of English language did not influence Japanese subjects' confrontation styles toward both interactants.

As was mentioned in research question 1 , no significant difference was observed with regard to U.S. 
respondent confrontation style concerning littering, when either a Japanese or U.S. casual friend threw an empty can from a moving car. It was assumed that U.S. subjects are more concerned with their environment than the Japanese, due, it was theorized, to more prominent newspaper and television coverage of, and national sensitivity to, environmental issues.

The data regarding the issue of confrontation style in combination with cultural commitment revealed some strong correlations (see Table VIII, p. 88). Among the Portland area college students surveyed, their reported Japanese language proficiency correlated negatively with their preference of confrontation style toward Japanese. The degree of confrontation appeared to be inversely related to the level of Japanese language proficiency. The more fluent Japanese respondents reported more indirect confrontation styles toward Japanese casual friends.

An explanation for this may be that learning Japanese language provides students with foreign language cultural sensitivity on a larger scale, allowing them many opportunities to meet and interact with people from Japanese cultures on campus.

There was also a strong negative correlation between the reported confrontation styles by U.S. subjects toward Japanese according to the former's experience during their stay in Japan. Whether the U.S. respondents had lived in 
Japan or not, all reported a preference for a more indirect confrontation style toward Japanese. This supports the above suggestion that the more intercultural interactions a person experiences the more sensitive that person might become to others in the U.S. from another culture. However, a person's length of stay in Japan did not influence over their confrontation style toward Japanese and this phenomenon was not also seen in the Japanese subjects of the present study (see Table $V$ on p.83).

A t test revealed significant differences between those respondents who had had the experience of living in Japan, and those who had not (see Tables IX on p. 89 and Table $X$ on pp. 92). Those in the former group reported a preference for even more indirect confrontation styles toward Japanese than those subjects who had never lived in Japan. For both groups, however, those who had experienced Iife in Japan and those who had not, there was a significant difference in confrontation style in their dealings with their Japanese casual friends, when compared with their U.S. casual friends in confrontation situations. One other such possible explanation for this difference in confrontation style is that people who have been to Japan and experienced difficulty adjusting to culture may later become more empathic toward expatriate Japanese and choose more indirect confrontation styles toward Japanese.

A third possible explanation is cultural 
isolation. U.S. individuals who live in small communities having no interaction with people from other cultures might be more conservative in their attitudes and opinions toward other cultures, and choose the same confrontation styles toward both Japanese and U.S. interactants. Yet, concerning this study, the U.S. subjects living in the Portland metropolitan area may have had more opportunity to interact with people from other cultures than in some other areas of the country. Therefore, U.S. individuals may interact with more sensitivity to people from other culture and chose passive/indirect confrontation styles.

JAPANESE AND U.S. SUBJECTS DO NOT REPORT GENDER AS A SIGNIFICANT VARIABLE DURING CONFRONTATION

In gender comparisons, neither the Japanese nor the U.S. sample showed a significant difference between male and female reported overall confrontation styles. (See Tables XI on p.94 and Table XIII on p. 97). This suggests that the culture to which one belongs seems to play a more decisive role than a person's gender in choosing patterns of confrontation. These results are consistent with Nomura's research on criticism (1980), Araki's research on the management of compliments (1982), Nagano's research on the handling of apologies (1985), and other studies in which men and women disclosed almost equally (Brooks, 1974; Kohen, 1975; Thase \& Paage, 1977; Montgomery and Norton, 1981; Cline \& Musolf, 1985). 
In supporting of the hypothesis in Japanese subjects, the Japanese male and female subjects reported a preference for similar confrontation styles when the confrontation was with other Japanese and U.S. casual friends with regard to confrontational situations (see Table XII on pp.95-96). In partial support of the hypothesis in U.S. male and female subjects, their reported confrontation styles, within the seven situations of this study, two significant differences emerged: lending money to U.S. casual friends and lending money to Japanese casual friends (see Table XIV on pp. 9899). U.S. male subjects reported preference for more indirect confrontation styles with regard to being asked to lend money with both Japanese and other U.S. friends. Money is a more private and sensitive topic in U.S. culture. "Possession of property is affected by a person's position in society and his needs, as well as by other considerations" (Stewart, 1971, p. 62). U.S. males, especially, might feel that money shows their value or status (whether they have much money or not) and they might not want to talk about it, as opposed to U.S. women who perhaps may be more open to talking about money matters. Except for the situation of lending money, U.S. males and U.S. females reported confrontation styles are similar with U.S. and Japanese casual friends in the other six situations. 


\section{CHAPTER VI}

FURTHER STUDY AND CONCLUSION

In this chapter, four areas will be addressed as a conclusion to this study. These areas are unexpected results, limitation of the research, future study, and the conclusion proper.

\section{UNEXPECTED RESULTS}

Two areas of unexpected results emerged from this study. First, no change in the Japanese reported confrontation style with Japanese and U.S. casual friends was observed; whereas the U.S. subjects did indeed report a change in their respective confrontational style in regard to both U.S. and Japanese casual friends. The U.S. respondents showed remarkably diverse response-patterns across both cultures, whereas their Japanese counterparts maintained much more symmetrical communication patterns.

Part of the explanation for this may be that college students were chosen as subjects. Gudykunst and Nishida (1980) mentioned that the tendency for Japanese college students' behavioral patterns in the U.S. is more likely to resemble U.S. college students' behavioral patterns, than those Japanese students' going to college in Japan. 
Japanese students, who come to study in the U.S., may already be a marginal group when compared with their peers in Japan, and thus might not feel any differences communicating with U.S. college students who have altered their confrontation styles to demonstrate more indirect behavior toward Japanese students.

Another possible explanation might involve the communication partner, depicted in the study as a "casual friend." In reality, subjects might prefer different confrontation styles, situationally dependent upon their communication partners (e.g., conversing with superiors, juniors, close friends, acquaintances or strangers). Dinges and Lieberman (1989) concluded that situational or communication partner variables did have an influence on interactant intercultural competence in their study of stressful intercultural work situations.

The second unexpected result was that no correlation emerged between the self-reported confrontation styles, and the demographic data of the Japanese subjects. The experience of extended living in the United States was expected to affect the Japanese subjects' reported confrontation styles in some matter, yet their reported confrontation styles appeared not to be influenced at all. (On the other hand, the U.S. subjects did indeed report that their confrontation styles differed depending upon their level of Japanese language proficiency, and/or their 
experience of living in Japan). All this would suggest that generally U.S. individuals might have more intercultural communication flexibility than Japanese.

\section{LIMITATIONS OF THE RESEARCH}

There were several problems in this study. First, because of the limited number of Japanese male students' in the Portland area, the respondents were not equally divided by male and female respondents. If the numbers of Japanese male, Japanese female, U.S. male, U.S. female respondents had been equal, the gender study could have been examined more minutely in the $\underline{t}$ test.

second, the seven situational categories proved not enough to acquire a whole understanding of the confrontation styles found within both Japanese and U.S. cultures. It might be of value to examine a greater variety of precise situations. However, limited time and the size of the study made it impractical to include more situations. Certain areas (e.g., religion, marriage, dating, physical condition, etc.), referred to in Altman and Taylor's study (1973) of intimacy-scaled topics of conversation, would perhaps provide possible avenues for future research. Third, the response scale was limited to twelve. This limited the choices of confrontation styles for each of the situations. Some of the respondents may have chosen other confrontation styles which did not exist 
as possible options in the Likert-type response scale used. Follow-up studies should consider on even greater range of confrontation styles.

Forth, the nine-page length of the questionnaire perhaps had a role in making some respondents' answers incomplete. For some questionnaires, a page in the second part was skipped. These questionnaires were not included in the data.

Fifth, this research collected self-reported responses from both sets of subjects. It is possible for there to be a certain degree of difference between self-reported respondences to hypothetical situations, and actual behavior in those situations. Future studies should consider observational behavioral measurement (for instance, placing subjects in more realistic situations, and capturing their behaviors on videotape).

\section{POSSIBILITIES FOR FUTURE RESEARCH}

This research studied Japanese and U.S. confrontation styles as influenced by Japanese and U.S. cultures. In any future replication of this study, several areas would provide more insights for examining confrontation styles. First, the results revealed that confrontational styles seem to differ according to the situation (e.g., littering, matters of money, criticism of class presentation, etc.). It might be valuable to examine this in a wider range of 
situations. For example, Altman and Taylor (1973)

presented 671 conversation topics measuring intimacy. Future research in this area should take this into account. Second, this study included only university students in the Portland area. Therefore, it would be useful to conduct similar studies using different populations (e.g., business persons, sojourners, spouses, etc.).

Third, This study compared Japanese and U.S. college students only in the United States. It would perhaps be of interest to run a similar study of Japanese and U.S. individuals living in Japan. A study such as this might perhaps provide a "mirror image" to the present study, with Japanese and U.S. individuals dealing with confrontation situations in the Japanese culture.

Fourth, U.S. subjects' confrontation styles reflected the influence of prior intercultural exposure (e.g., the experience of living in Japan and Japanese proficiency level). A study of the subjects' demographic background in this area, such as their experiences of living in other countries, taking other language courses, having nonnatives as relatives, or taking intercultural classes, might also be of interest.

\section{CONCLUSION}

This thesis focused on the similarities and differences in confrontation styles of Japanese and U.S. 
college students in the Portland area. Overall, the results indicated that Japanese and U.S. individuals generally reported preferring similar confrontation styles in five out of seven situations. Japanese respondents reported choosing more active/direct confrontation styles with regard to "criticizing a class presentation," and U.S. respondents reported choosing more active/direct confrontation style with regard to "littering."

In comparing Japanese and U.S. communication styles using intercultural and intracultural confrontation situations, clear differences emerged. Reported Japanese confrontation styles were generally similar toward other Japanese and toward U.S. casual friends. Yet, the reported U.S. confrontation styles with U.S. and Japanese casual friends were different. The U.S. subjects reported more indirect confrontation toward Japanese casual friends than toward U.S. casual friends in six of the seven confrontation situations.

Gender comparisons between Japanese male and female subjects in the confrontation situations were similar. Whereas gender comparisons between U.S. male and female subjects' confrontation styles were similar in six situations but different in one situation, "littering." This analysis of segments of communication style is a different approach to cross-cultural studies than has been previously conducted. This study demonstrated that the 
self-reported forms of confrontation preferred differed between the two cultures. This analysis of confrontation styles reveals some of the underlying values found within the two cultures, and suggests some potential points of difficulty and misunderstanding in Japanese and U.S. interaction. 


\section{REFERENCES}

Altman, I \& Taylor, D. A. (1973). Social penetration: The development of interpersonal relationships.

NY: Holt, Rinehart \& Winston.

Araki, S. (1982). The management of compliments by

Japanese and Americans. Unpublished master's thesis,

San Francisco State University.

Babbie, E. (1989). The practice of social research

(5th ed.). Belmont, CA: Wadsworth Publishing Company.

Barnlund, D. C. (1974). The Public and the private self in Japan and the United States. In J. C. Condon and M. Saito (Eds.), Intercultural encounters with Japan (pp. 27-96). Tokyo, Japan: The Simul Press.

Barnlund, D. C. (1975). Public and private self in Japan and the United States. Tokyo, Japan: The Simul Press

Berger, C. R. \& Calabrese, R. J. (1975). Some explorations in initial interaction and beyond: Toward a developmental theory of interpersonal communication. Human Communication Research, 1, 99-112.

Berryman-Fink, C. \& Brunner, C. (1987). The effects of sex of source and target on interpersonal conflict management. Southern Speech Communication Journal, 53, $38-48$.

Cathcart, D. \& Cathcart, R. (1985). Japanese social experience and concept of group. In Samovar, L. A. \& Porter, R. E. (Eds.), Intercultural communication: A reader. (4th ed. (pp. 190-199). Belmont, CA: wadsworth Publishing Company.

Clark, G., \& Takemura, K. (1979). Uniku na Nihonjun [Unique Japanese]. Tokyo, Japan: Kodansha.

Clark, G., (1986). Talk about Japan in English crosscultural dialogue. Tokyo, Japan; The Simul Press.

Cline, R. J. (1983). The acquaintance process as relational communication. Communication Yearbook 7, (pp. 396-413). Beverly Hills, CA: Sage Publications. 
Cline, R. J. \& Musolf, K. E. (1985). Disclosure as social exchange: Anticipated length of relationship, sex roles, and disclosure intimacy. Western Journal of Speech Communication, 49, 43-56.

Condon, J. (1985) "... So near the United States": Notes on communication between Mexicans and North Americans. In Samovar, L.A. \& Porter, R. (Eds.), Intercultural communication: A reader (4th ed.) (pp. 86-91). Belmont, CA: Wadsworth Publishing Company.

Condon, J.C. \& Yousef, F. (1986). An Introduction to Intercultural Communication. NY: Macmillan Publishing Company.

Connor, J. W. (1977). Tradition and change in three generations of Japanese Americans. Chicago: Nelson-Hall.

Critelli, J. W. \& Neumann, K. F. (1978). An interpersonal analysis of self-disclosure and feedback. Social Behavior and Personality. 6, 173-177.

Cushman, D. P. \& King, S. S. (1985). National and organizational cultures in conflict resolution: Japan, the United States, and Yugoslavia. In W. B. Gudykunst \& L. P. Stewart (Eds.), Communication, culture, and organizational processes (pp. 114-133). Beverly Hills, $C A$ : Sage Publications.

DeVito J. A. (1985) - Human Communication: the basic course (3rd ed.). NY: Harper and Row, Publishers.

Dinges, N. G. \& Lieberman, D. A. (1989). Intercultural communication competence: Coping with stressful work situations. International Journal of Intercultural Relations, 13, 371-385.

Doi, T. (1971). Amae no Kozo [The Anatomy of Dependence]. Tokyo, Japan: Kobundo.

Doi, T. (1987). The anatomy of dependence. (J. Bester (Trans.). Tokyo, Japan: Kodansha International.

Enloe, W. \& Lewin, P. (1987). Issues of integration abroad and readjustment to Japan of Japanese returnees. International Journal of Intercultural Relations, 11, 223-248. 
Folb, E. A. (1985). Who's got the room at the top? Issues of dominance and nondominance in intracultural

communication. In L. A. Samovar \& R. E. Porter (Eds.), Intercultural communication: A reader (4th ed.) (pp. 119 -127). Belmont, CA: Wadsworth Publishing Company.

Gilbert, S. J. \& Whiteneck, G. G. (1976). Toward a multidimensional approach to the study of self-disclosure. Human Communication Research, $\underline{2}$, 347-355.

Gudykunst, W. B., and Nishida, T. (1983). Social penetration in Japanese and American close friendships. Communication Year Book 7 (pp. 592-610). Beverly Hills, CA: Sage Publications.

Gudykunst, w. B. \& Nishida, T. (1984). Individual and cultural influences on uncertainty reduction. Communication Monographs, 51, 23-36.

Gudykunst, w. B. (1985a). An exploratory comparison of close intracultural and intercultural friendships. Communication Quartery, 33, 270-283.

Gudykunst, W. B. (1985b). Normative power and conflict potential in intergroup relationships. In $\mathrm{W} . \mathrm{B}$. Gudykunst, L. P. Stewart, \& L. Ting-Toomey (Eds.) Communication, culture, and organizational processes (155-173). Beverly Hills, CA: Sage Publications.

Gudykunst, W. B. \& Nishida, T. (1986a). Attributional confidence in low- and high-context cultures. Human Communication Research, 12, 525-549.

Gudykunst, W. B. \& Nishida, T. (1986b). The influence of cultural variability on perceptions of communication behavior associated with relationship terms. Human Communication Research, 13, 147-166.

Gudykunst, W.B. \& Hammer, M. R. (1987). "Strangers and Host" Uncertainty reduction based theory of intercultural adaptation. In Y.Y. Kim \& W.B. Gudykunst (Eds.), Cross-cultural adaptation: Current approaches (pp. 140-148). Beverly Hills, CA: Sage Publications.

Gudykunst, W. B., Sodetani, L.L., \& Sonoda, K.T. (1987). Uncertainty reduction in Japanese-American/Caucasian relationship in Hawaii. The Western Journal of Speech Communication, 51, 256-278.

Hall, E. T. (1976). Beyond Culture. Garden City, NY: Anchor Press. 
Hall, E. T. (1985). Context and meaning. In L. A. Samovar \& R. E. Porter (Eds.), Intercultural communication: A reader (4th ed.) (pp. 40-50). Belmont, CA: Wadsworth Publishing Company.

Hocker, J. L. \& Wilmot, W. W. (1985). Interpersonal conflict (2nd ed.). Dubuque, Iowa: Wm. C. Brown Publishers.

Hotta, M. (1991). Intercultural communication competence and intercultural adjustment of Japanese business sojourners and their spouses. Unpublished master's thesis. Portland state University.

Ide, Y. (1979) . Onna kotoba otoko kotoba [Female language and male language]. Tokyo, Japan: Nihon-KeizaiTsushinsha.

Inamura, H. (1980). Nihonjin no Kaigai futekio [Japanese inflexibility toward other countries]. Tokyo, Japan: NHK books.

Ishida, E. (1990). Worldminded attitudes of Japanese college students in Japan and in the United states. Unpublished master's thesis. Oregon State University.

Ishii, S. (1985) " Thought patterns as modes of rhetoric: The United States and Japan" In L. A. Samovar \& R. E. Porter (Eds.), Intercultural communication: A reader (4th Ed.), (pp. 97-102). Belmont, CA: Wadsworth Publishing Company.

Itasaka, G. (1976). Nihonjin no ronri kozo [Japanese logic constraction]. Tokyo, Japan: Kodansha-Gendai-Shinsho.

Jensen, J. V. (1985) . Perspective on nonverbal intercultural communication. In L. Samovar \& R. E. Porter (Eds.), Intercultural communication: A reader (4th ed.) . Belmont, CA: Wadsworth Publishing Company.

Jorden, E. H. (1983) . Japanese. New Haven, Conn: Yale University Press.

Jourard, S. M. (1971). Self-disclosure: An experimental analysis of the transparent Self. N.Y.: WilleyInterscience.

Keon, J. K. (1984). Use of cultural criterion group and discriminant analysis in acculturation studies. International Journal of Intercultural Relations, 8 , 29-43. 
Kindaichi, H. (1975). Nihonjin no gengo kozo [Japanese language expression]. Tokyo, Japan: Kodansha.

Kotowaza Ziten [Proverb dictionary] . (1987). Tokyo, Japan: Sogensha.

Krauss, E.S., Rohlen, T,P, \& Steinhoff, P.G. (1984). Conflict: An approach to the study of Japan. In E. S. Krauss, T. P. Rohlen, \& P. G. Steinhoff (Eds). Conflict in Japan. (pp. 3-15). Honolulu: University of Hawaii Press.

Kunihiro, M. (1976). The Japanese language and Intercultural communication. In Japan Center for International Exchange (Ed.), The silent power Japan's identity and world role. (pp. 35-50). Tokyo, Japan: The Simul Press.

Lebra, T. S. (1984). Nonconfrontational strategies for management of interpersonal conflict. In E. S. Krauss, T. P. Rohlen, and P. G. Steinhoff (Eds.), conflict in Japan. (pp. 41-60). Honolulu: University of Hawaii Press.

Littlejohn, S. W. (1984). Theories of human communication. Belmont, CA: Wadsworth Publishing Company.

Makino, S. (1978). Kotoba to kuukan [Language and space]. Tokyo, Japan: Tokaidaigaku Shupankai.

Miller, F. E., Roger, E., \& Bavelas, J. B. (1984). Identifying patterns of verbal conflict in interpersonal dynamics. The Western Journal of Speech Communication, 48, 231-246.

Mitsubishi Corporation. (1983). Japanese business glossary. Tokyo, Japan: Toyo-Keizai-Shinposha.

Montgomery, B. M. \& Norton, R. W. (1981). Sex differences and similarities in communicator style. Communication Monographs, 48, 121-132.

Morsbach, H. (1973). Aspects of nonverbal communication in Japan. The Journal of Nervous and Mental Disease, 4, 262-277.

Nadler, L. B., Keeshan-Nadler, M., \& Broome, B. J. (1985). Culture and the management of conflict situation. In w. B. Gudykunst, L. P. Stewart, \& S. Ting-Toomey (Eds.), Communication, culture, and organizational processes (pp. 155-173) . Beverly Hills, CA: Sage Publications. 
Nagano, M. (1985). "How to say I'm sorry": The use of apologies in Japan and the United States. Unpublished thesis. San Francisco State University.

Nakamura, H. (1964). Ways of thinking of eastern peoples: India-China-Tibet-Japan. In P. Wiener (Ed. and Trans.). Honolulu, Hawaii: East-West Center Press.

Nakane, C. (1974). The social system reflected in interpersonal communication. In $J$. Condon \& M. Saito (Eds.), Intercultural encounters with Japan (pp. 124131). Tokyo, Japan: The Simul Press.

Nakane, C. (1978). Tateshakai no Rikigaku [Dynamics of Vertical Society]. Tokyo, Japan: Kodansha.

Nakanishi, M. (1986). Perceptions of self-disclosure in initial interaction A Japanese sample. Human Communication Research, 13, 167-190.

Naotsuka, R. (1980). Obeijin ga chinmoku surutoki-Ibunkakan no communikeishon. [When Westerners fall into silence]. Tokyo, Japan: Taishukan.

Nippon Steel Corporation. (1984). Nippon: The land and its people. Tokyo, Japan: Kakuseisha.

Nomura, N. (1980). Patterns of Interpersonal Criticism in Japan and the United States. Unpublished master's thesis at San Francisco State University.

Nomura, N., and Barnlund, D. C. (1983). Patterns of interpersonal criticism in Japan and United States. International Journal of Interpersonal Relations, 7, $1-18$.

Okabe, R. (1983). Cultural assumptions of east and west, Japan and the United States. In W. B. Gudykunst (Ed.), Intercultural Communication Theory (pp. 21-44). Beverly Hills, CA: Sage Publications.

Papa, M. J. \& Natalle, E. J. (1989). Gender, strategy selection, and discussion satisfaction in interpersonal conflict. The Western Journal of Speech Communication, 53, 260-272.

Peason, J. C. (1985). Gender and communication. Dubuque, Iowa: Wm. C. Brown Publishers. 
Pennington, D. L. (1985). Intercultural communication. In L. A. Samovar \& R. E. Porter (Eds.), Intercultural communication: A reader (4th ed.) (pp. 30-39). Belmont, CA: Wadsworth Publishing Company.

Porter, R.E. \& Samovar, L.A. (1985). Approaching intercultural communication. In L. A. Samovar \& R. E. Porter (Eds.), Intercultural Communication: A Reader (4th ed.) (pp. 15-30). Belmont: Wadsworth Publishing Company.

Ramsey, S. (1985). To hear one and understand ten: Nonverbal behavior in Japan. In L. A. Samovar \& R. E. Porter (Eds.), Intercultural Communication: A Reader (4th ed.) (pp. 307-325). Belmont: Wadsworth Publishing Company.

Random House Inc.. (1987). Random house dictionary of the English Lanquage (2nd ed.). NY: Random House Inc.

Reischauer, E. O. (1978). The Japanese. Tokyo, Japan: Charles E. Tuttle.

Roloff, M. E. \& Greenberg, B. (1979). Sex differences in choice of modes of conflict resolution in real-life and television. Communication Quarterly, 27, 3-12.

Rosenfeld, L. B. \& Kendrick W. L. (1984). Choosing to be open: An empirical investigation of subjective reasons for self-disclosing. The Western Journal of Speech communication, 48, 326-343.

Sakamoto, N. and Naotsuka, R. (1982). Polite Fiction Why Americans and Japanese Seem Rude to Each Other. Tokyo, Japan: Kinseido.

Shiba, R. and Keen, D. (1984). Nihonjin to Nihopnbunka [Japanese and Japanese Culture]. Tokyo, Japan: Chuokoron.

Shin Nihonshi [New Japan History]. (1982). Tokyo, Japan: Jiyushobo.

Stewart, E. C. (1971). American Cultural Patterns: A CrossCultural Perspective Dimensions of International Education, Number Three. Regional Council for International Education. 
Stewart, L. P. (1985). Japanese and American management: Participative dicision making. In L. A. Samovar \& R. E. Porter (Eds.), Intercultural Communication: A Reader (4th ed.) (pp. 186-189). Belmont: Wadsworth Publishing company.

Suzuki, T. (1975). Tozasareta gengo-Nihongo no sekai [Closed language-the Japanese language world]. Tokyo, Japan: Shinchosha.

Taguchi, H. (1978). An Investigation of similarity of the Value system between the American and Japanese college students. Unpublished master's thesis at PSU.

Tardy, C. H. \& Hosman, L. A. (1982) . Self-monitoring and self-disclosure flexibility: A research note. The Western Journal of Speech Communication, 46, 92-97.

Ting-Toomey, S. (1985). Toward a theory of conflict and culture. In w. B. Gudykunst, L. P. Stewart, \& S. TingToomey, (Eds.), International and Intercultural Communication. (pp. 155-173). Beverly Hills, CA: Sage Publications.

Touche Ross and International Trade Institute of Portland state University. (1987) . Japanese business in oregon: An opinion survey and research profile. Portland, OR: Touche Ross and International Trade Institute of Portland state University.

Trommsdorff, G. (1983) . Value change in Japan. International Journal of Intercultural Relations, 7 , 337-360.

Tsurumi, K. (1972). Kokishin to Nihonjin [Japanese and curiosity]. Tokyo, Japan: Dodansha.

Tubbs, S. L. and Moss, S. (1983) - Human Communication (4th ed). NY: Random House.

Wagatsuma, H. \& Rosett, I.A. (1985). The implication of apology: Law and culture in Japan and United states. Paper presented in class at PSU.

Warfel, K. (1984). Gender schemas and perceptions of speech style. Speech Monographs, 51, 253-267.

Wetzel, P. J. (1988). Are "powerless" communication strategies the Japanese norm? Language Society, 17, 555-564. 
Wheeless, V. E. \& Duran, R. L. (1982). Gender orientation as a correlate of communicative competence. The Southern Speech Communication Journal, 48, 51-64. 
APPENDIX A

DEMOGRAPHIC DATA 
THE JAPANESE AND U.S. SUBJECTS DEMOGRAPHIC STATUS

Percentage

Japanese

Americans

(1) AGE

$20-25$
$26-30$
$31=40$
$41=50$
$51-55$

45.3

31.6

17.9

5.3

0

$34.3(\%)$

22.2

28.3

12.1

3.0

Mean

27.5

30.3

std. Dev.

6.136

8.343

$\mathrm{N}=95$

$\mathrm{N}=99$

(2) SCHOOL ATTENDED

PSU

PCC

Univ of oregon

Lewice \& Clark

Multnomah

Other univ. in oregon

other states

Univ. in Japan
$55.4(8)$

9.8

1.1

$3 \cdot 3$

2.2

20.7

3.3

4.3

$\mathrm{N}=92$
86.6

0

2.0

3.1

5.2

3.1

0

0

$\mathrm{N}=97$

0

\section{(3) ACADEMIC MAJOR}

Business

Engineering

Social study

Urban study

Liberal Art

Education

Theology

other

$\begin{array}{cc}31.9(8) & 11.2 \\ 4.3 & \\ 1.4 & 3.4 \\ 59.4 & 1.1 \\ 1.4 & 18.0 \\ 1.4 & 7.9 \\ 0 & 0 \\ & 0\end{array}$

$\mathrm{N}=69$
(\%)

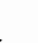
1 
DIFFERENCE BETWEEN THE JAPANESE AND

U.S. IN SOCIALIZATION

Percentage

Japanese U.S.

(1) MARITAL STATUS

Married

Single

Divorced

Separated

widower

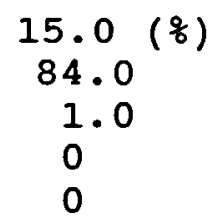

$\mathrm{N}=100$
23.0

62.0

12.0

3.0

0

$\mathrm{N}=100$

(2) CULTURE OF SPOUSE

Japanese

Non-Japanese Asian

Non-Japanese-Asian American

American

$\begin{array}{cr}53.8(8) & 17.4 \\ 0 . & 4.3 \\ 0 . & 4.3 \\ 46.2 & 73.9 \\ N=13 & N=23\end{array}$

58.3

41.7

$50.0(\%)$

50.0

$\mathrm{N}=84$

$\mathrm{N}=76$

$(\%) \quad 50.0(\%)$
50.0
$N=76$

(3) CLOSE OPPOSITE SEX FRIEND

Have close opposite sex friend Do not have

(4) CLOSE OPPOSITE SEX FRIENDS' CULTURE

Japanese

Non-Japanese Asian

Middle Eastern

Non-Japanese-Asian American

American

other

$\begin{array}{rr}54.0\left(\frac{8}{8}\right) & 12.8 \\ 4.0 & 2.6 \\ 14.0 & 2.6 \\ 2.0 & 5.1 \\ 22.0 & 69.2 \\ 0 & 7.7 \\ \mathrm{~N}=50 & \mathrm{~N}=39\end{array}$


DIFFERENCE BETWEEN THE JAPANESE AND

U.S. IN SOCIALIZATION

(continued)

Percentage

Japanese U.S.

(5) CULTURE MOST COMFORTABLE WITH

Japanese

Non-Japanese Asian

Middle Eastern

American

Japanese \& American

Little Difference

$$
\begin{array}{r}
65.3 \\
2.0 \\
1.0 \\
6.1 \\
3.1 \\
22.4
\end{array}
$$

3.0

1.0

0

26.0

1.0

69.0

$$
\mathrm{N}=98
$$

$\mathrm{N}=100$

(6) PREFERENCE CULTURE OF FUTURE SPOUSE

Japanese

Non-Japanese Asian

Middle Eastern

Japanese American

Non-Japanese-Asian American

American

other

Little Difference
75.3

0

1.4

0

0

13.7

1.4

21.9

$\mathrm{N}=73$
(\%)

$6.7(\%)$

5.3

0

1.3

1.3

33.3

2.7

49.3

$\mathrm{N}=75$

(7) PROPORTION OF FRIENDS WITH THE OWN CULTURE

$$
\text { value }
$$

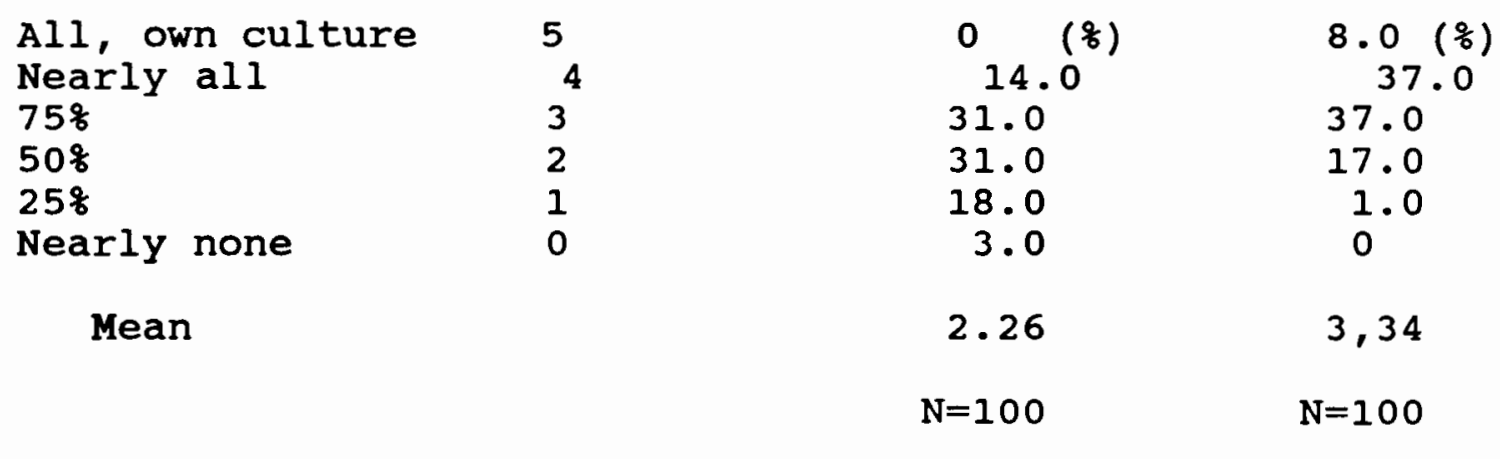


OTHER LANGUAGE PROFICIENCY LEVEL

Value

0

Not at all

A few words Often difficulty

Functional

Fluent

Mean
Percentage

Japanese

American

$$
5.0(8)
$$

9.0

16.0

55.0

15.0

43.4 (q)

22.2

27.3

7.0

0

2.750

.980

$\mathrm{N}=100$

$\mathrm{N}=99$ 
PREFERENCE OF STAYING IN THE OTHER CULTURE

\section{Percentage}

Japanese

American

(1) PREFERENCE OF STAYING IN THE OTHER COUNTRY

Japan

U.S.

Not mind
$22.2(\%)$

28.3

49.5

$\mathrm{N}=99$
21.9

65.8

12.3

$\mathrm{N}=73$

(2) PREFERENCE OF LENGTH OF STAY IN THE OTHER CULTURE

Less than 1 year

1 year - 2 years

2 years - 3 years

3 years - 4 years

4 years - 5 years

5 years - 6 years

6 years - 8 years

8 years - 10 years

10 years - 15 years

15 years - 20 years

Lifetime

Not know

$\begin{array}{rc}4.7(\%) & 10.2(\%) \\ 10.6 & 12.5 \\ 11.8 & 4.5 \\ 4.7 & 2.3 \\ 21.2 & 6.8 \\ 2.4 & 0 \\ 0 & 1.1 \\ 16.5 & 2.3 \\ 2.4 & 0 \\ 1.2 & 1.1 \\ 16.5 & 2.3 \\ 8.2 & 56.8 \\ \mathrm{~N}=85 & \mathrm{~N}=88\end{array}$


THE JAPANESE SUBJECTS

Percentage

(1) LENGTH OF FUTURE STAY IN THE U. $\mathrm{S}$.

Less than 6 months

23.2

15.2

6 months - 1 year

14.1

1 year - 2 years

2 years - 3 years

3 years - 4 years

9.1

4 years - 5 years

4.0

1.0

Lifelong

1.0

Not know

32.3

(2) PURPOSE OF STAY IN U.S.

65.0

19.0

4.0

4.0

3.0

5.0

To study English

To experience living U.S.

Business

To have Alemrican husband

To accompany Japanese husband's business

(3) PLANNED LENGTH OF STAY IN U.S.

Less than 6 months

6 months - 1 year

1 year - 2 years

2 years - 3 years

3 years - 4 years \& 6 months Lifetime
33.9

23.1

21.5

13.8

6.2

1.5 
STAYING IN THE OTHER CULTURE (continued)

THE U.S. SUBJECTS

Percentage

(1) EXPERIENCE OF STAYING IN JAPAN $N=100$

Had been to Japan

Had never been to Japan

$33(\%)$

67

(2) LENGTH OF STAYING IN JAPAN

$N=33$

Less than 1 month

1 month - 1 year

27.3

27.3

1 year - 2 years

24.2

2 years - 3 years

9.1

11 years

3.0

15 years

27 years and 10 months

6.1

3.0

(3) PURPOSE OF STAYING IN JAPAN

Travel

To experience living in Japan

To teach English

Business

others

21.2

30.3

9.1

(\%)

15.2

24.2

(4) INTERACTION WITH JAPANESE

Have interaction with Japanese

81.6

Have no interaction with Japanese

18.4

(5) FREQUENCY OF INTERACTION WITH JAPANESE

Everyday

Several times a week

Once a week

once a month
23.5

45.7

22.2

8.6 
APPENDIX B

INTERPERSONAL CRITICISM QUESTIONNAIRE 
0 . I probably would not feel dissatisfaction towards such speech and behavior.

1. I would probably attempt not to show my dissatisfaction to this person.

2. I would probably express my dissatisfaction to a third person. (This should not include cases in which you report this person's conduct to a superior.)

3. I would probably express my dissatisfaction to this person by a slight gesture or facial expression.

4. I would probably express my dissatisfaction to this person ambiguously.

5. I would probably express my dissatisfaction to this person humorously.

6. I would probably express my dissatisfaction to this person through constructive suggestions.

7. I would probably express my dissatisfaction to this person in a direct way.

8. I would probably express my dissatisfaction to this person with sarcastic remarks.

9. I would probably express my dissatisfaction to this person angrily.

10. I would probably express my dissatisfaction to this person in an insulting way. 
NOMURA'S CRITICAL EPISODES

1. In a coffee shop, ( ) has carelessly spilled coffee on your clothes. The clothes are your newest and favorite ones.

2. ( ) is listening to music on the radio in the next room. The music is too loud and you cannot study. you have an important exam tomorrow.

3. You were scheduled to go to a concert with ( ). You have been looking forward to the concert very much, but you have missed the concert because he/she has made you wait for an hour.

4. ( ) has criticized your association with a friend of the opposite sex. The criticism is completely unreasonable to you.

5. ( ) is driving a car. His/her driving is so reckless that you feel frightened.

6. You asked ( ) how to get to a certain record shop. You looked for the record shop, following the directions he/she gave, but the directions were entirely wrong.

7. You hear ( ) criticizing something you did. You think the accusation is unreasonable.

8. A week ago, you asked ( ) to make a flight reservation for you. When you phoned the airlines today for confirmation, you discover that he/she failed to call the airlines and the flight is now fully booked.

9. ( ) throws an empty soft drink can from the car window.

10. You go to a department store with ( ). He/she decided to buy a jacket for himself/herself. You think that his/her choice is a poor one and the jacket is unattractive.

11. You go to a movie with ( ). Afterward, you discuss the movie with him/her. You do not agree at all with his/her interpretation of the movie.

12. You discuss "the role of men and women in society" with ( ). You do not agree with his/her opinion at all. 


\section{SIX SELECTED EPISODES}

1. $\mathrm{x}$ is Iistening to music on the radio in the next room. The music is too loud and you cannot study. You have an important exam tomorrow.

2. You were scheduled to go to a concert with $\mathrm{X}$. You have been looking forward to the concert very much, but you have missed the concert because he/she has made you wait for an hour.

3. $\mathrm{X}$ has criticized your association with a friend of the opposite sex. The criticism is completely unreasonable to you.

4. You hear $X$ criticizing something you did. You think the accusation is unreasonable.

5. $X$ throws an empty soft drink can from the car window.

6. You discuss "the role of men and women in society" with $X$. You do not agree with his/her opinion at all. 
APPENDIX C

RANK ORDERING OF THE RESPONSE SCALE 
RANK ORDERING OF THE RESPONSE SCALE

Ordering of the twelve alternative ways of confronting by both Japanese and U.S.

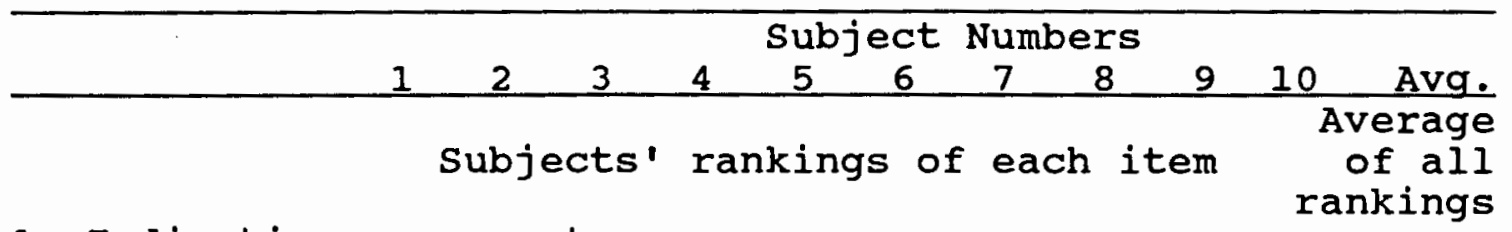

1. Indicating agreement

$\begin{array}{llllllllllll}\text { Japanese } & 1 & 2 & 1 & 1 & 1 & 1 & 1 & 1 & 3 & 1 & 1.3\end{array}$

$\begin{array}{llllllllllll}\text { U.S. } & 3 & 3 & 1 & 1 & 2 & 1 & 5 & 2 & 1 & 1 & 2.0\end{array}$

Total Avg. 1.15

2. Remaining silent

$\begin{array}{llllllllllll}\text { Japanese } & 2 & 1 & 2 & 3 & 4 & 2 & 3 & 3 & 1 & 2 & 2.3\end{array}$

$\begin{array}{llllllllllll}\text { U.S. } & 1 & 1 & 2 & 3 & 3 & 3 & 1 & 1 & 2 & 2 & 1.9\end{array}$

Total Avg. 2.1

3. Replying with nonverbal or verbal behavior

$\begin{array}{llllllllllll}\text { Japanese } & 3 & 3 & 5 & 5 & 2 & 3 & 4 & 4 & 4 & 3 & 3.6\end{array}$

$\begin{array}{llllllllllll}\text { U.S. } & 2 & 2 & 3 & 4 & 1 & 2 & 7 & 3 & 3 & 3 & 3.0\end{array}$

Total Avg. 3.3

4. Changing the subject

$\begin{array}{llllllllllll}\text { Japanese } & 4 & 5 & 3 & 2 & 5 & 5 & 2 & 2 & 2 & 5 & 3.5\end{array}$

$\begin{array}{llllllllllll}\text { U.S. } & 4 & 7 & 5 & 2 & 7 & 5 & 2 & 4 & 4 & 4 & 4.4\end{array}$

Total Avg. 3.95

5. Replying ambiguously

$\begin{array}{llllllllllll}\text { Japanese } & 5 & 4 & 4 & 4 & 3 & 4 & 5 & 5 & 5 & 4 & 4.4\end{array}$

$\begin{array}{llllllllllll}\text { U.S. } & 5 & 4 & 4 & 6 & 4 & 4 & 3 & 5 & 5 & 5 & 4.5\end{array}$

Total Avg. 4.4

6. Stating that discussion is not wanted

$\begin{array}{llllllllllll}\text { Japanese } & 8 & 6 & 9 & 9 & 9 & 9 & 9 & 9 & 8 & 9 & 8.5\end{array}$

$\begin{array}{llllllllllll}\text { U.S. } & 8 & 8 & 9 & 9 & 8 & 6 & 11 & 6 & 7 & 7 & 7.9\end{array}$

Total Avg. 8.4

7. Replying nonchalantly

$\begin{array}{llllllllllll}\text { Japanese } & 6 & 7 & 7 & 7 & 6 & 7 & 6 & 7 & 6 & 7 & 6.6\end{array}$

$\begin{array}{llllllllllll}\text { U.S. } & 6 & 5 & 6 & 7 & 6 & 7 & 6 & 7 & 6 & 8 & 6.4\end{array}$

$\begin{array}{llllllllllll}\text { Japanese } & 9 & 9 & 8 & 8 & 8 & 8 & 7 & 8 & 9 & 8 & 8.2\end{array}$

$\begin{array}{llllllllllll}\text { U.S. } & 9 & 9 & 8 & 10 & 9 & 9 & 9 & 9 & 9 & 9 & 9.0\end{array}$

Total Avg. 8.6

9. Replying half-jokingly

$\begin{array}{llllllllllll}\text { Japanese } & 7 & 8 & 6 & 6 & 7 & 6 & 8 & 6 & 7 & 6 & 6.7\end{array}$ $\begin{array}{llllllllllll}\text { U.S. } & 7 & 6 & 7 & 5 & 5 & 8 & 4 & 8 & 8 & 6 & 6.4\end{array}$ Total AVg. 6.55 
RANK ORDERING OF THE RESPONSE SCALE (continued)

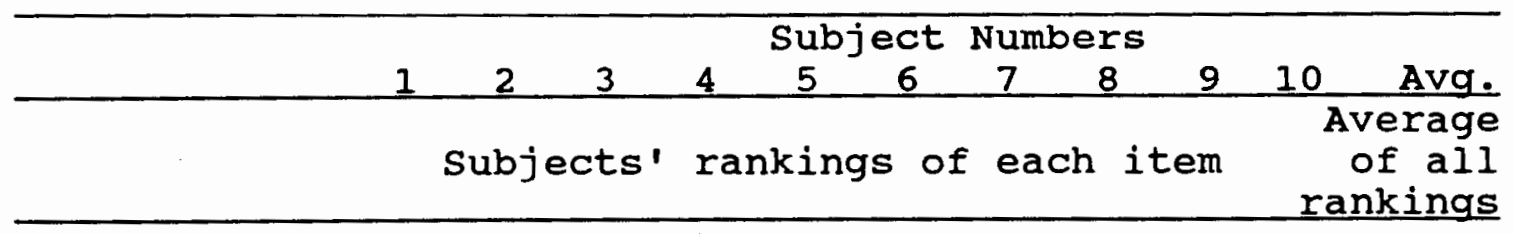

10. Arguing $\begin{array}{llllllllllll}\text { Japanese } & 10 & 10 & 10 & 10 & 10 & 10 & 10 & 11 & 11 & 11 & 10.3\end{array}$ $\begin{array}{llllllllllll}\text { U.S. } & 10 & 10 & 12 & 11 & 11 & 10 & 10 & 10 & 11 & 10 & 11.7\end{array}$ Total Avg. 10.4

11. Replying angrily

$\begin{array}{llllllllllll}\text { Japanese } & 11 & 11 & 11 & 11 & 11 & 11 & 11 & 10 & 10 & 10 & 10.7\end{array}$ $\begin{array}{llllllllllll}\text { U.S. } & 12 & 12 & 11 & 12 & 12 & 11 & 12 & 12 & 12 & 11 & 11.7\end{array}$ Total Avg. 11.2

12. Replying with a sarcastic or an insulting remark $\begin{array}{llllllllllll}\text { Japanese } & 12 & 12 & 12 & 12 & 12 & 12 & 12 & 12 & 12 & 12 & 12.0\end{array}$ U.S. $\begin{array}{llllllllll}11 & 11 & 10 & 8 & 10 & 12 & 8 & 11 & 10 & 12\end{array}$ 10.3 Total Avg. 11.15

Note: Subject number $\mathrm{N}=$ Ten Japanese subjects and U.S. subjects numbers

Average

= Japanese average and U.S. average of all subjects' rankings

Total average

= Average of Japanese and U.S. responses 
APPENDIX D

QUESTIONNAIRE 
THE INTRODUCTORY LETTER FOR THE QUESTIONNAIRE

(Japanese and U.S. Respondents)

Dear Respondent,

This questionnaire represents a portion of the thesis project of Toyoko Hattori, a candidate of the M.A. degree in speech Communication, which is supervised by $\mathrm{Dr}$. Devorah Lieberman, Professor of Speech Communication at Portland State University.

My purpose is to study the behaviors students exhibit in a variety of situations which could easily occur in everyday life. All responses will be kept strictly confidential. I alone will know whether you have chosen to participate or not.

Your participation is voluntary and in no way will affect your course grade.

You are free to withdraw from participation in this study at any time without jeopardizing your relationship with PSU. No participant will be identified in any papers or presentations that may result from the study.

Your participation in this project is greatly appreciated.

Sincerely Yours,

Toyoko Hattori

Department of

Speech Communication

Portland State University 
QUESTIONNAIRE

Part 1 (U.S. Respondents)

Reactions of students to a variety of Common situations (A)

A GENERAL INFORMATION

Please indicate your response by placing an $x$ in the appropriate blank or by providing the information requested.

1 What is your gender?

2 What is your nationality?

3 Year and place of birth:

Year 19 Place (city)

4 Which school are you attending?

5 What is your major?

6 What year of school are you in? Freshman

- Sophomore

_ Junior

- Senior

Male Female

7 a) What is your present marital status?

Post-baccalaureate study

- graduate study doctorate study part time student state
_- Married
- Single
b) If your $\begin{aligned} & \text { Divorced } \\ & \text { answer is "married," is your spouse: }\end{aligned}$ American
- Japanese
- Non-Japanese Asian (please specify)
Separated
widowed

8 a) If your answer is "single," "divorced," "separated," or "widowed," do you have a close relationship with a person of the opposite sex?

b) If you have a close relationship with a person of the opposite sex, is that person: 
9 a) About what proportion of your friends are Americans?

All

Nearly all

About 3/4
About $1 / 2$

About $1 / 4$

Nearly none

b) I $\bar{f}$ your answer is other than "all" indicate the nationality of your other friends, Japanese

_- Non-Japanese Asian (please specify) other (please specify)

10 What nationality do you feel most comfortable with: American

- Japanese

- Non-Japanese Asian (please specify)

- Other Asians (please specify)

- Makes little difference

11 a) Have you ever been to Japan?

b) If your answer is "yes," how much time have you spent in Japan? (your total year) years months weeks days

c) What was your purpose for staying in Japan? Please check the most suitable item. Travel

- Business

- Experience of staying in Japan

- Make Japanese friends

- Other (please specify)

12 a) Do you have the opportunity to interact with any Japanese people in your daily life? Yes No

b) If your answer is "yes," how often do you talk with them? Everyday

13 Do you speak Japanese? Once a week
Once a month

\section{fluent}

- functional

- often have difficulty

- know a few words Not at all

14 If you could choose to live either in the U.S. or Japan, which country would you prefer?

$$
\text { U.S. }
$$
Japan

- Makes little difference Do not know

15 If you could live in Japan indefinitely, how long would you like to stay? years months Do not know 
QUESTIONNAIRE

Part 1 (Japanese Respondents)

Reactions of students to a Variety of Common situations (J)

A GENERAL INFORMATION

Please indicate your response by placing an $\mathrm{x}$ in the appropriate blank or by providing the information requested.

1 What is your gender?

2 What is your nationality?

Male

Female

3 Please state your year of birth and hometown?

Year 19

Place (city)

Prefecture

4 How long have you been in the U.S.? (your total year) years months

5 What is your purpose of stay in the US? Please check

the most suitable purpose of your stay. study English

experience living in the US

make American friends

obtain a degree from an American university

other (please specify)

6 Which school are you attending?

7 What is your major?

8 What year of school are you in?

Freshman Post-baccalaureate study

- Sophomore

Junior

- graduate study

Senior

ESL

part time student

9 a) What is your present marital status? Married

- Single Divorced

Separated

- widowed

b) If your answer is "married," is your spouse: Japanese Non-Japanese Asian (please specify) American other (please specify)

10 a) If your answer is "single," "divorced," "separated," or "widowed," do you have a close relationship with a person of the opposite sex? Yes No

b) If you have a close relationship with a person of the opposite sex, is that person: Japanese Non-Japanese Asian (please specify)

- American white

- other (please specify) American black 
c) When chossing a spouse, what is your nationality preference? Write in ranking $(1,2,3 \ldots)$ of your preference. Japanese

- Non-Japanese Asian (specify)

- American white

- American black

_ No preference

_ Other (please specify)

11 a) About what proportion of your friends in the U.S. are Japanese?
All
Nearly all
About 3/4
About $1 / 2$
About $1 / 4$
Nearly none

b) If your answer is other than "all" indicate the nationarity of your other friends. Non-Japanese Asians (please specify)

- American white

- American black

- Other (please specify)

12 You feel most comfortable when you are with: Japanese

Non-Japanese Asians (please specify)

American white

American black

Other (please specify)

Makes ittle difference

13 What is your level of English proficiency?

Fluent

- Functional

- Have difficulty often

- Know a few words

Not at all

14 a) If you could choose to live either in the U.S. or Japan, which country would you prefer?

U.S.

Japan

- Does not matter

15 How long will you stay in the U.S.? years months

16 If you could live in the U.S. indefinitely, how long would plan to stay?

years months 
QUESTIONNAIRE

Part 2 (U.S. and Japanese Respondents)

This page can be removed to make its use more convenient

B. YOUR ATTITUDE TOWARD YOUR CASUAL FRIENDS IN VARIOUS SITUATIONS.

Explanations and Instructions PLEASE READ CAREFULLY.

In the following situations, describe your reaction by answering each of the following questions in two different ways:

1) Choose the number that best describes how you would react in each situation from the list provided.

2) Indicate your level of discomfort by marking the appropriate number from 0 (feel no discomfort) to 6 (feel greatest discomfort).

Please imagine yourself in the following situations which may occur between you and a friend:

1. A same sex American friend;

2. An opposite sex American friend;

3. A same sex Japanese friend;

4. An opposite sex Japanese friend.

There are no right or wrong answers to the questions. The only appropriate answer to each question is the one that best applies to you.

Response List

1. Indicate agreement with your friend even though you do not actually agree.

2. Remain silent.

3. Express yourself with a slight gesture or facial expression or a brief verbal exclamation.

4. Change the subject.

5. Express yourself in ambiguous language.

6. Express yourself nonchalantly.

7. Express yourself half-jokingly.

8. State that you do not want to discuss it.

9. Express yourself seriously.

10. Arguing your point of view.

11. Show your dissatisfaction or disagreement with a sarcastic or an insulting remark.

12. Express yourself angrily. 
SITUATIONS: Your attitudes toward a casual friend in various situations

1 a) You were planning to go to a concert with your friend. You have been looking forward to it very much, but on the day your friend came about one hour late so you missed the first half of the concert. Your friend offers no explanation.

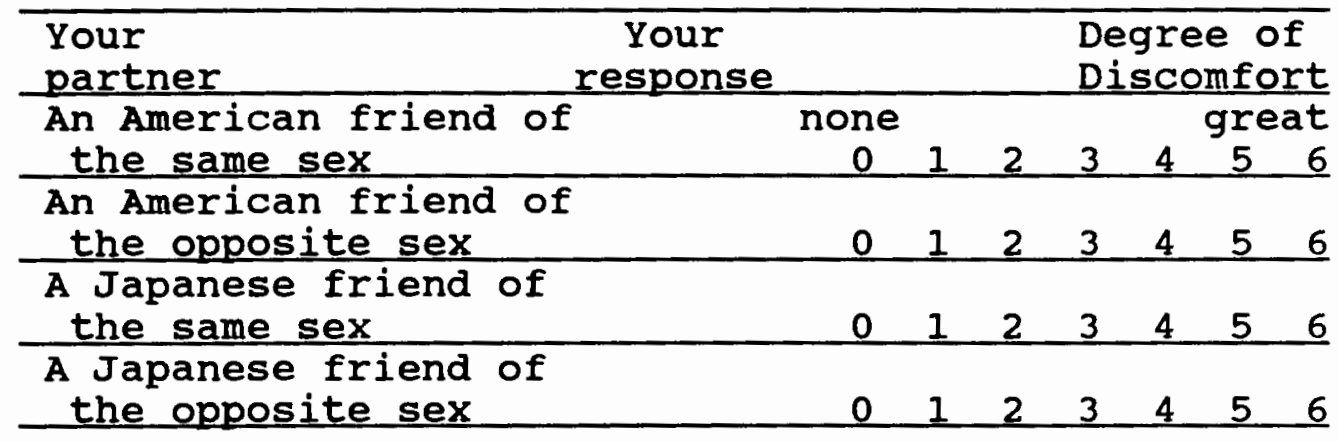

b) You inquire about his/her lateness, but he/she does not give you a satisfactory explanation and fails to understand your disappointment.

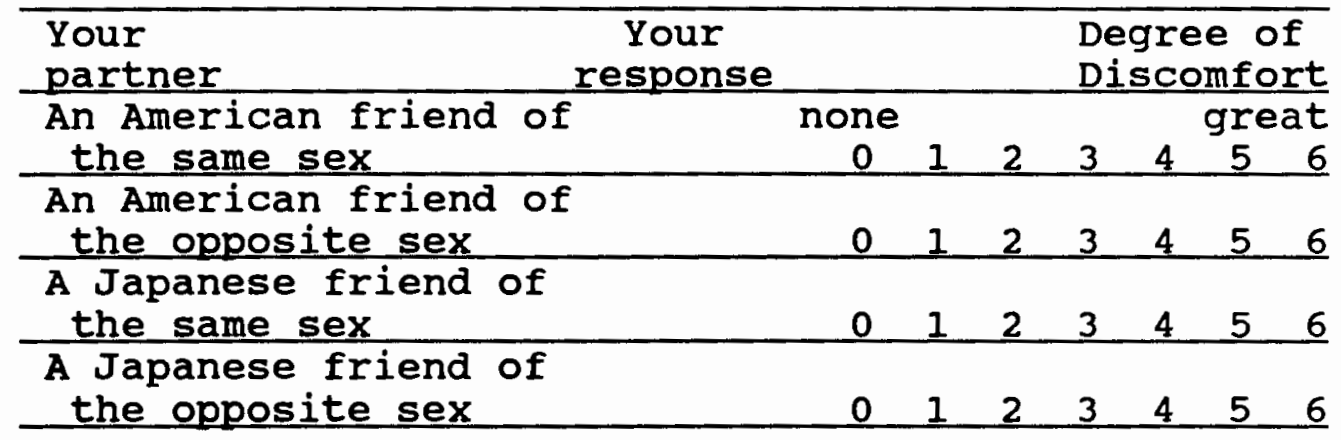

2 a) You have an important examination tomorrow morning. Your friend is listening to music in the next apartment. The music is too loud and you cannot study.

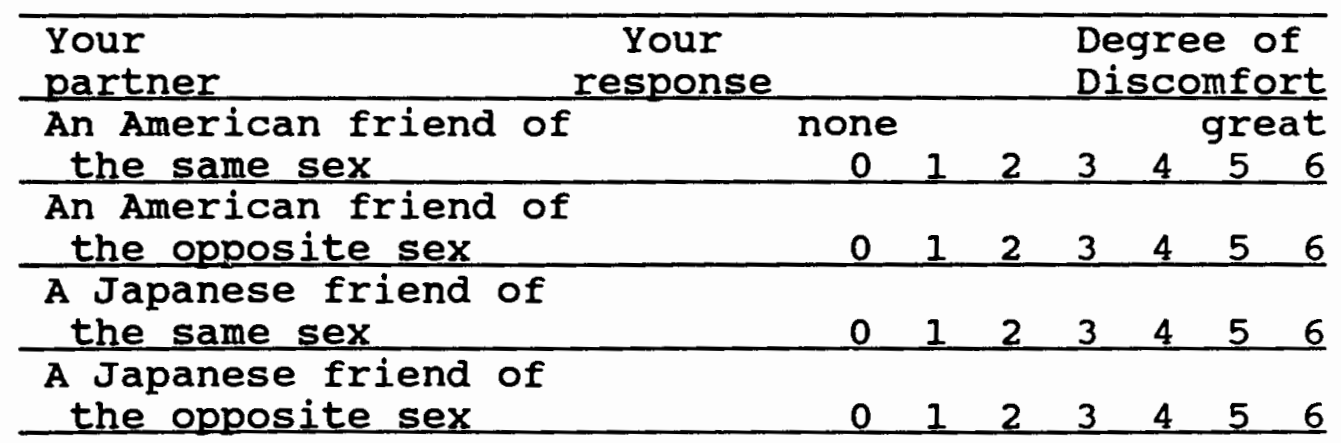


If your response does not include a verbal message in a), skip b). If your response includes a verbal message in a), answer b), too.

b) You mention to your friend that the music is too loud, and he/she disagrees and does not turn the volume down.

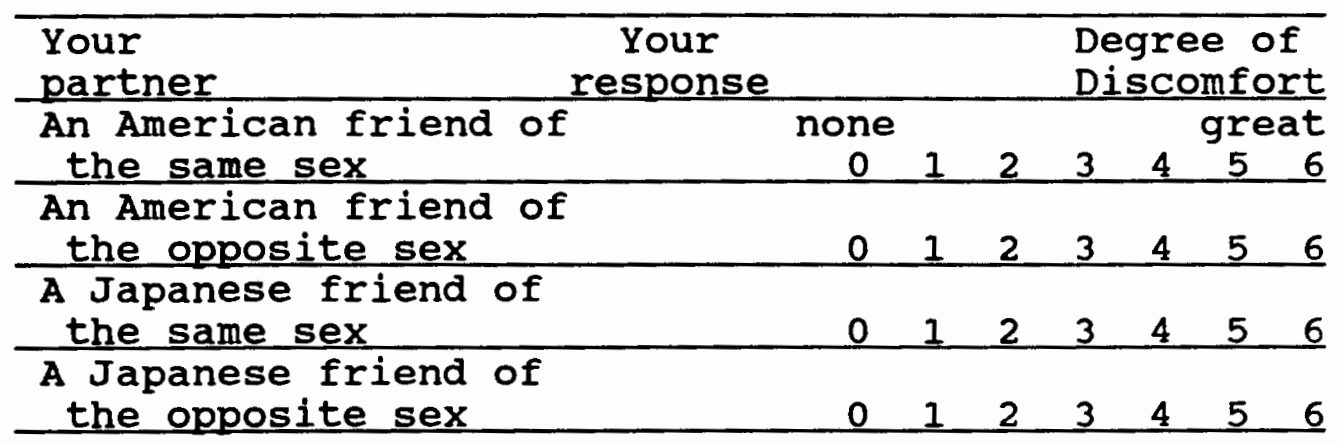

3 a) Your friend has criticized your association with a friend of the opposite sex. The criticism is completely unreasonable to you.

\begin{tabular}{lccccccccc}
\hline $\begin{array}{l}\text { Your } \\
\text { partner }\end{array}$ & $\begin{array}{c}\text { Your } \\
\text { response }\end{array}$ & & $\begin{array}{c}\text { Degree of } \\
\text { Discomfort }\end{array}$ \\
\hline $\begin{array}{c}\text { An American friend of } \\
\text { the same sex }\end{array}$ & $\begin{array}{c}\text { none } \\
0\end{array}$ & 1 & 2 & 3 & 4 & $\begin{array}{c}\text { great } \\
5\end{array}$ & 6 \\
\hline $\begin{array}{l}\text { An American friend of } \\
\text { the opposite sex }\end{array}$ & 0 & 1 & 2 & 3 & 4 & 5 & 6 \\
\hline $\begin{array}{c}\text { A Japanese friend of } \\
\text { the same sex }\end{array}$ & 0 & 1 & 2 & 3 & 4 & 5 & 6 \\
\hline $\begin{array}{l}\text { A Japanese friend of } \\
\text { the opposite sex }\end{array}$ & 0 & 1 & 2 & 3 & 4 & 5 & 6 \\
\hline
\end{tabular}

b) Your friend persists in criticizing this person.

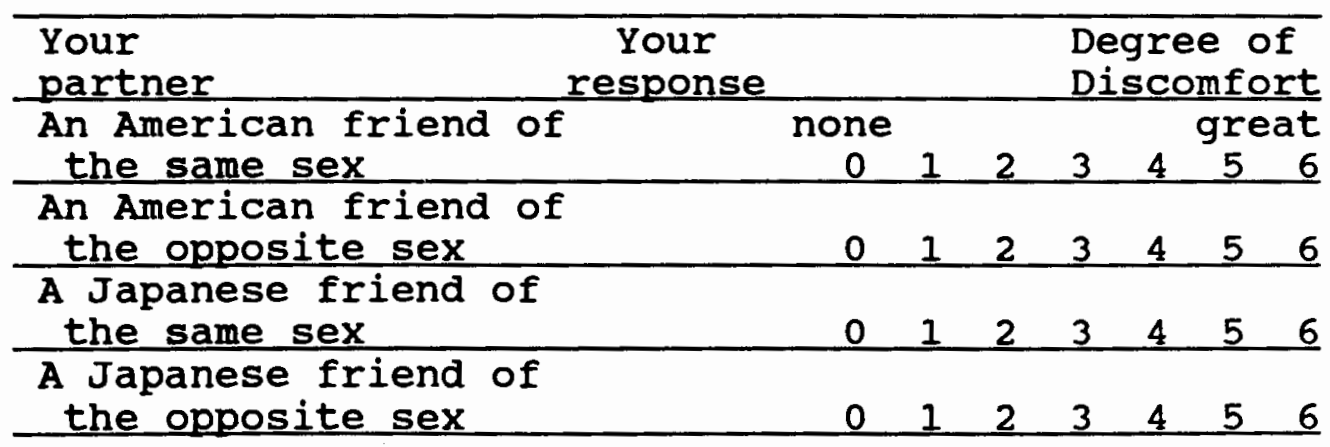


4 a) Your friend criticizes a class presentation you did. You think the accusation is unreasonable.

\begin{tabular}{lccccccccc}
\hline $\begin{array}{l}\text { Your } \\
\text { partner }\end{array}$ & $\begin{array}{c}\text { Your } \\
\text { response }\end{array}$ & & \multicolumn{3}{c}{$\begin{array}{c}\text { Degree of } \\
\text { Discomfort }\end{array}$} \\
$\begin{array}{l}\text { An American friend of } \\
\text { the same sex }\end{array}$ & $\begin{array}{c}\text { none } \\
0\end{array}$ & 1 & 2 & 3 & 4 & 5 & \multicolumn{3}{c}{$\begin{array}{c}\text { great } \\
5\end{array}$} \\
\hline $\begin{array}{l}\text { An American friend of } \\
\text { the opposite sex }\end{array}$ & 0 & 1 & 2 & 3 & 4 & 5 & 6 \\
\hline $\begin{array}{c}\text { A Japanese friend of } \\
\text { the same sex }\end{array}$ & 0 & 1 & 2 & 3 & 4 & 5 & 6 \\
\hline $\begin{array}{l}\text { A Japanese friend of } \\
\text { the opposite sex }\end{array}$ & 0 & 1 & 2 & 3 & 4 & 5 & 6 \\
\hline
\end{tabular}

b) Your friend continues to criticize your behavior and questions the reasoning of your presentation.

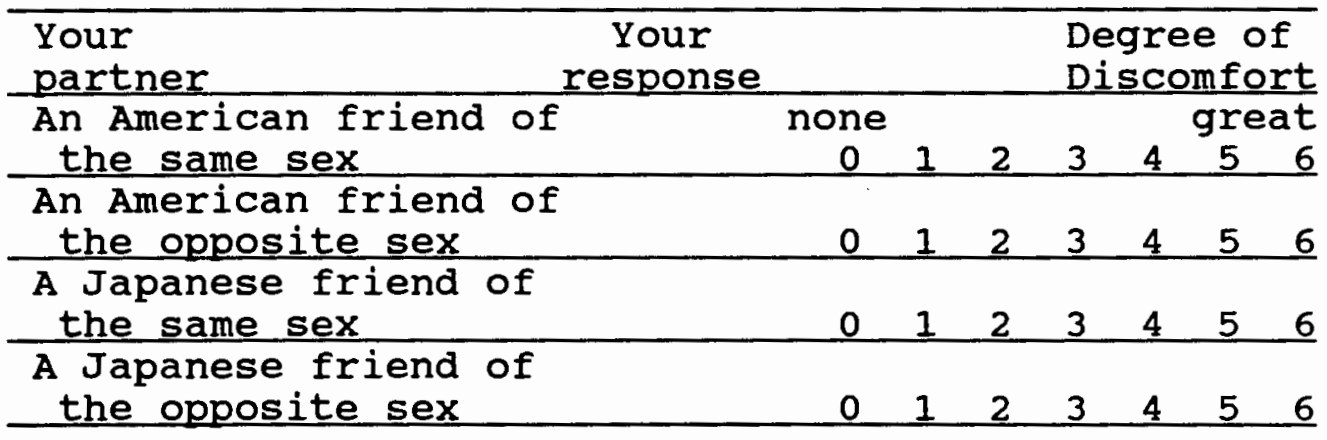

5 a) You are riding in a car with your friend. your friend throws an empty soft drink can out of the window.

\begin{tabular}{lccccccccc}
\hline $\begin{array}{l}\text { Your } \\
\text { partner }\end{array}$ & $\begin{array}{c}\text { Your } \\
\text { response }\end{array}$ & & \multicolumn{2}{c}{$\begin{array}{c}\text { Degree of } \\
\text { Discomfort }\end{array}$} \\
\hline $\begin{array}{c}\text { An American friend of } \\
\text { the same sex }\end{array}$ & $\begin{array}{c}\text { none } \\
0\end{array}$ & 1 & 2 & 3 & 4 & 5 & $\begin{array}{c}\text { great } \\
5\end{array}$ \\
\hline $\begin{array}{l}\text { An American friend of } \\
\text { the opposite sex }\end{array}$ & 0 & 1 & 2 & 3 & 4 & 5 & 6 \\
\hline $\begin{array}{c}\text { A Japanese friend of } \\
\text { the same sex }\end{array}$ & 0 & 1 & 2 & 3 & 4 & 5 & 6 \\
\hline $\begin{array}{l}\text { A Japanese friend of } \\
\text { the opposite sex }\end{array}$ & 0 & 1 & 2 & 3 & 4 & 5 & 6 \\
\hline
\end{tabular}

If your response does not include a verbal message in a), skip b). If your response includes a verbal message in a), answer b). 
5 b) You state your opinion, and your friend indicates that what you have said is unimportant.

\begin{tabular}{lllllllllll}
\hline $\begin{array}{l}\text { Your } \\
\text { partner }\end{array}$ & $\begin{array}{c}\text { Your } \\
\text { response }\end{array}$ & & $\begin{array}{c}\text { Degree of } \\
\text { Discomfort }\end{array}$ \\
\hline $\begin{array}{c}\text { An American friend of } \\
\text { the same sex }\end{array}$ & $\begin{array}{c}\text { none } \\
0\end{array}$ & 1 & 2 & 3 & 4 & $\begin{array}{c}\text { great } \\
5\end{array}$ & 6 \\
\hline $\begin{array}{c}\text { An American friend of } \\
\text { the opposite sex }\end{array}$ & 0 & 1 & 2 & 3 & 4 & 5 & 6 \\
\hline $\begin{array}{c}\text { A Japanese friend of } \\
\text { the same sex }\end{array}$ & 0 & 1 & 2 & 3 & 4 & 5 & 6 \\
\hline $\begin{array}{l}\text { A Japanese friend of } \\
\text { the opposite sex }\end{array}$ & 0 & 1 & 2 & 3 & 4 & 5 & 6 \\
\hline
\end{tabular}

6 a) You discuss "the role of men and women in society" with your friend, but your opinions differ sharply.

\begin{tabular}{lccccccccc}
\hline $\begin{array}{l}\text { Your } \\
\text { partner }\end{array}$ & $\begin{array}{c}\text { Your } \\
\text { response }\end{array}$ & & \multicolumn{3}{c}{$\begin{array}{c}\text { Degree of } \\
\text { Discomfort }\end{array}$} \\
$\begin{array}{c}\text { An American friend of } \\
\text { the same sex }\end{array}$ & $\begin{array}{c}\text { none } \\
0\end{array}$ & 1 & 2 & 3 & 4 & $\begin{array}{c}\text { great } \\
5\end{array}$ & 6 \\
\hline $\begin{array}{l}\text { An American friend of } \\
\text { the opposite sex }\end{array}$ & 0 & 1 & 2 & 3 & 4 & 5 & 6 \\
\hline $\begin{array}{c}\text { A Japanese friend of } \\
\text { the same sex }\end{array}$ & 0 & 1 & 2 & 3 & 4 & 5 & 6 \\
\hline $\begin{array}{l}\text { A Japanese friend of } \\
\text { the opposite sex }\end{array}$ & 0 & 1 & 2 & 3 & 4 & 5 & 6 \\
\hline
\end{tabular}

If your response does not include a verbal message in a), skip b). If your response includes a verbal message in a), answer b).

b) You express your opinion on the subject, but he/she persists in attempting to persuade you to agree with him/her.

\begin{tabular}{lccccccccc}
\hline $\begin{array}{l}\text { Your } \\
\text { partner }\end{array}$ & $\begin{array}{c}\text { Your } \\
\text { response }\end{array}$ & & \multicolumn{3}{c}{$\begin{array}{c}\text { Degree of } \\
\text { Discomfort }\end{array}$} \\
\hline $\begin{array}{c}\text { An American friend of } \\
\text { the same sex }\end{array}$ & $\begin{array}{c}\text { none } \\
0\end{array}$ & 1 & 2 & 3 & 4 & $\begin{array}{c}\text { great } \\
5\end{array}$ \\
\hline $\begin{array}{c}\text { An American friend of } \\
\text { the opposite sex }\end{array}$ & 0 & 1 & 2 & 3 & 4 & 5 & 6 \\
\hline $\begin{array}{c}\text { A Japanese friend of } \\
\text { the same sex }\end{array}$ & 0 & 1 & 2 & 3 & 4 & 5 & 6 \\
\hline $\begin{array}{l}\text { A Japanese friend of } \\
\text { the opposite sex }\end{array}$ & 0 & 1 & 2 & 3 & 4 & 5 & 6 \\
\hline
\end{tabular}


7 a) Your friend borrowed money from you and promised to pay you back the next day. When you met your friend a day later, he/she never mentioned the money to you. Several days later, you and this same friend go to a coffee shop. Your friend again asks to borrow money. You do not want to lend $\mathrm{him} / \mathrm{her}$ more money until the original debt has been paid.

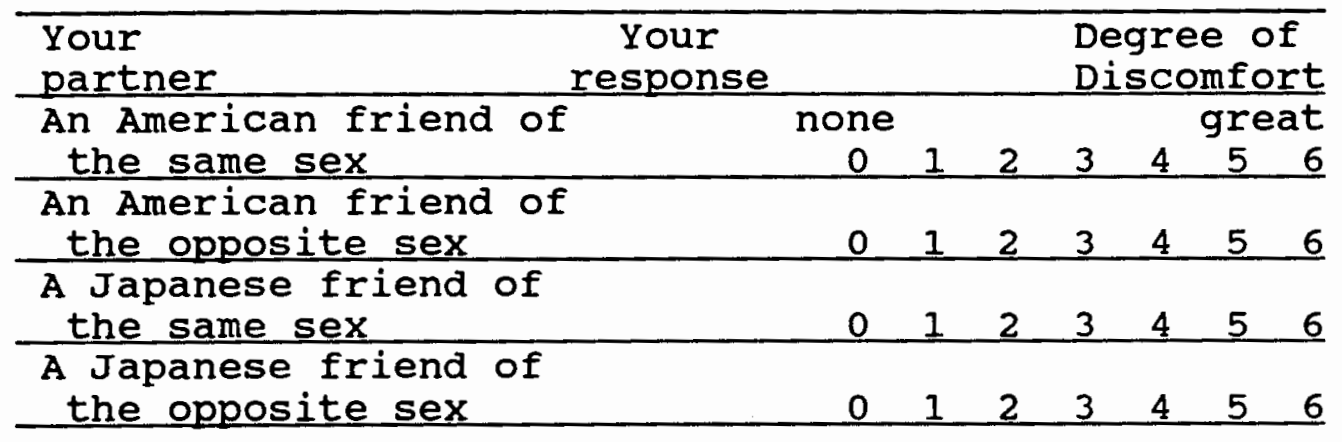

b) Your friend repeatedly insists that you loan him money a second time.

\begin{tabular}{lccccccccc}
\hline $\begin{array}{l}\text { Your } \\
\text { partner }\end{array}$ & $\begin{array}{c}\text { Your } \\
\text { response }\end{array}$ & & \multicolumn{2}{c}{$\begin{array}{c}\text { Degree of } \\
\text { Discomfort }\end{array}$} \\
\hline $\begin{array}{l}\text { An American friend of } \\
\text { the same sex }\end{array}$ & $\begin{array}{c}\text { none } \\
0\end{array}$ & 1 & 2 & 3 & 4 & 5 & 5 \\
\hline $\begin{array}{l}\text { An Amereat } \\
\text { the opposite sex }\end{array}$ & 0 & 1 & 2 & 3 & 4 & 5 & 6 \\
\hline $\begin{array}{l}\text { A Japanese friend of } \\
\text { the same sex }\end{array}$ & 0 & 1 & 2 & 3 & 4 & 5 & 6 \\
\hline $\begin{array}{l}\text { A Japanese friend of } \\
\text { the opposite sex }\end{array}$ & 0 & 1 & 2 & 3 & 4 & 5 & 6 \\
\hline
\end{tabular}


APPENDIX E

VARIABLES 
VARIABLES

Variables to measure confrontation style with a friend.

Situation 1: Being late for a concert.

var.20 - from the same culture and the same sex

var.27 - from the same culture and the opposite sex

var.34 - from the other culture and the same sex

var.41 - from the other culture and the opposite sex

Situation 2: Making continuous noise during study. var.21 - from the same culture and the same sex

var.28 - from the same culture and the opposite sex

var.35 - from the other culture and the same sex

var.42 - from the other culture and the opposite sex

situation 3: Criticizing a friend of the opposite sex. var.22 - from the same culture and the same sex

var.29 - from the same culture and the opposite sex

var.36 - from the other culture and the same sex

var.43 - from the other culture and the opposite sex

Situation 4: Criticizing a class presentation. var.23 - from the same culture and the same sex

var.30 - from the same culture and the opposite sex

var.37 - from the other culture and the same sex

var.44 - from the other culture and the opposite sex

Situation 5: Littering.

var.24 - from the same culture and the same sex

var.31 - from the same culture and the opposite sex

var.38 - from the other culture and the same sex

var.45 - from the other culture and the opposite sex

Sitaution 6: Disagreeing with gender role in society.

var.25 - from the same culture and the same sex

var.32 - from the same culture and the opposite sex

var.39 - from the other culture and the same sex

var.46 - from the other culture and the opposite sex

Situation 7: Asking to lend money

var.26 - from the same culture and the same sex

var. 33 - from the same culture and the opposite sex

var.40 - from the other culture and the same sex

var.47 - from the other culture and the opposite sex 
THE MEANS OF VARIABLES

Variables in relation

Japanese

American

to confrontation styles

Male Female

Male Female

Situation 1

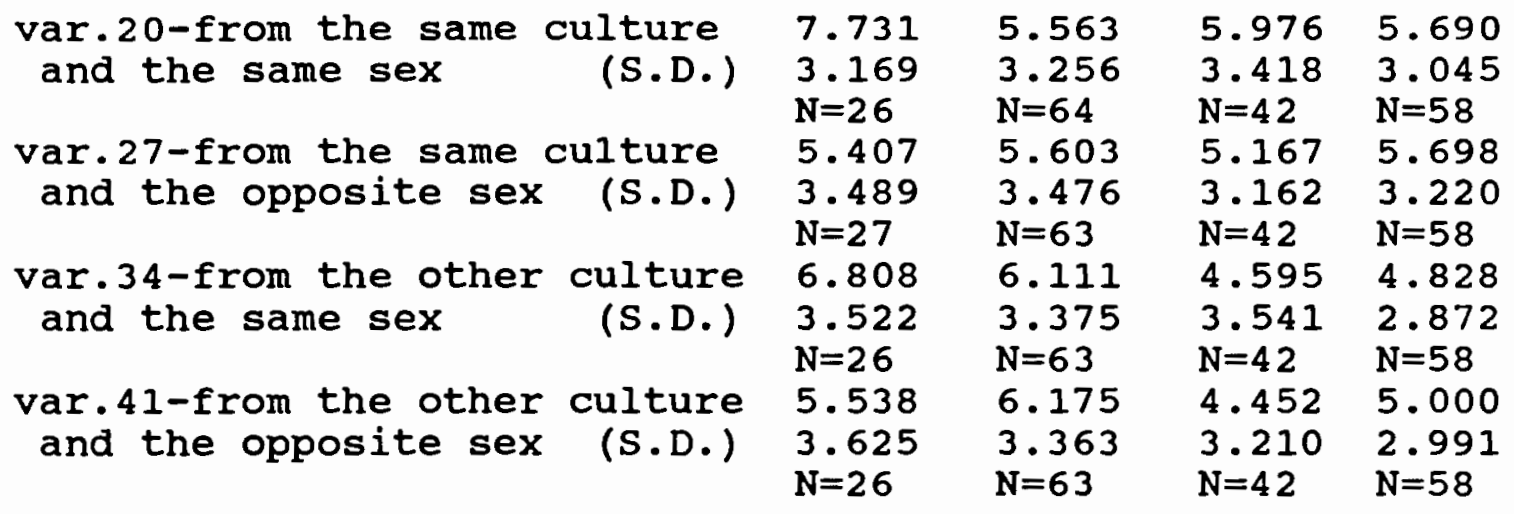

Situation 2

var.21-from the same culture and the same sex

(S.D.)

8.111

7.525

7.462

6.889

2.592

2.700

2.979

3.100

$\mathrm{N}=27$

$\mathrm{N}=59$

$\mathrm{N}=40$

$\mathrm{N}=54$

var.28-from the same culture

7.185

7.534

7.412

7.057

and the opposite sex (S.D.)

3.064

2.696

2.935

3.053

$\mathrm{N}=27$

$\mathrm{N}=58$

$\mathrm{N}=40$

$\mathrm{N}=53$

var.35-from the other culture

7.429

7.526

and the same sex

(S.D.) 3.084

2.798

6.525

6.075

$\mathrm{N}=28$

$\mathrm{N}=58$

var.42-from the other culture

7.296

7.603

3.040

3.210

$\mathrm{N}=40$

$\mathrm{N}=53$

and the opposite sex

(S.D.)

2.959

2.714

6.675

6.151

$\mathrm{N}=27$

$\mathrm{N}=58$

3.094

3.195

$\mathrm{N}=40 \quad \mathrm{~N}=54$

Situation 3

var.22-from the same culture and the same sex

(S.D.)

var.29-from the same culture and the opposite sex (S.D.)

var.36-from the other culture and the same sex

(S.D.)

var.43-from the other culture and the opposite sex
(S.D.)
7.267

2.947

$\mathrm{N}=30$

7.133

2.956

$\mathrm{N}=30$

6.500

3.192

$\mathrm{N}=30$

6.467

2.991

$\mathrm{N}=30$
6.014

2.988

$\mathrm{N}=69$

6.014

3.027

$\mathrm{N}=69$

6.304

2.907

$\mathrm{N}=69$

6.333

2.863

$\mathrm{N}=69$
7.061

6.431

3.214

$\mathrm{N}=41$

3.056

6.598

$\mathrm{N}=58$

3.113

$\mathrm{N}=41$

6.845

2.961

$\mathrm{N}=58$

6.305

5.879

3.116

$N=41$

2.932

$\mathrm{N}=58$

6.012

6.086

2.785

2.952

$\mathrm{N}=41$

$\mathrm{N}=58$ 
THE MEANS OF VARIABLES

(continued)

Variables in relation

to confrontation styles
Japanese

Male Female
American

Male Female

Situation 4

var.23-from the same culture

6.967

(S.D.)

and the same sex

var.30-from the same culture

and the opposite sex

(S.D.)

var.37-from the other culture and the same sex

(S.D.)

var.44-from the other culture and the opposite sex
(S.D.)

$\begin{array}{llll}6.967 & 6.935 & 6.325 & 6.164 \\ 2.312 & 2.233 & 2.723 & 2.993 \\ \mathrm{~N}=30 & \mathrm{~N}=69 & \mathrm{~N}=40 & \mathrm{~N}=58 \\ 6.717 & 6.891 & 6.000 & 5.871 \\ 2.420 & 2.161 & 2.691 & 2.951 \\ \mathrm{~N}=30 & \mathrm{~N}=69 & \mathrm{~N}=40 & \mathrm{~N}=58 \\ 6.167 & 6.725 & 5.575 & 5.612 \\ 2.705 & 2.121 & 2.784 & 2.972 \\ \mathrm{~N}=30 & \mathrm{~N}=69 & \mathrm{~N}=40 & \mathrm{~N}=58 \\ 6.133 & 6.754 & 5.625 & 5.595 \\ 2.738 & 2.158 & 2.764 & 3.043 \\ \mathrm{~N}=30 & \mathrm{~N}=69 & \mathrm{~N}=40 & \mathrm{~N}=58\end{array}$

Situation 5

var.24-from the same culture and the same sex

(S.D.)

var.31-from the same culture and the opposite sex (S.D.)

var.38-from the other culture and the same culture (S.D.)

var.45-from the other culture and the opposite sex (S.D.)

$\begin{array}{llll}5.077 & 3.417 & 5.919 & 5.973 \\ 3.236 & 2.632 & 3.192 & 3.481 \\ \mathrm{~N}=26 & \mathrm{~N}=60 & \mathrm{~N}=37 & \mathrm{~N}=55 \\ 5.173 & 3.500 & 5.514 & 6.213 \\ 3.379 & 2.665 & 3.150 & 3.461 \\ \mathrm{~N}=26 & \mathrm{~N}=60 & \mathrm{~N}=37 & \mathrm{~N}=54 \\ 5.192 & 3.862 & 5.649 & 5.750 \\ 3.175 & 2.717 & 3.318 & 3.417 \\ \mathrm{~N}=26 & \mathrm{~N}=58 & \mathrm{~N}=37 & \mathrm{~N}=54 \\ 5.077 & 3.914 & 5.162 & 5.991 \\ 3.199 & 2.736 & 3.296 & 3.402 \\ \mathrm{~N}=26 & \mathrm{~N}=58 & \mathrm{~N}=37 & \mathrm{~N}=5\end{array}$

Situation 6

\begin{tabular}{|c|c|c|c|c|}
\hline $\begin{array}{l}\text { var.25-from the same culture } \\
\text { and the same sex } \\
\text { (S.D.) }\end{array}$ & $\begin{array}{l}5.185 \\
2.481 \\
\mathrm{~N}=27\end{array}$ & $\begin{array}{l}5.765 \\
2.612 \\
N=66\end{array}$ & $\begin{array}{l}6.714 \\
2.550 \\
\mathrm{~N}=35\end{array}$ & $\begin{array}{l}6.796 \\
3.006 \\
N=54\end{array}$ \\
\hline $\begin{array}{l}\text { var.32-from the same culture } \\
\text { and the opposite sex (S.D.) }\end{array}$ & $\begin{array}{l}4.926 \\
2.556 \\
\mathrm{~N}=27\end{array}$ & $\begin{array}{l}5.826 \\
2.815 \\
\mathrm{~N}=66\end{array}$ & $\begin{array}{l}6.229 \\
2.680 \\
\mathrm{~N}=35\end{array}$ & $\begin{array}{l}7.074 \\
2.990 \\
N=54\end{array}$ \\
\hline $\begin{array}{l}\text { var.39-from the other culture } \\
\text { and the same sex }\end{array}$ & $\begin{array}{l}5.407 \\
2.515 \\
\mathrm{~N}=27\end{array}$ & $\begin{array}{l}6.136 \\
2.195 \\
\mathrm{~N}=66\end{array}$ & $\begin{array}{l}5.941 \\
2.795 \\
\mathrm{~N}=34\end{array}$ & $\begin{array}{l}5.778 \\
2.976 \\
N=54\end{array}$ \\
\hline $\begin{array}{l}\text { var.46-from the other culture } \\
\text { and the opposite sex (S.D.) }\end{array}$ & $\begin{array}{l}5.148 \\
2.492 \\
N=27\end{array}$ & $\begin{array}{l}6.439 \\
2.266 \\
N=66\end{array}$ & $\begin{array}{l}5.857 \\
2.746 \\
\mathrm{~N}=35\end{array}$ & $\begin{array}{l}6.259 \\
3.145 \\
\mathrm{~N}=54\end{array}$ \\
\hline
\end{tabular}


THE MEANS OF VARIABLES

(continued)

\begin{tabular}{lccccc}
\hline $\begin{array}{l}\text { Variables in relation } \\
\text { to confrontation styles }\end{array}$ & \multicolumn{2}{c}{$\begin{array}{c}\text { Japanese } \\
\text { Male }\end{array}$} & \multicolumn{2}{c}{$\begin{array}{c}\text { American } \\
\text { Fale }\end{array}$} & Male \\
Fomale
\end{tabular}


APPENDIX F

CODING DATA 


\section{CODING GUIDE I-I}

The item numbers for the Japanese are indicated by *, otherwise, the numbers are both for the Japanese and U.S. subjects.

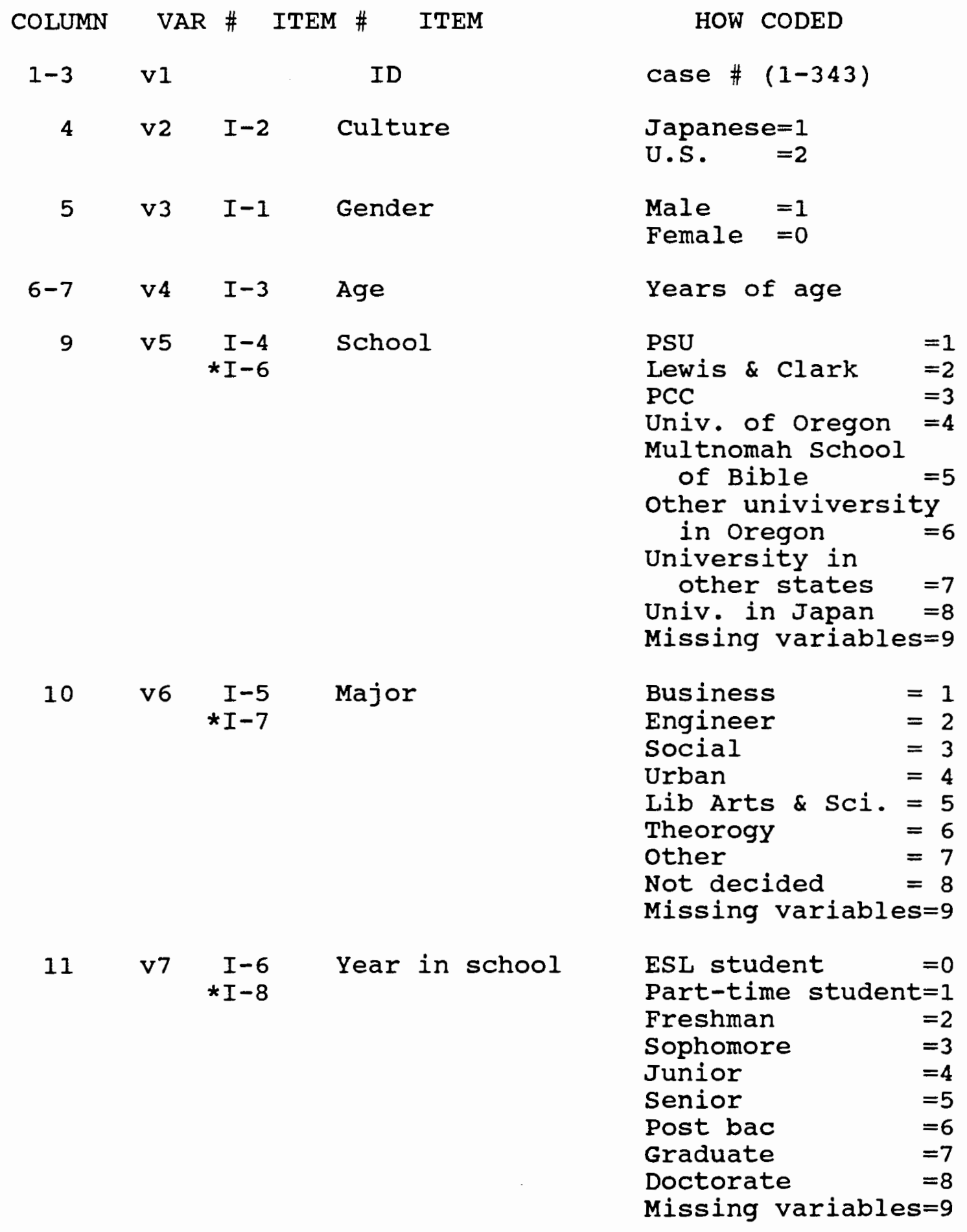




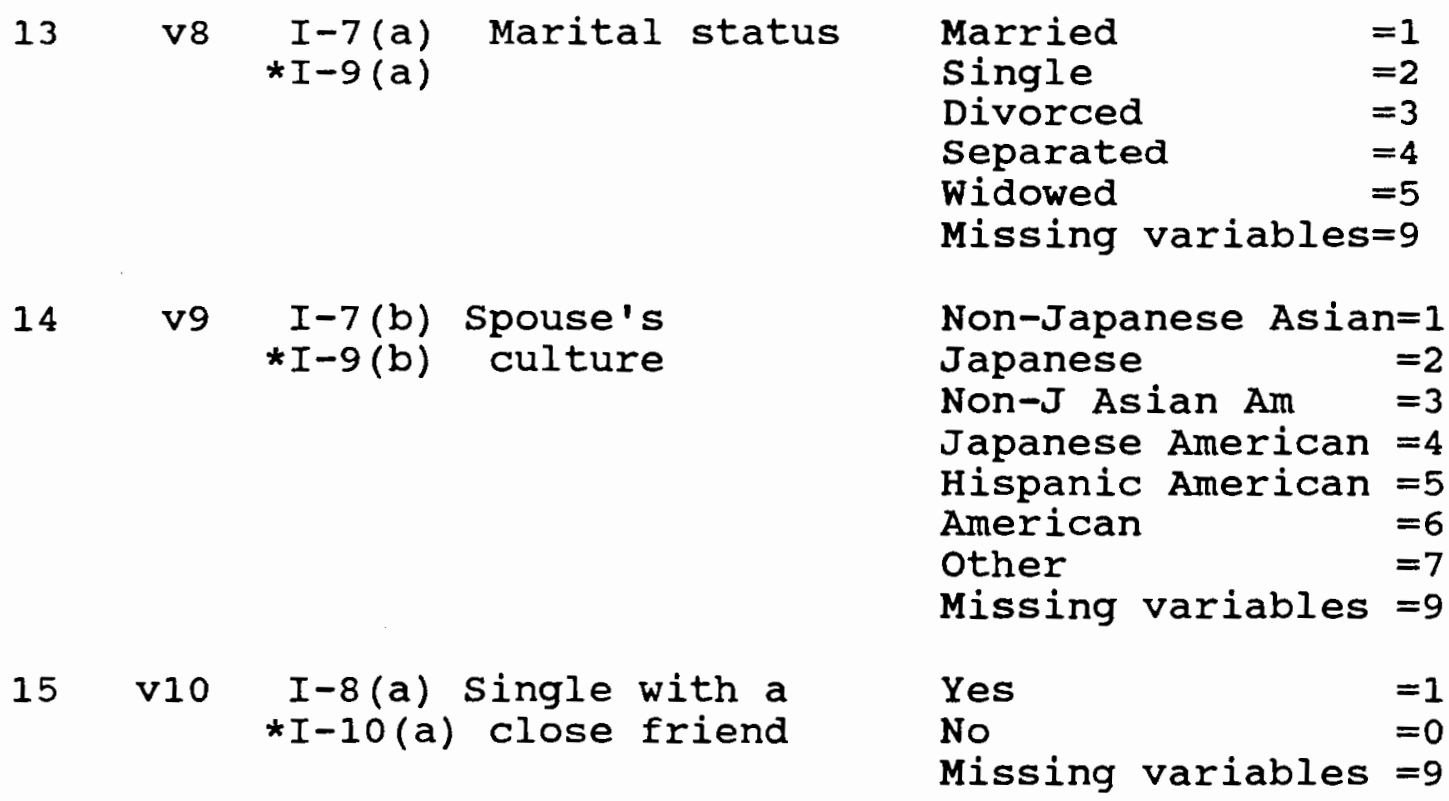

16 v11 I-8(b) The close friend's *I-10(b) culture The same as var. 9

17 V12 I-8(c) Cultural preference for spouse

18 v13 *I-10(C) Ranking $(1,2,3 \ldots)$

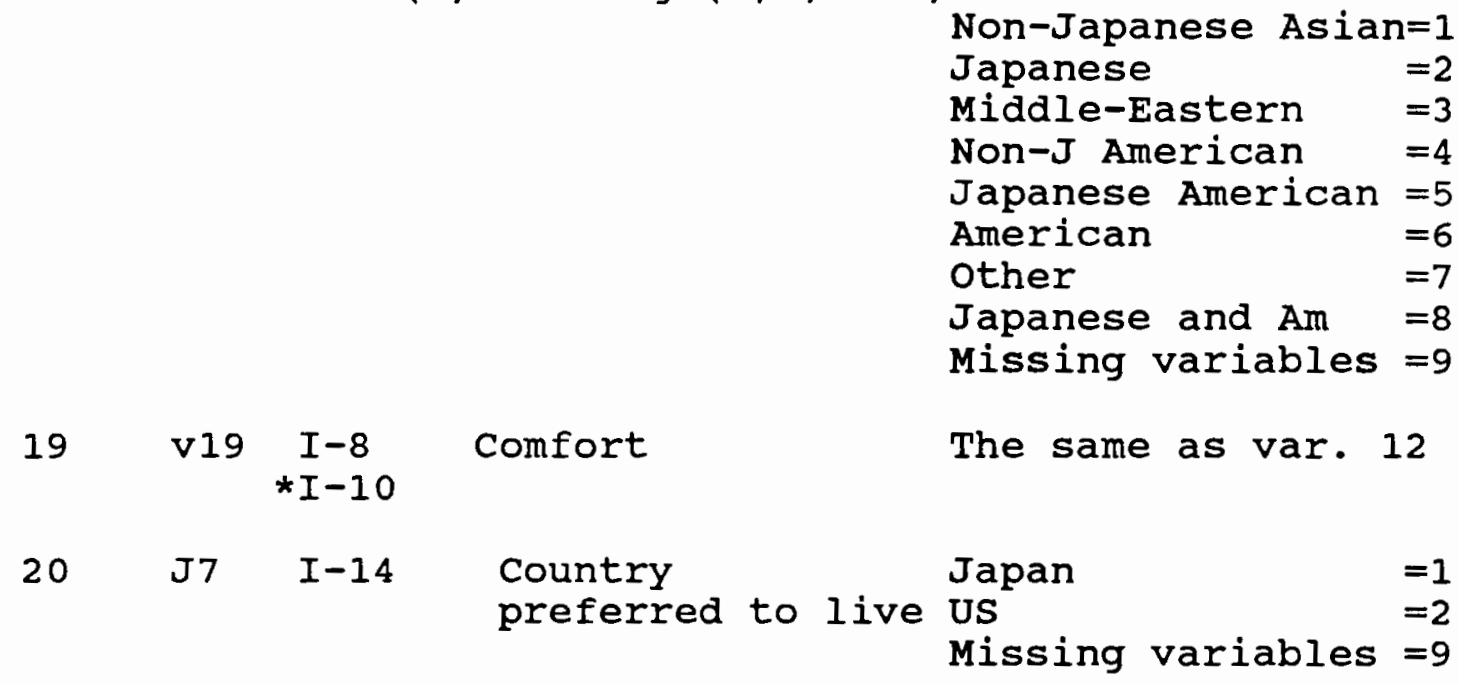




\section{CODING GUIDE I-2}

Variable signs, Japanese and Americans represent questions which are applicable only to the Japanese and to the American respectively.

JAPANESE SUBJECTS

22 J1 I-3(c) Hometown

27 J2 I-9(a) Population of Japanese friends

$\begin{array}{cccc}23-25 & \text { J3 } & \text { I-4 } & \begin{array}{c}\text { Length of stay } \\ \text { in the U.S. }\end{array} \\ 26 & \text { J4 } & \text { I-5 } & \text { Purpose of }\end{array}$

31 J5 I-1I Competence of English

$\begin{array}{ll}\text { Kyushu region } & =1 \\ \text { Chugoku region } & =2 \\ \text { Kinki region } & =3 \\ \text { Shikoku region } & =4 \\ \text { Chubu region } & =5 \\ \text { Kanto region } & =6 \\ \text { Tohoku region } & =7 \\ \text { Hokkaido } & =8 \\ \text { Okinawa } & =9\end{array}$

Nearly all $=1$

About $3 / 4=2$

$1 / 2 \quad=3$

$1 / 4=4$

Nearly none $\quad=5$

Missing variables $=9$

Months of stay

Study English =1 Experience of US $=2$ Make U.S. friends $=3$ obtain a degree in the U.S. $=4$ other $=5$

Missing variables $=9$

Very fluently $\quad=1$ Functionally $=2$ often difficulty $=3$ Understanding few words

Not at all $=5$

32-34 J6 I-12 Future plan to stay in U.S.

Months

35-37 J8 I-14 Desire length to stay in US
Permanently $\quad=5$

About 10 years $=4$

1 or 2 years $=3$

A few months $\quad=2$

A few weeks $\quad=1$

Not at all $\quad=0$ 


\section{CODING GUIDE I-2}

(continued)

U.S. SUBJECTS

39 A1 I-3(c) Hometown

Portland area $=1$

Oregon $=2$

Other Northwest $=3$ (BC, WA, Idaho, Alaska, Montana) california $=4$

Hawaii $=5$

Other state $\quad=6$

Japan $\quad=7$

Other $\quad=8$

Missing variables $=9$

40 A2 I-7(a) Proportion The same as Var. J2 of U.S. friends

44 A3 I-11(a) Experience Yes staying in Japan No $=0$

Missing variables $=9$

45-47 A4 I-11(b) Length of stay in Japan

Months of stay

48

A5 I-11(c) Purpose of stay in Japan

$\begin{array}{ll}\text { Travel } & =1 \\ \text { Business } & =2 \\ \text { Experience } & =3 \\ \text { Make Japanese } & \\ \quad \text { friends } & =4 \\ \text { Teaching English } & =5 \\ \text { Other } & =6 \\ \text { Missing variables } & =9\end{array}$

49

$$
\text { A6 I-12(a) Interaction }
$$
with Japanese

Yes $=1$

NO $=0$

50

A7 I-12(b) Frequencies of interaction with Japanese

Once a month $\quad=1$

once a week $\quad=2$

Several times

a week $=3$

Everyday

$=4$

51 A8 I-13 Competence of Japanese

Same as var. J5. 
12

$$
\begin{array}{clll}
16-29 & \text { v20 } & \text { Q1 } & \text { Confrontation } \\
-v 26 & -Q 7 & \text { Style } \\
& & \\
& & \\
& & \text { Friend with } \\
& \text { same culture } \\
& \text { \& same sex) }
\end{array}
$$

Confrontation

style

(Friend with

same culture

\& opposite sex)
Agreement $=0$

Silent $\quad=1$

Gesture $\quad=2$

Subject change $=3$

Ambiguously $=4$

Nonchalantly $\quad=5$

Half-jokingly $=6$

Stating $=7$

Seriously $\quad=8$

Arguing $=9$

Sarcasticly/ $=10$

insultingly $=10$

Angrily $=11$

Same as var. 20-26
13

16-29 v34 Q1

$-v 40 \quad-Q 7$

Confrontation

style

(Friend with

other culture

\& same sex)

45-58 V41 Q1 Confrontation

$-47-Q 7 \quad$ style

(Friend with

other culture

\& opposite sex)
Same as var. $20-26$

Same as var. $20-26$ 